\title{
Inorganic, Radioisotopic, and Organic Analysis of 241-AP-101 Tank Waste
}

\author{
S. K. Fiskum \\ P. R. Bredt \\ J. A. Campbell \\ L. R. Greenwood \\ O. T. Farmer \\ G. J. Lumetta \\ G. M. Mong \\ R. T. Ratner \\ C. Z. Soderquist \\ R. G. Swoboda \\ M. W. Urie \\ J. J. Wagner
}

June 2000

Prepared for

British Nuclear Fuels Ltd., Inc.

Under contract W375-LC-98-41698

Battelle, Pacific Northwest Division

Richland, Washington 99352 



\section{DISCLAIMER}

This report was prepared as an account of work sponsored by an agency of the United States Government. Neither the United States Government nor any agency thereof, nor any of their employees, make any warranty, express or implied, or assumes any legal liability or responsibility for the accuracy, completeness, or usefulness of any information, apparatus, product, or process disclosed, or represents that its use would not infringe privately owned rights. Reference herein to any specific commercial product, process, or service by trade name, trademark, manufacturer, or otherwise does not necessarily constitute or imply its endorsement, recommendation, or favoring by the United States Government or any agency thereof. The views and opinions of authors expressed herein do not necessarily state or reflect those of the United States Government or any agency thereof. 


\section{DISCLAIMER}

Portions of this document may be illegible in electronic image products. Images are produced from the best available original document. 


\section{Summary}

Battelle received five samples from Hanford waste tank 241-AP-101, taken at five different depths within the tank. No visible solids or organic layer were observed in the individual samples. Individual sample densities were measured, then the five samples were mixed together to provide a single composite. The composite was homogenized and representative sub-samples taken for inorganic, radioisotopic, and organic analysis. All analyses were performed on triplicate sub-samples of the composite material. ${ }^{\text {I }}$ The sample composite did not contain visible solids or an organic layer. A subsample held at $10^{\circ} \mathrm{C}$ for seven days formed no visible solids.

The characterization of the 241-AP-101 composite samples included:

- Inductively-coupled plasma spectrometry for $\mathrm{Ag}, \mathrm{Al}, \mathrm{Ba}, \mathrm{Bi}, \mathrm{Ca}, \mathrm{Cd}, \mathrm{Cr}, \mathrm{Cu}, \mathrm{Fe}$, $\mathrm{K}, \mathrm{La}, \mathrm{Mg}, \mathrm{Mn}, \mathrm{Na}, \mathrm{Nd}, \mathrm{Ni}, \mathrm{P}, \mathrm{Pb}, \mathrm{Pd}, \mathrm{Ru}, \mathrm{Rh}, \mathrm{Si}, \mathrm{Sr}, \mathrm{Ti}, \mathrm{U}, \mathrm{Zn}$, and $\mathrm{Zr}$ (Note: Although not specified in the test plan, As, B, Be, Co, Li, Mo, Sb, Se, Sn, $\mathrm{Tl}, \mathrm{V}, \mathrm{W}$, and $\mathrm{Y}$ were also measured and reported for information only)

- Radioisotopic analyses for total alpha and total beta activities, ${ }^{3} \mathrm{H},{ }^{14} \mathrm{C},{ }^{60} \mathrm{Co},{ }^{79} \mathrm{Se}$, ${ }^{90} \mathrm{Sr},{ }^{99} \mathrm{Tc}$ as pertechnetate, ${ }^{106} \mathrm{Ru} / \mathrm{Rh},{ }^{125} \mathrm{Sb},{ }^{134} \mathrm{Cs},{ }^{137} \mathrm{Cs},{ }^{152} \mathrm{Eu},{ }^{154} \mathrm{Eu},{ }^{155} \mathrm{Eu},{ }^{238} \mathrm{Pu}$, ${ }^{239+240} \mathrm{Pu},{ }^{241} \mathrm{Am},{ }^{242} \mathrm{Cm}$, and ${ }^{243+244} \mathrm{Cm}$

- Inductively-coupled plasma mass spectrometry for ${ }^{237} \mathrm{~Np},{ }^{239} \mathrm{Pu},{ }^{240} \mathrm{Pu},{ }^{99} \mathrm{Tc},{ }^{126} \mathrm{Sn}$, ${ }^{129} \mathrm{I},{ }^{231} \mathrm{~Pa},{ }^{233} \mathrm{U},{ }^{234} \mathrm{U},{ }^{235} \mathrm{U},{ }^{236} \mathrm{U},{ }^{238} \mathrm{U},{ }^{241} \mathrm{AMU},{ }^{242} \mathrm{AMU},{ }^{243} \mathrm{AMU}, \mathrm{As}, \mathrm{B}, \mathrm{Be}, \mathrm{Ce}$, $\mathrm{Co}, \mathrm{Cs}, \mathrm{Eu}, \mathrm{I}, \mathrm{Li}, \mathrm{Mo}, \mathrm{Pr}, \mathrm{Rb}, \mathrm{Sb}, \mathrm{Se}, \mathrm{Ta}, \mathrm{Te}, \mathrm{Th}, \mathrm{Tl}, \mathrm{V}$, and $\mathrm{W}$

- Total U by kinetic phosphorescence analysis

- Ion chromatography for $\mathrm{Cl}, \mathrm{F}, \mathrm{NO}_{2}, \mathrm{NO}_{3}, \mathrm{PO}_{4}, \mathrm{SO}_{4}$, acetate, formate, oxalate, and citrate

- Density, inorganic carbon and organic carbon by two different methods, mercury, free hydroxide, ammonia, and cyanide

The 241-AP-101 composite met all contract limits (molar ratio of analyte to sodium or ratio of becquerels of analyte to moles of sodium) defined in Specification 7 for Envelope A. ${ }^{2}$ Except for a few cases, the characterization results met or surpassed the quality control requirements established by the governing quality assurance plan and met or surpassed the minimum reportable quantity requirements specified by BNFL.

\footnotetext{
' Specific inorganic, radiochemical, and organic analytes of interest and reporting requirements were defined in CCN: 01260 Letter to Eugene Morrey and translated to the laboratory personnel via ASR 5778, test instructions BNFL-TP-29953-81 and -83.

${ }^{2}$ As provided by Tank Waste Remediation System Privatization Contract DE-AC27-96-RL13308, Mod 14 (4/18/00) Table TS-7.1 LAW Chemical Composition, Soluble Fraction Only and Table TS-7.2 LAW Radionuclide Content, Soluble Fraction Only.
} 


\section{Terms and Abbreviations}

\begin{tabular}{ll} 
AEA & alpha energy analysis \\
ASR & analytical services request \\
AMU & atomic mass units \\
BNFL & BNFL, Inc; subsidiary of British Nuclear Fuels, Ltd. \\
CCV & continuing calibration verification \\
COC & chain of custody \\
CVAA & cold vapor atomic absorption \\
EQL & estimated quantitation level \\
GEA & gamma energy analysis \\
HASQARD & Hanford analytical services quality assurance requirements document \\
IC & ion chromatography \\
ICP & inductively coupled plasma/atomic emission spectrometry \\
ICP/MS & inductively coupled plasma/mass spectrometry \\
IDL & instrument detection limit \\
ISE & ion specific electrode \\
KPA & kinetic phosphorescence analyzer \\
LCS & laboratory control standard \\
MDL & method detection limit \\
MRQ & minimum reportable quantity \\
MSA & method of standard addition \\
NA & not applicable \\
NIST & National Institute of Standards and Technology \\
NP & not performed \\
QA & quality assurance \\
QC & quality control \\
RPD & relative percent difference \\
RSD & relative standard deviation \\
SAL & Shielded Analytical Laboratory \\
SBMS & standards based management system \\
SRM & Standard Reference Material \\
TC & total carbon \\
TCLP & toxicity characteristic leaching procedure \\
TIC & total inorganic carbon \\
TOC & total organic carbon \\
TRU & transuranic \\
& \\
\hline
\end{tabular}




\section{Units}

${ }^{\circ} \mathrm{C}-{ }^{\circ} \mathrm{F}$

$\mathrm{Bq}$

$\mathrm{g}$

$\mathrm{g} / \mathrm{mL}$

$\mu \mathrm{g} / \mathrm{mL}$

$\mu \mathrm{Ci} / \mathrm{mL}$

$\mathrm{mL}$

$\mathrm{mmole} / \mathrm{mL}$

$\mathrm{M}$ degrees Centigrade / degrees Fahrenheit becquerel (disintegrations per second)

gram

gram per milliliter

microgram per milliliter

microcurie per milliliter

milliliter

millimole per milliliter

molarity, moles per liter 


\section{Contents}

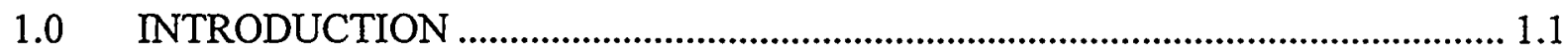

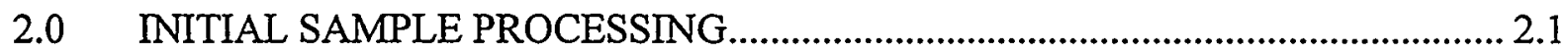

2.1 Sample Density and Homogenization.................................................................. 2.1

2.2 Sample Digestion for Analysis ................................................................................. 2.1

2.3 Sample Precipitation at Reduced Temperature............................................................. 2.3

2.4 Remaining AP-101 Composite Material..................................................................... 2.3

3.0 ANALYTICAL RESULTS ............................................................................ 3.1

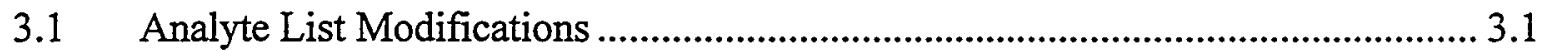

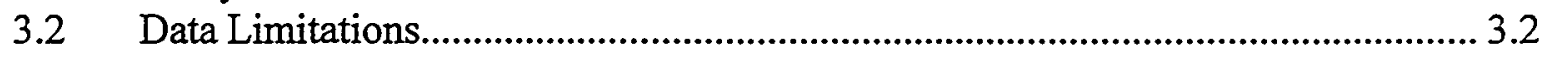

3.3 General Observations.......................................................................................... 3.2

4.0 PROCEDURES, QUALITY CONTROL, AND DATA EVALUATION …….......... 4.1

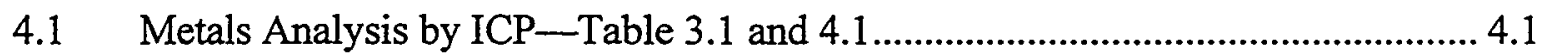

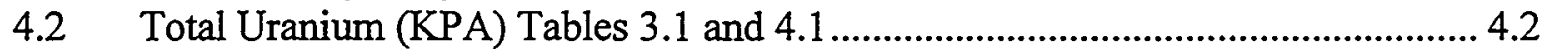

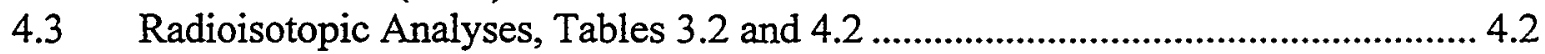

4.4 Inductively-Coupled Plasma-Mass Spectrometry, Tables 3.3. and 4.3 .............. 4.5

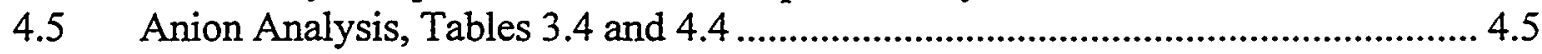

4.6 Miscellaneous Analytes, Tables 3.5 and 4.5 ...................................................... 4.7

4.7 Density ........................................................................................................... 4.9

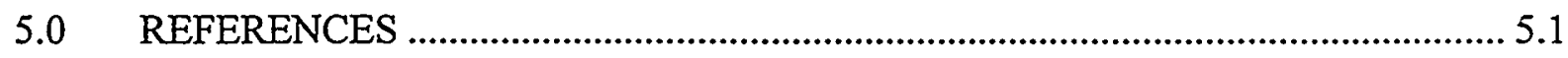

APPENDIX A: TANK 241-AP-101 GRAB SAMPLES.............................................. A.1

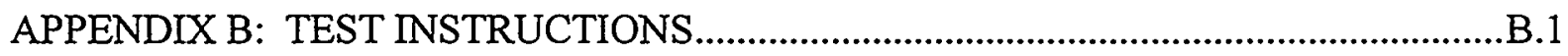

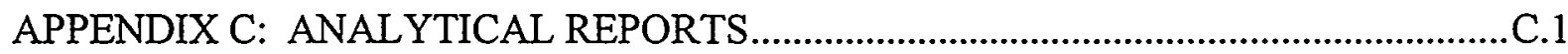




\section{Figures}

Figure 2.1. Sample Processing

\section{Tables}

Table 2.1. 241-AP-101 Sample Densities and Volumes 2.1

Table 3.1. 241-AP-101 Composite, ICP Metals Results.................................................................3.3

Table 3.2. 241-AP-101 Composite, Radionuclide Results ...............................................................

Table 3.3. 241-AP-101 Composite, ICP-MS Stable Element Results ............................................. 3.5

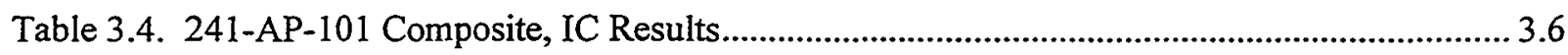

Table 3.5. 241-AP-101 Composite, Miscellaneous Analyte Results ................................................ 3.7

Table 4.1. 241-AP-101 Composite, ICP Metals QC Results ........................................................... 4.10

Table 4.2. 241-AP-101 Composite, Radionuclide QC Results......................................................4.11

Table 4.3. 241-AP-101 Composite, ICP-MS Stable Element QC Results..................................... 4.12

Table 4.4. 241-AP-101 Composite, IC QC Results ........................................................................ 4.13

Table 4.5. 241-AP-101 Composite, Miscellaneous Analyte QC Results......................................... 4.14 


\subsection{Introduction}

This report presents the inorganic, organic and radioisotopic analytical results for a composite sample obtained from tank 241-AP-101 (AP-101). This work was conducted in response to a request by BNFL. ${ }^{3}$ The results of the analyses are used to assess the waste composition relative to the contract limits defined in Specification 7 for envelope $A$.

Hanford waste tank 241-AP-101 was sampled on February 8, 2000 from Riser 002 at depths of 10, $100,190,290$, and 400 inches from the tank bottom, collecting nominally $130 \mathrm{~mL}$ per sample. ${ }^{4}$ These samples were received under chain-of-custody by the Radiochemical Processing Laboratory Shielded Analytical Laboratory. All samples were clear yellow with no visible settled or suspended solids. The AP-101 grab samples were mixed to form one large composite sample according to Test Plan BNFL-TP-29953-083. Sub-samples from this homogenized AP-101 composite sample were then delivered to various laboratories for specific analyses as defined in the analytical service request (ASR) 5778. The sample was given an internal tracking number of 00-1701. All analyses were run in triplicate.

The PNNL standards based management system (SBMS) quality assurance plan was used in support of all analytical operations and is in compliance with HASQARD. The inorganic, radioisotopic, and organic analytes of interest, recommended methods, detection limits, and quality assurance parameters were defined by BNFL. The quality requirements were included in ASR 5778. Analyte determinations were performed according to project-approved procedures.

This report presents the physical observations from AP-101 and individual density measurements from the various tank depths sampled. Precipitate production was evaluated at $10^{\circ} \mathrm{C}$ for seven days on a composite subsample. Also presented are the inorganic, radioisotopic, and organic analytical results for the triplicate AP-101 composite samples. Analyte results are compared to Specification 7 Envelope A limits, where applicable. Data limitations are also described. Quality control, detection limits, and other quality control indicators are discussed relevant to the reporting method.

\footnotetext{
${ }^{3}$ Statement of Work for 241-AP-101 Samples. Transmitted via letter: ME Johnson to EV Morrey, Contract No. DE-AC06-96RL13308-W375-Request for Proposal to Conduct Revised Analysis of Tank 241-AP-101 Samples, CCN: 012160.

${ }^{4}$ Wood, R. F., Letter Report, CH2M Hill, Hanford Group, Inc., to J.J. Short, DOE-ORP, "Sample Management Document Package for Grab Samples form Tank 241-AP-101," Letter No. CHG-0000767 dated February 15, 2000.
} 


\subsection{Initial Sample Processing}

\subsection{Sample Density and Homogenization}

The samples from the five different sampling depths were confirmed to be clear and yellow with no suspended or settled solids, as indicated on the chain-of-custody form. Each sample density was taken by determining the net sample mass in a $25-\mathrm{mL}$ glass volumetric flask. ${ }^{5}$ The individual densities, given in Table 2.1, show a slight decrease with increasing sampling elevation.

Table 2.1. 241-AP-101 Sample Densities and Volumes

\begin{tabular}{|r|ccccc|}
\hline Sample ID & 1AP-00-1 & 1 AP-00-4 & 1 AP-00-7 & 1 AP-00-10 & 1AP-00-13 \\
\cline { 2 - 6 } Elevation (inches)* & 400 & 290 & 190 & 100 & 10 \\
Density $(g / m L)$ & 1.290 & 1.291 & 1.291 & 1.320 & 1.328 \\
Mass received $(g)$ & 174.3 & 170.2 & 169.7 & 173.6 & 172.2 \\
Volume received $(m L)$ & 135.2 & 131.8 & 131.5 & 131.6 & 129.7 \\
\hline
\end{tabular}

*Elevation is the distance from the tank bottom to the mouth of the sample bottle.

The entire contents of each sample container were transferred to a 1-L jar; the net mass transferred was calculated by difference from the full and empty container masses. ${ }^{6}$ The $860-\mathrm{g}(659.8-\mathrm{mL})$

AP-101 composite was sealed and stirred for 54 minutes using a magnetic stir bar. A $101-\mathrm{mL}$ subsample was transferred to a glass bottle and sealed. For subsequent precipitation/crystallization testing at reduced temperature. Portions of the remaining composite material were used for subsequent analyses. The composite sample did not show signs of phase separation or precipitation. The overall sample processing is summarized in Figure 2.1.

\subsection{Sample Digestion for Analysis}

After sample homogenization, the AP-101 composite sub-samples were delivered directly to the laboratories for various measurements including mercury, cyanide, hydroxide, tritium, total organic carbon, total inorganic carbon, ammonia, ion chromatography (inorganic and organic ions), ${ }^{14} \mathrm{C}$, pertechnetate, ${ }^{79} \mathrm{Se}$, and gamma spectrometry. The AP-101 composite density (see Table 3.5) was determined in the Shielded Analytical Laboratory (SAL).

The SAL processed 5-mL aliquots in triplicate according to PNL-ALO-128, $\mathrm{HNO}_{3}-\mathrm{HCl}$ Acid Extraction of Liquids for Metals Analysis Using a Dry-Block Heater, for subsequent ICP and ICP/MS analyses. The acid extracted solutions were brought to a nominal $25-\mathrm{mL}$ volume and absolute volumes determined based on final solution weights and densities. This acid digestion resulted in a solution with a small amount of white floating particulates. The floating particulates were removed by filtration. The filtrates were analyzed by ICP and ICP/MS. Along with the samples, the SAL processed a reagent blank, a toxicity characteristic leach protocol (TCLP)-metals spiked blank, and TCLP-metals spiked sample. The TCLP metals spike included Ag, As, $\mathrm{Ba}, \mathrm{Cd}, \mathrm{Cr}, \mathrm{Ni}, \mathrm{Pb}, \mathrm{Se}, \mathrm{Tl}$, and $\mathrm{Zn}$.

\footnotetext{
${ }^{5}$ PNNL Test Instruction Number 29953-81, Rev. 0, Density Measurements on As-Received AP-101 Samples, Paul Bredt, 2/10/00

6 PNNL Test Instruction Number BNFL-TP-29953-83, Rev. 0, "AP-101 Homogenization and Subsampling," by Paul Bredt, 3/31/00
} 


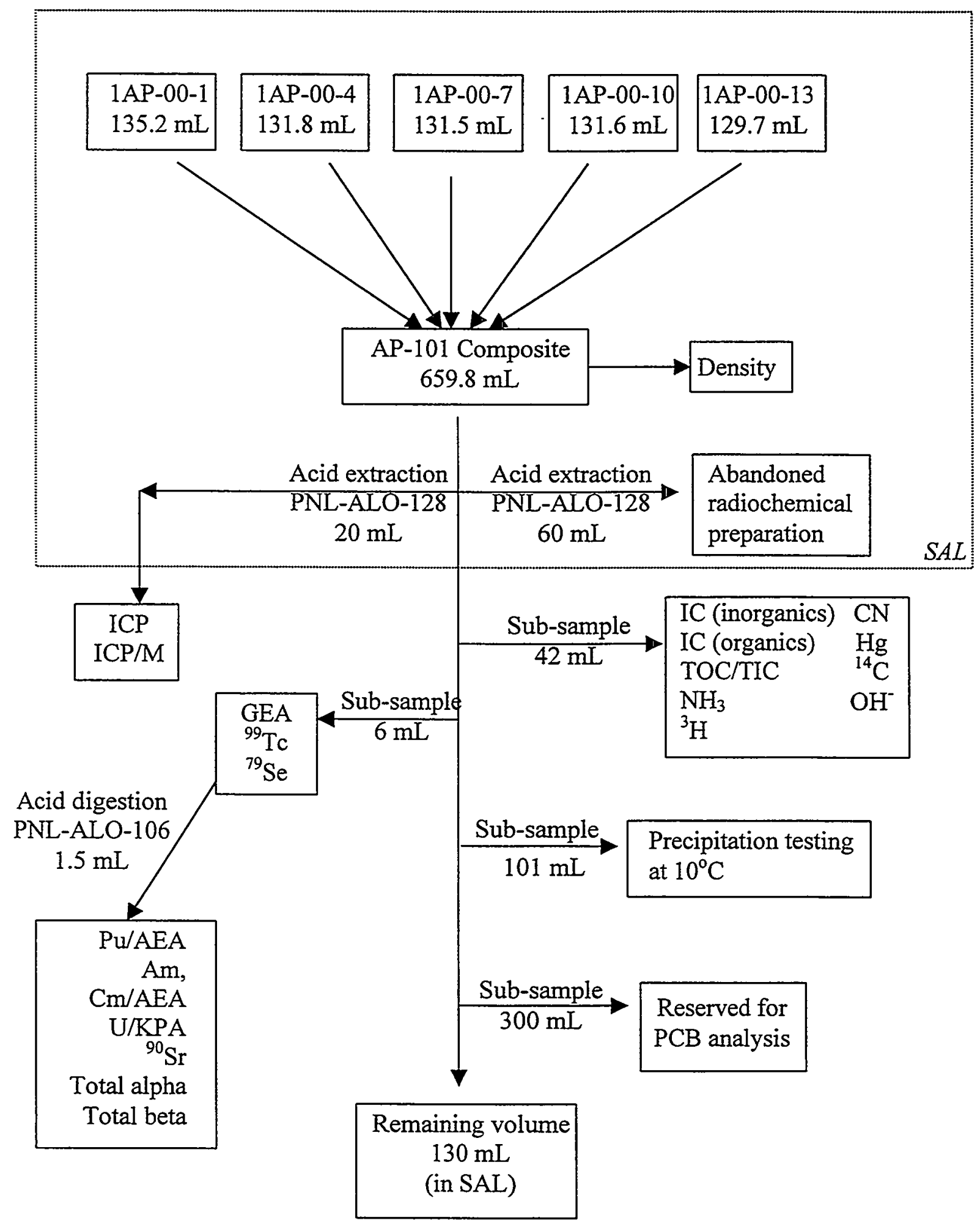

Figure 2.1. 241-AP-101 Sample Processing 
The SAL also processed $20 \mathrm{~mL}$ AP-101 composite aliquots in triplicate according to PNL-ALO-128. The acid extraction was insufficient to neutralize the $20-\mathrm{mL}$ sample and it resulted in a small amount of solid residue formation (settled on the vial bottom as opposed to floating particulates). Additional $8 \mathrm{M} \mathrm{HNO}_{3}$ was added to one aliquot to dissolve the residual solids. This resulted in severe foaming as well as visible NOx production. Continued $8 \mathrm{M} \mathrm{HNO}_{3}$ addition resulted in mixed-phases consisting of whitish floating material on top of a near colorless solution. Acid digestion/neutralization of the three 20-mL aliquots of AP-101 composite was abandoned in favor of performing a nitric acid digestion on 0.5-mL aliquots according to PNL-ALO-106, Acid Digestion for Preparation of Samples for Radiochemical Analysis. Nitric acid additions and heating continued until all organic/nitric reactions had visibly ceased. The samples were then brought to volume in $10-\mathrm{mL}$ volumetric flasks with $2 \mathrm{M}$ $\mathrm{HNO}_{3}$. A reagent blank was run with the samples. These digestions were used for the subsequent analyses of total alpha, total beta, ${ }^{239+240} \mathrm{Pu},{ }^{238} \mathrm{Pu},{ }^{241} \mathrm{Am},{ }^{242} \mathrm{Cm},{ }^{243+244} \mathrm{Cm}$, total $\mathrm{U}$ by kinetic phosphorescence analysis (KPA), and ${ }^{90} \mathrm{Sr}$. A laboratory control sample (LCS) was not available for radiochemical analyses. Post digestion blank spikes and matrix spikes were prepared at the time of radiochemical separation.

\subsection{Sample Precipitation at Reduced Temperature}

A $101-\mathrm{mL}$ aliquot of the AP-101 composite was visually inspected using a video camera installed in the HLRF hot cell. The sample contained a very a small amount of particulate material. This was removed by filtering through a $0.45-\mu \mathrm{m}$ nylon membrane. The clarified liquid was transferred to a clean glass jar and was then placed in a cooling bath at $10^{\circ} \mathrm{C}$. The sample was inspected daily (excluding weekends) for a period for seven days. No solids formed after seven days. Thus, the AP101 solution appears to be stable towards precipitation at $10^{\circ} \mathrm{C}$.

\subsection{Remaining AP-101 Composite Material}

The combined total volume sampled for the various analyses was $529-\mathrm{mL}$. The amount remaining after all sampling events were completed is nominally $130-\mathrm{mL}$ or $171 \mathrm{-g}$. 


\subsection{Analytical Results}

Tables 3.1 through 3.5 provide inorganic, radioisotopic, and organic analytical results for the triplicate AP-101 composite samples. The average of the triplicate values and the relative standard deviation (RSD) are also given. Results are reported in $\mu \mathrm{g} / \mathrm{mL}$ or $\mu \mathrm{Ci} / \mathrm{mL}$. The reference date for radioisotope activities is the analysis date. The nominal propagated uncertainties are also provided as $1-\sigma$ unless otherwise noted.

Preparation blank results are also reported, as appropriate. Several analytes were measured directly, requiring no preparation blank (e.g., GEA, IC, and hydroxide). In these instances, the preparation blank field is empty. Generally, analyte concentrations in the preparation blanks were either insignificant relative to the sample analyte concentration or at or near the method detection limit. This indicates processing steps did not result in significant sample contamination (except in the case of $B$, see discussion in section 3.2).

Specification 7 for Envelope A defines limits for several analytes relative to sodium concentration (moles analyte per mole $\mathrm{Na}$ or $\mathrm{Bq}$ analyte per mole $\mathrm{Na}$ ). These ratio limits are provided in conjunction with as-measured ratios. In all cases the mole or $\mathrm{Bq}$ analyte to moles $\mathrm{Na}$ ratio did not exceed the limits defined in Specification 7 for Envelope A.

Specific quality control and quality assurance discussions are given in Section 4.0.

\subsection{Analyte List Modifications}

The analyte list provided by the client was extracted from Contract Specification 7. Several modifications to this analyte list had to be incorporated as follows:

- The Pu separation and subsequent analysis by AEA requires ${ }^{239} \mathrm{Pu}$ and ${ }^{240} \mathrm{Pu}$ be measured together as a sum, not as separate isotopes. The alpha energy peaks from these isotopes are non-resolvable. The lower of the two MRQs for these analytes was used for compliance purposes.

- The laboratory was directed to determine pertechnetate $\left({ }^{99} \mathrm{TcO}_{4}{ }^{+7}\right)$ using separations and beta counting techniques, as opposed to total ${ }^{99} \mathrm{Tc}$. The procedure was modified slightly to exclude the sample oxidation step. Also, instead of measuring the ${ }^{99} \mathrm{Tc}$ by liquid scintillation, sample preparations were counted with gas-flow proportional counters.

- Analysis for ${ }^{135} \mathrm{Cs}$ was not performed as requested by gamma spectrometry. There are no gamma-emissions associated with this isotope.

- Analyte concentrations, in addition to the required and opportunistic analytes, are provided in Tables 3.1 and 3.4. These additional analytes were measured as part of the method and are provided for additional information.

- Total carbon was measured using the furnace oxidation method as opposed to individual measurements of TOC and TIC. This method is considered reliable for only total carbon. 


\subsection{Data Limitations}

- The reported fluoride results, average $2900 \mu \mathrm{g} / \mathrm{mL}$, represent the summation of fluoride, acetate, and formate concentrations, as these are not resolvable on the inorganic anion analysis IC system. The acetate and formate were quantified on the organic anion IC system. The sum of these two analytes is $2840 \mu \mathrm{g} / \mathrm{mL}$. This indicates very little fluoride is present in AP-101.

- The reported acetate results represent the summation of glycolate and acetate, as these are not resolvable on the organic IC system.

- ICP-MS analytes at AMU-241, 242, and 243, were measured relative to a ${ }^{239} \mathrm{Pu}$ standard and the reported results are considered semi-quantitative. They are listed in the stable element data Table 3.3. with concentration units of $\mu \mathrm{g} / \mathrm{mL}$. Although these elements are unstable, an activity concentration cannot be applied without knowing the specific activity, and thus the analyte identity. For example, if ${ }^{241} \mathrm{AMU}$ is assigned to $\mathrm{Am}$, then the activity becomes $<0.038 \mu \mathrm{Ci} / \mathrm{mL}$; if ${ }^{241} \mathrm{AMU}$ is assigned to $\mathrm{Pu}$, then the activity becomes $<1.2 \mu \mathrm{Ci} / \mathrm{mL}$.

- The ${ }^{126} \mathrm{Sn}$ and ${ }^{231} \mathrm{~Pa}$ ICP-MS analytes were determined relative to related isotopes and the reported results are considered semi-quantitative.

- Boron was present in the preparation blank at $40 \%$ of the sample concentration indicating the sample boron concentration could be biased high by the digestion method.

- Arsenic was present in the preparation blank at $10 \%$ of the sample concentration indicating the sample arsenic concentration could be biased high by the digestion method.

- The alpha summation is a better representation of the total alpha activity than the total alpha determination for this matrix. Solids loading on the total alpha mount resulted in some alpha attenuation.

- The acid digestion preparations for ICP and ICP-MS were filtered to remove a small amount of floating particulates. This leaves open the possibility that one or more analyses could be biased low.

\subsection{General Observations}

- The total ${ }^{99} \mathrm{Tc}$ measured by ICP-MS agreed well with the pertechnetate analysis (separations and beta counting), indicating the ${ }^{99} \mathrm{Tc}$ in AP-101 is present in the pertechnetate form.

- The U concentrations determined by KPA and ICP-MS agreed within the 2- $\sigma$ uncertainty.

- The total beta activity is equivalent to the ${ }^{137} \mathrm{Cs}$ activity indicating ${ }^{137} \mathrm{Cs}$ is the primary Bemitting isotope in this waste.

- The phosphorous concentration is virtually identical to the phosphate concentration indicating the phosphorous is primarily present as phosphate.

- Generally the analyte concentrations measured by both ICP-MS and ICP were consistent. 
Table 3.1. 241-AP-101 Composite, ICP Metals Results

\begin{tabular}{|c|c|c|c|c|c|c|c|c|c|}
\hline $\begin{array}{r}\text { Lab ID } \\
\text { Sample ID } \\
\text { Run date } \\
\text { Units } \\
\end{array}$ & $\begin{array}{c}\text { PB-1701 } \\
\text { prep blank } \\
4 / 11 / 00 \\
\mu \mathrm{g} / \mathrm{mL} \\
\end{array}$ & $\begin{array}{l}00-1701 \\
\text { sample } \\
4 / 11 / 00 \\
\mu g / \mathrm{mL}\end{array}$ & $\begin{array}{c}\text { 00-1701D } \\
\text { duplicate } \\
4 / 11 / 00 \\
\mu g / \mathrm{mi}\end{array}$ & $\begin{array}{c}00-1701 \mathrm{~T} \\
\text { triplicate } \\
4 / 11 / 00 \\
\mu \mathrm{g} / \mathrm{mL}\end{array}$ & $\begin{array}{c}\text { Average } \\
\mu \mathrm{g} / \mathrm{mL}\end{array}$ & $\begin{array}{c}\text { RSD } \\
\% \\
\end{array}$ & $\begin{array}{c}\text { Average } \\
\mathrm{M} \\
\end{array}$ & $\begin{array}{c}\text { Measured } \\
\text { Mole analyte } \\
\text { per mole Na } \\
\text { Ratio }\end{array}$ & $\begin{array}{c}\text { Specification } 7 \\
\text { Envelope A } \\
\text { Limits } \\
\text { Mole analyte } \\
\text { per mole Na } \\
\text { Ratio } \\
\end{array}$ \\
\hline \multicolumn{10}{|l|}{ Analyte $^{(l)}$} \\
\hline $\mathrm{Ag}$ & $<0.12$ & $<0.63$ & $<0.63$ & $<0.62$ & $<0.63$ & & & & \\
\hline Al & 4.5 & 7,380 & 6,680 & 6,760 & 6,940 & 5.5 & $2.6 \mathrm{E}-1$ & $4.6 \mathrm{E}-2$ & $2.5 \mathrm{E}-1$ \\
\hline $\mathrm{Ba}$ & $<0.05$ & {$[0.32]$} & {$[0.34]$} & [0.33] & {$[0.33]$} & 3.0 & {$[2.4 \mathrm{E}-6]$} & {$[4.3 \mathrm{E}-7]$} & $1.0 \mathrm{E}-4$ \\
\hline $\mathrm{Bi}$ & $<0.48$ & $<2.5$ & $<2.5$ & $<2.5$ & $<.5$ & & & & \\
\hline $\mathrm{Ca}$ & {$[1.4]$} & [7.8] & [7.5] & [7.7] & [7.7] & 2.0 & {$[1.9 \mathrm{E}-4]$} & [3.4E-5] & $4.0 \mathrm{E}-2$ \\
\hline $\mathrm{Cd}$ & $<0.07$ & {$[2.0]$} & [1.9] & {$[2.0]$} & {$[2.0]$} & 2.9 & [1.7E-5] & {$[3.1 \mathrm{E}-6]$} & $4.0 \mathrm{E}-3$ \\
\hline $\mathrm{Cr}$ & $<0.1$ & 158 & 137 & 135 & 143 & 8.9 & $2.8 \mathrm{E}-3$ & $4.9 \mathrm{E}-4$ & $6.9 \mathrm{E}-3$ \\
\hline $\mathrm{Cu}$ & {$[0.18]$} & [1.7] & [1.5] & {$[1.5]$} & [1.6] & 7.4 & & & \\
\hline $\mathrm{Fe}$ & {$[0.38]$} & [2.9] & {$[2.4]$} & [2.2] & [2.5] & 14 & {$[4.5 \mathrm{E}-5]$} & {$[8.0 \mathrm{E}-6]$} & $1.0 \mathrm{E}-2$ \\
\hline $\mathrm{K}$ & $<9.7$ & 31,700 & 30,500 & 31,500 & 31,200 & 2.1 & $8.0 \mathrm{E}-1$ & $1.4 \mathrm{E}-1$ & $1.8 \mathrm{E}-1$ \\
\hline $\mathrm{La}$ & $<0.24$ & $<1.3$ & $<1.3$ & $<1.2$ & $<1.3$ & & $<9.4 \mathrm{E}-6$ & $<1.7 \mathrm{E}-6$ & 8.3E-5 \\
\hline $\mathrm{Mg}$ & $<0.48$ & $<2.5$ & $<2.5$ & $<2.5$ & $<.5$ & & & & \\
\hline $\mathrm{Mn}$ & $<0.24$ & $<1.3$ & $<1.3$ & $<1.2$ & $<1.3$ & & & & \\
\hline $\mathrm{Na}$ & 14 & 132,000 & 125,000 & 131,000 & 129,300 & 2.9 & $5.62 \mathrm{E}+0$ & & \\
\hline Nd & $<0.48$ & $<2.5$ & $<2.5$ & $<2.5$ & $<2.5$ & & & & \\
\hline $\mathrm{Ni}$ & 1.6 & 8.6 & 7.7 & 7.5 & 7.9 & 7.6 & $1.4 \mathrm{E}-4$ & $2.4 \mathrm{E}-5$ & $3.0 \mathrm{E}-3$ \\
\hline $\mathbf{P}$ & $<0.48$ & 371 & 290 & 281 & 314 & 16 & $1.0 \mathrm{E}-2$ & $1.8 \mathrm{E}-3$ & $3.8 \mathrm{E}-2$ \\
\hline $\mathrm{Pb}$ & $<0.48$ & [15] & [15] & [15] & {$[15]$} & 0 & [7.2E-5] & [1.3E-5] & $6.8 \mathrm{E}-4$ \\
\hline Pd & $<3.6$ & $<19$ & $<19$ & $<19$ & $<19$ & & & & \\
\hline $\mathbf{R h}$ & $<1.5$ & $<7.6$ & $<7.6$ & $<7.5$ & $<7.6$ & & & & \\
\hline $\mathbf{R u}$ & $<5.3$ & $<28$ & $<28$ & $<27$ & $<28$ & & & & \\
\hline $\mathrm{Si}$ & [24] & 143 & 132 & 137 & 137 & 4.0 & & & \\
\hline $\mathrm{Sr}$ & $<0.07$ & $<0.38$ & $<0.38$ & $<0.37$ & $<0.38$ & & & & \\
\hline $\mathrm{Ti}$ & $<0.12$ & $<0.63$ & $<0.63$ & $<0.62$ & $<0.63$ & & & & \\
\hline $\mathrm{U}$ & $<9.7$ & {$[68]$} & [62] & {$[56]$} & {$[62]$} & 9.7 & {$[2.6 \mathrm{E}-4]$} & {$[4.6 \mathrm{E}-5]$} & $1.2 \mathrm{E}-3$ \\
\hline $\mathrm{U}(\mathrm{KPA})^{(2)}$ & 0.0054 & 51.7 & 51.2 & 50.3 & 51.1 & 1.4 & $2.1 E-4$ & $3.8 \mathrm{E}-5$ & $1.2 \mathrm{E}-3$ \\
\hline $\mathrm{U}(\mathrm{ICP}-\mathrm{MS})^{(3)}$ & $<0.14$ & 58.9 & 52.9 & 54.1 & 55.3 & 5.7 & $2.3 \mathrm{E}-4$ & $4.1 \mathrm{E}-5$ & $1.2 \mathrm{E}-3$ \\
\hline $\mathrm{Zn}$ & {$[0.91]$} & {$[5.8]$} & [5.5] & [5.4] & {$[5.6]$} & 3.7 & & & \\
\hline $\mathrm{Zr}$ & $<0.24$ & {$[1.4]$} & [1.4] & [1.3] & {$[1.4]$} & 4.2 & & & \\
\hline \multicolumn{10}{|c|}{ Additional analyte information } \\
\hline As* & $<1.21$ & $<6.3$ & $<6.3$ & $<6.2$ & $<6.3$ & & & & \\
\hline $\mathrm{Be}^{*}$ & $<0.05$ & {$[1.1]$} & {$[1.0]$} & {$[1.0]$} & {$[1.0]$} & 5.6 & & & \\
\hline $\mathrm{B}^{*}$ & 6.62 & 15 & 14 & 15 & 15 & 2.6 & & & \\
\hline $\mathrm{Co}^{*}$ & $<0.24$ & $<1.3$ & $<1.3$ & $<1.2$ & $<1.3$ & & & & \\
\hline $\mathrm{Li}^{*}$ & $<0.15$ & $<0.76$ & $<0.76$ & $<0.75$ & $<0.76$ & & & & \\
\hline $\mathrm{Mo}^{*}$ & $<0.24$ & [12] & {$[10]$} & {$[9.8]$} & {$[11]$} & 11 & & & \\
\hline $\mathrm{Se}^{*}$ & $<1.2$ & $<6.3$ & $<6.3$ & $<6.2$ & $<6.3$ & & & & \\
\hline Sn & $<7.3$ & {$[60]$} & $<38$ & $<37$ & $<38$ & & & & \\
\hline $\mathrm{T}^{*}$ & $<2.4$ & $<13$ & $<13$ & $<12$ & $<13$ & & & & \\
\hline $\mathrm{V}^{*}$ & $<0.24$ & $<1.3$ & $<1.3$ & $<1.2$ & $<1.3$ & & & & \\
\hline$W^{*}$ & $<9.7$ & $<51$ & $<51$ & $<50$ & $<51$ & & & & \\
\hline$Y$ & $<0.24$ & $<1.3$ & $<1.3$ & $<1.2$ & $<1.3$ & & & & \\
\hline
\end{tabular}

(1) Overall error for reported results is estimated to be within $+/-15 \%, 2-\sigma$; however results in brackets "[ ]" are less than the estimated quantitation level (i.e., 10 -times MDL) and error is anticipated to exceed $+1-15 \%$.

(2) $U$ (KPA) indicates $U$ determination by kinetic phosphorescence on $4 / 26 / 00$ with an uncertainty of $3 \%, 1-\sigma$.

(3) U (ICP-MS) indicates opportunistic U determination by ICP-MS on $4 / 18 / 00$, with an uncertainty of $3.5 \%$, based on one standard deviation triplicate sample summing all $U$ isotopes.

*Analytes on ICP-MS Specification 7 list. 
Table 3.2. 241-AP-101 Composite, Radionuclide Results

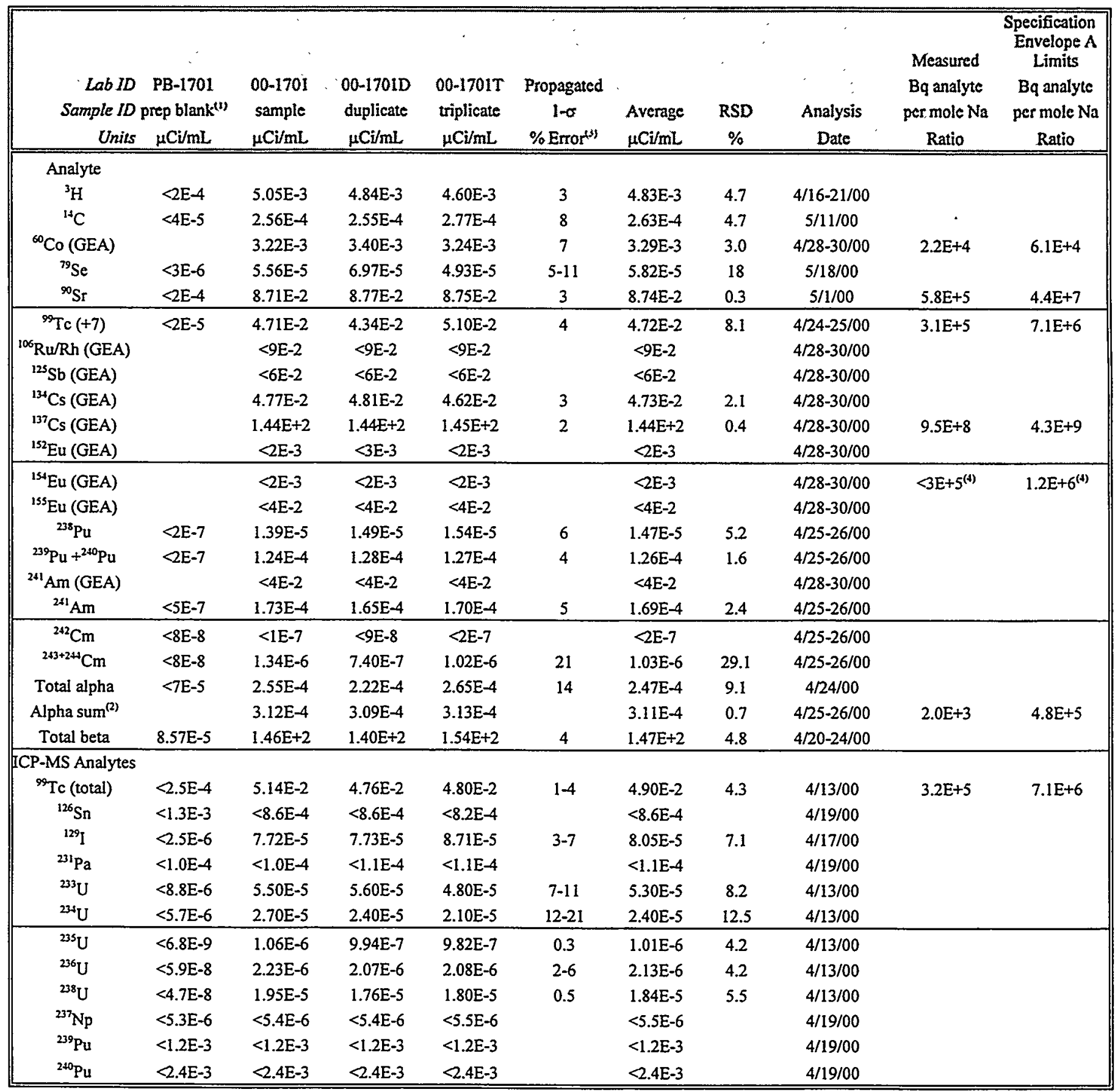

(1) Samples run directly by GEA and did not require a preparation blank.

(2) Alpha sum refers to the summation of ${ }^{238} \mathrm{Pu},{ }^{239+240} \mathrm{Pu},{ }^{241} \mathrm{Am}$, and ${ }^{243+244} \mathrm{Cm}$ alpha activities.

(3) The error represents the error of each reported sample concentration. In some cases, the error was identical and a single error value is given. In other cases, the reported values had varying errors and the error range is given.

(4) Based on the summation of ${ }^{154} \mathrm{Eu}$ and ${ }^{155} \mathrm{Eu}$. 
Table 3.3. 241-AP-101 Composite, ICP-MS Stable Element Results

\begin{tabular}{|c|c|c|c|c|c|c|c|}
\hline $\begin{array}{r}\text { Lab ID } \\
\text { Sample ID } \\
\text { Run date } \\
\text { Units }\end{array}$ & $\begin{array}{c}\text { PB-1701 } \\
\text { prep blank } \\
4 / 13-19 / 00 \\
\mu \mathrm{g} / \mathrm{mL}\end{array}$ & $\begin{array}{c}00-1701 \\
\text { sample } \\
4 / 13-19 / 00 \\
\mu \mathrm{g} / \mathrm{mL}\end{array}$ & $\begin{array}{c}00-17010 \\
\text { duplicate } \\
4 / 13-19 / 00 \\
\mu \mathrm{g} / \mathrm{mL}\end{array}$ & $\begin{array}{c}00-1701 \mathrm{~T} \\
\text { triplicate } \\
4 / 13-19 / 00 \\
\mu \mathrm{g} / \mathrm{mL}\end{array}$ & $\begin{array}{c}\text { Propagated } \\
1-\sigma \\
\% \text { Enror }\end{array}$ & $\begin{array}{l}\text { Average } \\
\mu \mathrm{g} / \mathrm{mL}\end{array}$ & $\%$ \\
\hline \multicolumn{8}{|l|}{ Analyte } \\
\hline As & 0.13 & 1.46 & 1.15 & 1.18 & $2-4$ & 1.26 & 14 \\
\hline B & 6.42 & 15.5 & 15.3 & 17.2 & 1 & 16.0 & 6.5 \\
\hline $\mathrm{Be}$ & 0.012 & 1.32 & 1.28 & 1.35 & $1-2$ & 1.32 & 2.7 \\
\hline $\mathrm{Ce}$ & $<0.079$ & $<0.077$ & $<0.075$ & $<0.072$ & & $<0.077$ & \\
\hline Co & 0.014 & 0.356 & 0.331 & 0.369 & $1-3$ & 0.352 & 5.5 \\
\hline${ }^{133} \mathrm{Cs}$ & 0.014 & 4.96 & 4.90 & 5.40 & 1 & 5.09 & 5.4 \\
\hline Eu & $<0.017$ & $<0.016$ & $<0.016$ & $<0.015$ & & $<0.016$ & \\
\hline${ }^{127} \mathrm{I}$ & $<0.013$ & 2.42 & 2.49 & 2.73 & $2-5$ & 2.55 & 6.4 \\
\hline $\mathbf{L i}$ & $<0.064$ & 0.323 & 0.329 & 0.367 & 1 & 0.340 & 7.0 \\
\hline Mo & $<0.013$ & 15.9 & 13.4 & 14.1 & $1-2$ & 14.5 & 8.9 \\
\hline $\mathrm{Pr}$ & $<0.018$ & $<0.018$ & $<0.017$ & $<0.017$ & & $<0.018$ & \\
\hline $\mathbf{R b}$ & 0.017 & 3.92 & 3.78 & 4.22 & 1 & 3.97 & 5.7 \\
\hline $\mathrm{Sb}$ & 0.029 & 0.045 & 0.041 & 0.040 & $4-10$ & 0.042 & 7.2 \\
\hline $\mathrm{Se}$ & $<2.3$ & $<2.3$ & $<2.3$ & $<2.3$ & & $<2.3$ & \\
\hline $\mathrm{Ta}$ & $<0.087$ & $<0.087$ & $<0.089$ & $<0.089$ & & $<0.089$ & \\
\hline $\mathrm{Te}$ & $<0.17$ & $<0.17$ & $<0.16$ & $<0.16$ & & $<0.17$ & \\
\hline Th & $<0.011$ & $<0.011$ & $<0.011$ & $<0.011$ & & $<0.011$ & \\
\hline$\overline{\mathrm{TI}}$ & $<0.0055$ & 0.0192 & 0.0168 & 0.0165 & $3-8$ & 0.018 & 8.5 \\
\hline $\mathrm{U}$ & $<0.14$ & 58.9 & 52.9 & 54.1 & 3.5 & 55.3 & 5.7 \\
\hline V & $<0.79$ & $<0.77$ & $<0.75$ & $<0.72$ & & $<0.77$ & \\
\hline W & $<0.089$ & 28.5 & 28.4 & 28.9 & $2-5$ & 28.6 & 0.9 \\
\hline${ }^{241} \mathrm{AMU}$ & $<0.011$ & $<0.011$ & $<0.011$ & $<0.011$ & & $<0.011$ & \\
\hline${ }^{242} \mathrm{AMU}$ & $<0.010$ & $<0.010$ & $<0.010$ & $<0.010$ & & $<0.010$ & \\
\hline${ }^{243} \mathrm{AMU}$ & $<0.0069$ & $<0.0071$ & $<0.0072$ & $<0.0072$ & & $<0.0072$ & \\
\hline
\end{tabular}

Note: the last 3 listed elements, AMU-241,242, and 243, were listed in this table with a concentration of $\mu \mathrm{g} / \mathrm{mL}$ as opposed to the radionuclide table in units of $\mu \mathrm{Ci} / \mathrm{mL}$. In order to determine the concentration in $\mu \mathrm{Ci} / \mathrm{mL}$, the mass would have to be assigned to a radioisotope and multiplied by the specific activity. Thus if AMU-24l is assigned to $\mathrm{Am}$, then the activity becomes $<0.038 \mu \mathrm{Ci} / \mathrm{mL}$; if $\mathrm{AMU}-241$ is assigned to $\mathrm{Pu}$, then the activity becomes $<1.2 \mu \mathrm{Ci} / \mathrm{mL}$. The same concept is applicable to the other two masses.

(1) The error represents the error of each reported sample concentration. In some cases, the error was identical and a single error value is given. In other cases, the reported values had varying errors and the error range is given. 
Table 3.4. 241-AP-101 Composite, IC Results

\begin{tabular}{|c|c|c|c|c|c|c|c|c|}
\hline $\begin{array}{r}\text { Lab ID } \\
\text { Sample ID } \\
\text { Units }\end{array}$ & $\begin{array}{c}00-1701 \\
\text { sample } \\
\mu \mathrm{g} / \mathrm{mL}\end{array}$ & $\begin{array}{c}00-1701 \mathrm{D} \\
\text { duplicate } \\
\mu \mathrm{g} / \mathrm{mL}\end{array}$ & $\begin{array}{l}00-1701 T \\
\text { triplicate } \\
\mu \mathrm{g} / \mathrm{mL}\end{array}$ & $\begin{array}{l}\text { Averàge } \\
\mu \mathrm{g} / \mathrm{mL}\end{array}$ & $\begin{array}{c}\text { RSD } \\
\% \\
\end{array}$ & $\begin{array}{c}\text { Average } \\
\text { M }\end{array}$ & $\begin{array}{c}\text { Measured } \\
\text { Mole analyte } \\
\text { per mole } \mathrm{Na} \\
\text { Ratio }\end{array}$ & $\begin{array}{c}\text { Specification } 7 \\
\text { Envelope A } \\
\text { Limits } \\
\text { Mole analyte } \\
\text { per mole } \mathrm{Na} \\
\text { Ratio }\end{array}$ \\
\hline \multicolumn{9}{|c|}{ Inorganic Anions ${ }^{(1)}$, nun date $4 / 23-24 / 00$} \\
\hline Fluoride ${ }^{(2)}$ & 2,880 & 2,880 & 2,940 & 2,900 & 1.2 & $1.5 \mathrm{E}-1$ & 2.7E-2 & $9.1 E-2$ \\
\hline Chloride & 2,000 & 1,920 & 2,010 & 1,980 & 2.5 & $5.6 \mathrm{E}-2$ & $9.9 \mathrm{E}-3$ & $3.7 \mathrm{E}-2$ \\
\hline Nitrite & 42,200 & 41,000 & 42,400 & 41,900 & 1.8 & $9.1 \mathrm{E}-1$ & $1.6 \mathrm{E}-1$ & $3.8 \mathrm{E}-1$ \\
\hline Nitrate & 133,000 & 130,000 & 133,000 & 132,000 & 1.3 & $2.1 E+0$ & $3.8 \mathrm{E}-1$ & 8.0E-1 \\
\hline Phosphate & 1,040 & 1,000 & 1,020 & 1,020 & 2.0 & $1.1 E-2$ & $1.9 \mathrm{E}-3$ & $3.8 \mathrm{E}-2$ \\
\hline Sulfate & 4,070 & 3,940 & 4,080 & 4,030 & 1.9 & $4.2 \mathrm{E}-2$ & $7.5 \mathrm{E}-3$ & $1.0 \mathrm{E}-2$ \\
\hline \multicolumn{9}{|c|}{ Organic Anions ${ }^{(3)}$, nun date $5 / 11-13 / 00$} \\
\hline Acetate $^{(4)}$ & 1,540 & 1,790 & 1,600 & 1,640 & 8.0 & & & \\
\hline Formate & 1,130 & 1,260 & 1,200 & 1,200 & 5.4 & & & \\
\hline Oxalate & 1,800 & 1,780 & 1,820 & 1,800 & 1.1 & & & \\
\hline Citrate & $<890$ & $<890$ & $<890$ & & & & & \\
\hline \multicolumn{9}{|c|}{ Additional analyte information from Inorganic Anion analysis } \\
\hline Bromide & $<500$ & $<500$ & $<500$ & & & & & \\
\hline
\end{tabular}

(1) Overall error for reported results is estimated to be within $+/-15 \%, 2-\sigma$.

(2) The fluoride results represents the summation of fluoride, acetate, and formate.

(3) Overall error for the reported results is estimated to be within $+/-30 \%, 2-\sigma$.

(4) The acetate value represents the summation of acetate and glycolate. 
Table 3.5. 241-AP-101 Composite, Miscellaneous Analyte Results

\begin{tabular}{|c|c|c|c|c|c|c|c|c|c|c|}
\hline $\begin{array}{r}\text { Lab ID } \\
\text { Sample ID } \\
\text { Units } \\
\end{array}$ & $\begin{array}{c}\text { PB-1701 } \\
\text { prep blank } \\
\mu \mathrm{g} / \mathrm{mL}\end{array}$ & $\begin{array}{c}00-1701 \\
\text { sample } \\
\mu \mathrm{g} / \mathrm{mL} \\
\end{array}$ & $\begin{array}{c}00-17010 \\
\text { duplicate } \\
\mu \mathrm{g} / \mathrm{mL}\end{array}$ & $\begin{array}{c}00-1701 \mathrm{~T} \\
\text { triplicate } \\
\mu \mathrm{g} / \mathrm{mL}\end{array}$ & $\begin{array}{c}\text { Average } \\
\mu \mathrm{g} / \mathrm{mL}\end{array}$ & $\begin{array}{c}\mathrm{RSD} \\
\% \\
\end{array}$ & $\begin{array}{c}\text { Average } \\
\mathrm{M} \\
\end{array}$ & Run Date & $\begin{array}{c}\text { Measured } \\
\text { Mole analyte } \\
\text { per mole Na } \\
\text { Ratio }\end{array}$ & $\begin{array}{c}\text { Specification } 7 \\
\text { Envelope A } \\
\text { Limits } \\
\text { Mole analyte } \\
\text { per mole Na } \\
\text { Ratio }\end{array}$ \\
\hline \multicolumn{11}{|l|}{ Analyte $^{(l)}$} \\
\hline \multicolumn{11}{|l|}{ Persulfate Method ${ }^{(2)}$} \\
\hline TIC & & 6,550 & 6,400 & 6,430 & 6,460 & 1.2 & $5.4 \mathrm{E}-1$ & $4 / 13-14 / 00$ & $9.58 \mathrm{E}-2$ & $3.0 \mathrm{E}-1$ \\
\hline TOC & & 1,860 & 1,980 & 2,030 & 1,960 & 4.5 & $1.6 \mathrm{E}-1$ & $4 / 13-14 / 00$ & $2.91 \mathrm{E}-2$ & $5.0 \mathrm{E}-1$ \\
\hline $\mathrm{TC}^{(3)}$ & & 8,410 & 8,390 & 8,460 & 8,420 & 0.4 & & $4 / 13-14 / 00$ & & \\
\hline TC, Furnace Method ${ }^{(2)}$ & & 8,530 & 8,670 & 8,620 & 8,610 & 0.8 & & $4 / 13-14 / 00$ & & \\
\hline Mercury & 0.026 & $<0.025$ & $<0.025$ & 0.032 & & & $<2 \mathrm{E}-7$ & $5 / 11 / 00$ & $<3 E-8$ & $1.4 E-5$ \\
\hline Cyanide & & 5.81 & 5.56 & 5.73 & 5.70 & 2.2 & & $5 / 11 / 00$ & & \\
\hline Ammonia $^{(4)}$ & & 1.83 & 1.70 & 1.61 & 1.71 & 6.5 & & $4 / 11 / 00$ & & \\
\hline Total hydroxide & & 42,300 & 41,100 & 40,500 & 41,300 & 2.2 & $2.4 \mathrm{E}+0$ & $5 / 11 / 00$ & & \\
\hline Units & & $\mathrm{g} / \mathrm{mL}$ & $\mathrm{g} / \mathrm{mL}$ & $\mathrm{g} / \mathrm{mL}$ & $\mathrm{g} / \mathrm{mL}$ & $\%$ & & & & \\
\hline Density & & 1.307 & 1.309 & 1.308 & 1.308 & 0.076 & & $4 / 5 / 00$ & & \\
\hline
\end{tabular}

(1) Overall error for the reported results (except for ammonia) is estimated to be within $+/-15 \%, 2-\sigma$.

(2) Reporting units are $\mu \mathrm{g} \mathrm{C/mL} \mathrm{solution.}$

(3) Total carbon is the sum of the TIC and TOC of the persulfate oxidation method.

(4) Error is estimated to be $+/-20 \%, 2-\sigma$. 


\subsection{Procedures, Quality Control, and Data Evaluation}

A discussion of procedures, data quality, and quality control is provided below for each analytical method. The PNL-ALO-128 preparative blank spike and matrix spike recoveries are relevant to ICP and specifically included TCLP metals. However, two of the TCLP metals (As and Se) are included in the ICP-MS analysis. Other analytical methods, as well as ICP, generally relied on post digestion blank spikes and post digestion matrix spikes for use in data quality assessments. Analytical instrument calibration and calibration verification was performed in accordance with the SBMS Quality Assurance Program. This QA program is in compliance with HASQARD. Raw data including bench sheets, instrument printouts, data reduction, and calibration files are maintained or cross-referenced in the project files.

\subsection{Metals Analysis by ICP-Tables 3.1 and 4.1}

The PNL-ALO-128 acid extracted samples required 5, 10 and 50-fold dilutions in order to quantify all analytes of interest according to PNL-ALO-211. The detected analytes at or above the estimated quantitation level (EQL) are reported with an uncertainty of $\pm 15 \%(2-\sigma)$, and is equivalent to ten times the MDL. Values in brackets "[]" are less than the EQL, and have uncertainties greater than $\pm 15 \%$. Non-detected analytes are reported as less than the MDL. As the MDL is approached, uncertainty increases to $100 \%$.

Quality control for the ICP analysis consists of sample duplicates, process blanks, serial dilution, matrix spikes, laboratory control standards (LCS) or blank spikes, post spikes, verification check standards, and high calibration standards. Matrix spike and LCS recovery and precision quality control parameters were also defined by BNFL. These quality control parameters were evaluated in detail and are summarized below.

Replicates: All analytes of interest were recovered within the precision tolerance limit of $\leq 15 \%$ relative standard deviation (RSD) except for $\mathrm{P}$ where the RSD was $16 \%$.

Preparation blanks: All preparation blank analytes of interest were within tolerance limit of $\leq \mathrm{EQL}$ or $<5 \%$ of sample concentration in the prepared samples.

Serial dilution: Results from serial dilution were within tolerance limit of $\leq 10 \%$ for all analytes tested after correcting for dilution.

Matrix spikes: All matrix-spiked analytes of interest were recovered within tolerance limits of $75 \%$ to $125 \%$ recoveries except silver, barium and lead. Silver recovery (about 35\%), barium recovery (about 30\%) and lead recovery (about 65\%) were all low and may be related to the presence of sulfate and/or carbonate in the sample. Low silver recovery is probably due to the small amount of hydrochloric acid used during sample processing resulting in some silver chloride precipitation.

LCS: All LCS aliquots had a small amount of precipitate remaining after processing that required filtration. All analytes of interest were recovered within tolerance limit of $80 \%$ to $120 \%$ recoveries except silver. Low recovery of silver in the blank spike (about $69 \%$ ) was probably due to the small amount of hydrochloric acid used during sample preparation resulting in some silver chloride precipitating from solution. The LCS for silver recovery was $69 \%$, below QC Acceptance Criteria of $80 \%-120 \%$. 
Post-spiked samples: All analytes of interest were recovered within tolerance of $75 \%$ to $125 \%$ except silicon and palladium. Silicon recovery (147\%) exceeded tolerance limit. Palladium recovery (53\%) exceeded tolerance limit. All other analytes of interest above EQL were within tolerance. Palladium was found low in the group B spike. Single element palladium at $2.0 \mu \mathrm{g} / \mathrm{ml}$ measured at the beginning, middle and end of the run, were well within the tolerance limit. Palladium was not detected in the sample aliquots.

Verification check standards: Concentrations of all analytes were within the tolerance limit of $\pm 10 \%$ accuracy in standards (except palladium). The calibration blank concentration was acceptable, less than two times the IDL. The palladium in the QC check standard was low (about $42 \%$ to $48 \%$ ), however, a single element standard of palladium at $2.0 \mu \mathrm{g} / \mathrm{ml}$ measured at the beginning, middle and end of the ICP run was well within tolerance limit indicating acceptable palladium accuracy. Palladium was not detected in the sample aliquots.

High calibration standard check: Verification of the high-end calibration for all analytes measured was within tolerance limits of $\pm 5 \%$ accuracy.

Detection limits: The reported MDLs for all analytes were less than the BNFL MRQs and in most cases, the EQLs were less than the MRQs ( $\mathrm{Ba}, \mathrm{La}, \mathrm{Rh}, \mathrm{Ru}$, and Si EQLs were higher than the associated MRQs).

\subsection{Total Uranium (KPA) Tables 3.1 and 4.1}

Triplicate PNL-ALO-106 acid digested samples were measured for total uranium according to procedure PNNL-ALO-4014 using Kinetic Phosphorescence Analysis (KPA). The triplicate results showed excellent agreement with a RSD of $1 \%$. A small amount of uranium was detected in the acid digestion process blank; however, the level was a factor of 10,000 lower than the uranium measured in the samples. A blank prepared at the time of the analysis did not detect any uranium. Uranium continuing calibration verification (CCV) standards analyzed before and after the samples agreed within $3 \%$ of the known values. A specific blank spike and a matrix spike were not run. The U(KPA) analysis results agreed well with the U(ICP-MS) analysis results.

\subsection{Radioisotopic Analyses, Tables 3.2 and 4.2}

Gamma energy analysis (GEA), pertechnetate, tritium, ${ }^{14} \mathrm{C}$, and ${ }^{79} \mathrm{Se}$ analyses were performed on asreceived samples, i.e., acid digestion of sub-samples was not performed. Other radioisotopic analyses were performed using the PNL-ALO-106 acid digested samples. Because a radioisotopic LCS is not available, post digestion spikes, tracers, and/or carriers were used, as appropriate, for monitoring process control.

\section{Gamma Spectrometry}

Triplicate $100-\mu \mathrm{L}$ aliquots of the AP-101 original material were prepared into 2-mL geometries with deionized water (no acid digestion was applied). The small aliquot size was necessary to reduce the detector dead time attributed to the high ${ }^{137} \mathrm{Cs}$ activity. The samples were counted and analyzed directly by GEA according to procedure PNL-ALO-450. Because no sample manipulation was performed other than simple aliquoting and diluting, no preparation blank was prepared. In order to meet the required detection limits, the samples were counted for 14 hours each. Despite the longer counting time, the ${ }^{241} \mathrm{Am}$ MRQ was not met; this isotope however was quantified using radiochemical separations. Only ${ }^{137} \mathrm{Cs},{ }^{134} \mathrm{Cs}$, and ${ }^{60} \mathrm{Co}$ could be identified in the gamma spectra. The triplicate concentrations of ${ }^{137} \mathrm{Cs},{ }^{134} \mathrm{Cs}$, and ${ }^{60} \mathrm{Co}$ agreed to within $\pm 3 \%$, well within the $<15 \%$ RSD acceptance 
criteria. The other requested analyte concentrations were below the minimum reportable quantities. Analysis for ${ }^{135} \mathrm{Cs}$ by GEA was not possible because this isotope has no $\gamma$-emissions.

\section{Pertechnetate}

The radiochemical ${ }^{99} \mathrm{Tc}$ determination was requested to measure only $\mathrm{Tc}$ in the +7 oxidation state (pertechnetate). To this end, all sample manipulations had to be non-oxidizing so as not to alter the original Tc oxidation state. Small aliquots from the as-received material (no digestion) were taken for analysis according to procedure PNL-ALO-432. A blank was prepared and run in parallel with the samples. This procedure normally requires the use of a sodium dichromate addition to oxidize the Tc to the +7 oxidation state. The sodium dichromate addition was omitted and the procedure was otherwise performed as written. The separated fractions were then counted according to RPG-CMC408. One sample was also counted by gamma spectrometry (according to PNL-ALO-450) to verify the absence of ${ }^{137} \mathrm{Cs}$. Pertechnetate was added to the blank spike and matrix spike and their recoveries were $99 \%$ and $84 \%$, respectively, well within project requirements. The sample activity propagated $1-\sigma$ uncertainty was $4 \%$. The RSD of the triplicate samples was $8 \%$, again well within the project-required $<15 \% \mathrm{RSD}$. The blank contained no measurable ${ }^{99} \mathrm{Tc}$ with a detection limit well below the MRQ.

Comparison of the pertechnetate values to the ICP-MS generated values show excellent agreement. This indicates the ${ }^{99} \mathrm{Tc}$ present in AP-101 is primarily in the +7 oxidation state.

Total Alpha

The total alpha activity was determined by direct-plating small aliquots of the acid-digested samples onto planchets according to RPG-CMC-4001. The samples were then counted on Ludlum detectors according to RPG-CMC-408. The sample activities resulted in a $9 \% \mathrm{RSD}$, well within the $<15 \%$ RSD acceptance criteria. Alpha activity was not found in the preparation blank. The blank spike ${ }^{239} \mathrm{Pu}$ recovery was $99 \%$ and the matrix spike ${ }^{239} \mathrm{Pu}$ recovery was only $55 \%$. The low matrix spike recovery is attributed to the solids loading on the planchet from the sample matrix salts that attenuate/absorb the alpha emissions. This is a physical problem with the sample as it is presented to the detector and does not indicate the analysis is out of control. What this does indicate is that the analytical method (which does not correct for solids loading) is probably biased low by as much as $45 \%$ for this matrix. A better indication of the total alpha activity is given by the summation of the alpha emitters $\left({ }^{239+240} \mathrm{Pu},{ }^{238} \mathrm{Pu},{ }^{241} \mathrm{Am},{ }^{243+244} \mathrm{Cm}\right.$ and $\left.{ }^{242} \mathrm{Cm}\right)$, where matrix effects have been eliminated through radiochemical separations. These alpha-emitter summations range from $18 \%$ to $39 \%$ higher than the total alpha activity found by direct plating. The RSD for the summation method is $\pm 1 \%$.

\section{Total Beta}

The total beta activity was determined by directly plating small aliquots of the acid-digested samples onto planchets according to RPG-CMC-4001. The samples were then counted on a low-background alpha/beta gas-flow proportional counter according to RPG-CMC-408. The detectors were calibrated for beta activity relative to ${ }^{90} \mathrm{Sr}{ }^{90} \mathrm{Y}$. The beta energy of ${ }^{137} \mathrm{Cs}$ is similar to that of ${ }^{90} \mathrm{Sr}$ and will have a counting efficiency similar to that of pure ${ }^{90} \mathrm{Sr}$. The total beta analyses compared to the ${ }^{137} \mathrm{Cs}$ determinations shows that virtually all of the beta activity is due to ${ }^{137} \mathrm{Cs}$ as the two activity concentrations are in excellent agreement. The 5\% RSD is within the experimental error. The blank spike and matrix spike showed excellent ${ }^{90} \mathrm{Sr}{ }^{90} \mathrm{Y}$ recoveries at $100 \%$ and $103 \%$, respectively.

Plutonium, Americium, and Curium Analyses of $\mathrm{Pu}, \mathrm{Am}$, and $\mathrm{Cm}$ were conducted on the acid-digested samples. The $\mathrm{Pu}$ and $\mathrm{Am} / \mathrm{Cm}$ separations were performed according to PNL-ALO-417; the separated fractions were precipitation plated according to PNL-ALO-496; and the samples were counted by alpha spectrometry according to 
PNL-ALO-422. Plutonium recovery was traced with ${ }^{242} \mathrm{Pu}$. The curium chemistry is known to follow the americium and both these isotopes were traced with ${ }^{243} \mathrm{Am}$. Plutonium radiochemical yields were excellent at $>90 \%$. Radiochemical yields for Am ranged from $70 \%$ to $86 \%$. In both cases, ample counts were obtained to define analyte and tracer activities. Neither $\mathrm{Pu}, \mathrm{Am}$ nor $\mathrm{Cm}$ were detected in the preparation blank. The blank spike and matrix spike for Pu resulted in $98 \%$ and $101 \%$ yield-corrected recovery. This indicates the chemistry and analyses were not biased. The blank spike and matrix spike for the Am (and $\mathrm{Cm}$ ) fractions resulted in $94 \%$ and $91 \%$ yield-corrected recovery. The ${ }^{239+240} \mathrm{Pu}$ RSD was $2 \%$ and the ${ }^{238} \mathrm{Pu}$ RSD was $5 \%$. The ${ }^{241} \mathrm{Am}$ RSD was $2 \%$ and the ${ }^{243+244} \mathrm{Cm}$ RSD was $29 \%$. This latter high RSD reflects the much higher uncertainty associated with the analytical results, which were approximately 5 orders of magnitude less than the requested MRQ.

\section{Strontium-90}

The Sr separation was performed on the acid-digested samples according to PNL-ALO-476 and radiochemical yields were traced with ${ }^{85} \mathrm{Sr}$. The separated fractions were then beta-counted according to RPG-CMC-408 and gamma counted according to PNL-ALO-450 (for ${ }^{85} \mathrm{Sr}$ determination and ${ }^{137} \mathrm{Cs}$ impurity assessment). Two of the separated fractions contained a small amount of ${ }^{137} \mathrm{Cs}$ and a correction to the beta count rate was applied for these samples. Strontium-90 was not found in the preparation blank. The RSD was $0.3 \%$, indicative of excellent precision. The LCS and matrix spike recoveries were $92 \%$ and $99 \%$, respectively, indicating good accuracy.

\section{Tritium}

Aliquots of AP-101 composite were diluted in water and distilled for ${ }^{3} \mathrm{H}$ determination according to procedure PNL-ALO-418. Two serial distillations were required to isolate tritium from ${ }^{137} \mathrm{Cs}$. Tritium was then measured using liquid scintillation counting according to procedure PNL-ALO-474. The first distillation showed the presence of higher-energy beta activity, most likely due to ${ }^{137} \mathrm{Cs}$. A second distillation succeeded in removing most of this contamination; however, two of the triplicate samples required subtraction of weak beta contamination using the ratio of the counts in the tritium energy region to the counts at higher energies, as determined from the first counting results. The triplicate results showed good agreement with a RSD of 5\%. A blank spike showed good recovery at $96 \%$. No tritium was detected in a blank processed with the samples.

Selenium-79

Direct AP-101 composite sub-samples were analyzed in triplicate for ${ }^{79} \mathrm{Se}$ following procedure PNLALO-440. Each sample was spiked with $20 \mathrm{mg}$ Se carrier in solution for yield correction. The samples were passed through mixed-bed anion and cation exchange resins that removed most radiochemical interferences. Selenium was distilled as selenium bromide and then reduced to elemental form. The chemical yield was determined gravimetrically by weighing the recovered elemental selenium. The selenium was then dissolved and the ${ }^{79} \mathrm{Se}$ activity was determined by liquid scintillation counting according to procedure PNL-ALO-474. The liquid scintillation spectra did not show clear evidence for a ${ }^{79} \mathrm{Se}$ peak and there appeared to be some weak beta contamination evident in the higher energy region of the beta spectrum. Hence, the results probably have a slight high bias. The measured ${ }^{79} \mathrm{Se}$ activity (averaging $5.8 \mathrm{E}-5 \mu \mathrm{Ci} / \mathrm{ml}$ ) was below the requested MRQ of $9.0 \mathrm{E}-5$ $\mu \mathrm{Ci} / \mathrm{ml}$ and only slightly above the nominal MDL of $2 . \mathrm{E}-5 \mu \mathrm{Ci} / \mathrm{ml}$. The sample RSD of $18 \%$ exceeded the RSD acceptance criterion of $<15 \%$; however, measurement uncertainties were as high as $11 \%(1-\sigma)$ and the sample activities were only a factor of three higher than the MDL. A ${ }^{79} \mathrm{Se}$ standard was not available, thus ${ }^{14} \mathrm{C}$ (similar beta endpoint energy as ${ }^{79} \mathrm{Se}$ ) was used to calibrate the liquid scintillation detector. For the same reason a blank spike and a sample spike could not be run. The sample carrier recoveries were generally low at $27 \%$ to $63 \%$ and the blank recovery was $68 \%$. All sample activities were corrected for radiochemical yield. The process blank did not show any evidence of contamination. 
Carbon-14

Direct samples of the AP-101 composite were analyzed in triplicate for ${ }^{14} \mathrm{C}$ following procedure PNLALO-482. The samples were combusted in a Coulometrics Carbon Analyzer Furnace causing oxidation of all carbon species present to $\mathrm{CO}_{2}$. A natural carbon compound was added as a carrier and all of the $\mathrm{CO}_{2}$ released was collected in a sodium hydroxide trap. An aliquot of the trap solution was then counted by liquid scintillation counting according to procedure PNL-ALO-474. The triplicate results showed good agreement with a RSD of 5\%. The blank spike and sample spike showed good recoveries at $97 \%$ and $96 \%$, respectively. Carbon-14 was not detected in the blank.

\subsection{Inductively-Coupled Plasma-Mass Spectrometry, Tables 3.3. and 4.3}

Splits from the acid extraction (PNL-ALO-128) were submitted for ICP-MS analysis according to procedure PNL-ALO-280, Rev. 1. The sample splits were from the same processed solutions as were delivered for ICP analysis. A preparative blank and TCLP-spiked blank and sample were also submitted for ICP-MS analysis (As and Se were the relevant spiked analytes).

Values for the following isotopes were obtained using responses from related isotopes: ${ }^{126} \mathrm{Sn}$ (obtained from ${ }^{118} \mathrm{Sn}$ ), ${ }^{231} \mathrm{~Pa}$ (obtained from ${ }^{232} \mathrm{Th}$ ), and ${ }^{240} \mathrm{Pu},{ }^{241} \mathrm{AMU},{ }^{242} \mathrm{AMU},{ }^{243} \mathrm{AMU}$ (obtained from ${ }^{239} \mathrm{Pu}$ ). Because the concentrations of these isotopes were determined indirectly, ${ }^{126} \mathrm{Sn},{ }^{231} \mathrm{~Pa}$, ${ }^{240} \mathrm{Pu},{ }^{241} \mathrm{AMU},{ }^{242} \mathrm{AMU}$, and ${ }^{243} \mathrm{AMU}$ results should be considered semi-quantitative.

In general, the results for the quality control samples (i.e., calibration verification standards, duplicates, blank spike, sample spike, and post digestion sample spikes) were well within acceptance criteria. One of the CCV results for tellurium and tantalum and the spike recovery for thallium, were outside the acceptance window ( $<20 \%$ for the CCV and $<30 \%$ for the Spike). Tellurium and tantalum did have another $\mathrm{CCV}$ result that was acceptable. The CCV results for thallium were acceptable. The RSDs for all detected analytes were $<15 \%$. The MDL for ${ }^{231} \mathrm{~Pa}$ was slightly above the MRQ. The preparation blank for As and B represented $10 \%$ and $40 \%$ of the measured sample concentrations, higher than the 5\% acceptance criteria defined in the QA plan.

The ${ }^{99} \mathrm{Tc}$ values reported assume that the $\mathrm{Ru}$ present is exclusively fission-product $\mathrm{Ru}$, and therefore does not have an isotope at mass to charge ratio $(\mathrm{m} / \mathrm{z}) 99$; i.e., everything observed at $\mathrm{m} / \mathrm{z} 99$ is due to ${ }^{99} \mathrm{Tc}$. From the appearance of the Ru isotopic abundance, this appears to be a reasonable assumption; the isotopic fingerprint exhibited is not natural. Good agreement between the total ${ }^{99} \mathrm{Tc}$ and the pertechnetate (radiochemical determination) values were obtained.

\subsection{Anion Analysis, Tables 3.4 and 4.4}

Anion analysis was conducted according to two different methods in an effort to achieve the desired specificity. One method, PNL-ALO-212, Determination of Inorganic Anions by Ion Chromatography, is optimized for determination of inorganic anions. The other method, AOAM-1, Method for the Analysis and Quantification of Organic Acids in Simulated and Actual Hanford Tank Wastes by Ion Chromatography, is optimized for the determination of organic acids. Both methods were used to evaluate the anionic analytes of interest on unprocessed AP-101 composite sub-samples. Oxalate concentration was determined by the inorganic anion method, however the reliability of the organic anion method is considered to provide superior oxalate results.

Inorganic Anions 
The AP-101 composite sub-samples were diluted 2000 to 5000 fold at the IC workstation to ensure that all anions reported were measured within the calibration range. All client-defined MRQs were met at the dilutions analyzed. From recoveries demonstrated on some of the verification standards, the AP-101 sample matrix had an adverse effect on the IC column and some reported results may be $10 \%$ to $20 \%$ low. By further diluting the sample, this effect could be minimized, but at the expense of meeting the MRQs (particularly phosphate and sulfate).

For the IC column and parameters used, the IC system cannot separate fluoride, acetate, and formate; the IC system quantifies and reports all as fluoride. Acetate (and/or glycolate) and formate were quantified in the organic anion analysis, the sum of these nearly equaling the "fluoride" concentration. An upper bound to the fluoride concentration can be calculated by subtracting the acetate and formate sum from the reported fluoride concentration providing $50+1-960 \mu \mathrm{g} \mathrm{F} / \mathrm{mL}$ or $<1000 \mu \mathrm{g} \mathrm{F} / \mathrm{mL}$.

Duplicates: The RSD was $<3 \%$ for all anions, well within the $<15 \%$ RSD acceptance criterion.

Matrix Spike: The matrix spike recoveries for all anions, except nitrate, were within the spiking acceptance criteria of $75 \%$ to $125 \%$. The high nitrate concentration of the sample relative to the nitrate spiking level (i.e., sample concentration was 10 times greater than the spike concentration) significantly impacts the ability to measure the nitrate spike. No attempt was made to spike the samples at an additional spiking level. A 10,000x dilution provided a result of $130,000 \mu \mathrm{g} / \mathrm{mL}$ nitrate, in good agreement with the $2000 \mathrm{x}$ dilution. This indicates the matrix effects on nitrate determination are negligible.

Blank Spike: The blank spike recoveries for all anions, except nitrate, were within the Laboratory Control Samples (LCS) acceptance criteria of $80 \%$ to $120 \%$. The nitrate recovery was slightly low at $78 \%$. It should be noted that the blank spike nitrate recovery was not consistent with other control standards analyzed during the analysis run (e.g., Verification Check Standards).

System Blank/Processing Blanks: A dozen system blanks were processed during the analysis of the samples. No anions were detected in the system blanks above the method detection limit.

Quality Control Calibration Verification Check Standards: Over twenty mid-range verification standards were analyzed throughout the analysis runs. Numerous verification standards analyzed just after the analysis of some of the AP-101 samples demonstrated low recoveries (i.e., recoveries ranging from $80 \%$ to $90 \%$ ). Failure of the verification standard was only observed in those standards analyzed just after the AP-101 samples that were prepared with the least dilution. Numerous reruns were performed alternating the AP-101 (at various dilutions) and the verification standard to obtain valid data.

\section{Organic Anions}

Sample A.P-101 was diluted 2000 -fold to give acceptable total ion loading on the column. The reported acetate concentration represents the summation of acetate and glycolate, since both ions co-elute under the sample analysis conditions. From tank waste and solubility studies, the acetate and glycolate concentrations are tank waste type dependent. That is, for one tank waste the component may be entirely acetate; for another tank with a different fill history, the component may be primarily glycolate, or a combination of both analytes (Sharma et al. 1998, Camaioni et al. 1998, Barney 1996, Ashby et al. 1994). 
The RSD of the triplicate values were well within the $<15 \%$ acceptance criteria. The method detection limits are given in Table 4.4. The oxalate MDL was below the client-directed MRQ; other analyte MRQs were undefined.

Matrix spiking was done in triplicate at a level approximately 1.5 times the level of analyte in the final diluted samples. This level of spiking is at a challenging level for accurate quantitation; the reported levels are near the lowest calibration point for each analyte. The acetate matrix spike recoveries were $175 \%, 91 \%$, and $105 \%$, averaging $124 \%$. The formate matrix spike recoveries were $71 \%, 104 \%$ and $79 \%$, averaging $84 \%$. The oxalate matrix spike recoveries were $122 \%, 92 \%$, and $129 \%$, averaging $114 \%$. The value for acetate in the matrix spike sample should be considered suspect, as the peak quantitation had to be done by estimation (since the peak size was so small). The other data represent quantitation that was extracted directly from electronic integration data. Overall, the average data for MS and MSD were within acceptable limits. The LCS consisted of a mixture of formate and oxalate and resulted in 89.3 and $103.8 \%$ recoveries, respectively.

\subsection{Miscellaneous Analytes, Tables 3.5 and 4.5}

Inorganic and Organic Carbon

The AP-101 composite analysis was performed by the hot persulfate wet oxidation method according to PNL-ALO-381 and by the furnace oxidation method according to PNL-ALO-380. The hot persulfate method uses acid decomposition for TIC and acidic potassium persulfate oxidation at 92$95^{\circ} \mathrm{C}$ for TOC, all on the same sample, with TC being the sum of the TIC and TOC. The furnace oxidation method determines TC by oxidizing all forms of carbon (i.e., inorganic and organic) in oxygen at $1000^{\circ} \mathrm{C}$. Although the ASR requested TOC and TIC by the furnace method, the method is considered reliable only for TC. For the sample matrix analyzed, the furnace method and hot persulfate method should provide equivalent TC results; this was confirmed, with the average hot persulfate TC being $8420 \mu \mathrm{g} / \mathrm{ml}$ and the furnace TC being $8610 \mu \mathrm{g} / \mathrm{ml}$, an RPD of about $2 \%$.

Per procedures, all sample results were corrected for average percent recovery of system calibration standards and were also corrected for contribution from the blank. Precision and bias were estimated to be $\pm 15 \%(2-\sigma)$.

The TIC standard is calcium carbonate and TOC/TC standard is $\alpha$-Glucose. The standard materials were used in solid form for system calibration check standards as well as matrix spikes. The QC for the methods involves calibration blanks, system calibration standards, sample duplicates, and one matrix spike per matrix type.

Calibration Standards: The QC system calibration check standards were all within acceptance criteria of $90 \%$ to $110 \%$, with the average recovery being about $99 \%$ for TIC and $99 \%$ for TOC over the two days that the hot persulfate analyses were performed and about $100 \%$ for TC for the furnace analyses.

Calibration Blanks: The calibration blanks run at the beginning, middle, and end of the analysis run were acceptable and the standard deviations for the TIC and TOC blanks were near the historical pooled standard deviation used to establish the method detection limits. On the May $12^{\text {th }}$ run, the TOC blanks were about 2 to 3 times higher than normal, but were quite consistent. Because the blank results were subtracted from the sample results, the high blanks should have no effect on the reported data within the reported uncertainty. 
Replicates: All RSDs were less than 5\%, indicating good precision between all measurements. The RSDs met the acceptance criterion of $<15 \%$.

Matrix Spike: The accuracy of the carbon measurements can be estimated by the recovery results from the matrix spike. The matrix spike for both the hot persulfate and furnace method demonstrated recoveries of about $96 \%$ to $99 \%$ for TIC, TOC, and TC; well within the acceptance criteria of $75 \%$ to $125 \%$ recovery.

Laboratory Control Sample: No LCS was included in the carbon analysis procedure.

\section{Mercury}

The samples were analyzed by cold vapor atomic absorption spectrophotometry for inorganic mercury according to PNNL-ALO-201. Four aliquots of $0.2 \mathrm{ml}$ including one for matrix spike, was processed and diluted to a final volume of $25 \mathrm{ml}$ per procedure PNNL-ALO-131; no additional dilution was performed. Concentration of all sample aliquots measured were near instrument detection limit and several times lower than MRQ $(1.5 \mu \mathrm{g} / \mathrm{ml})$. The low calibration standard was defined as the instrument detection limit (DL) for the reported results and assumes non-complex aqueous matrices. Routine precision and bias is typically $\pm 15 \%(2-\sigma)$ or better for non-complex aqueous samples that are free of interference.

Following are results of quality control checks performed during $\mathrm{Hg}$ analyses. In general, quality control checks met the requirements of the governing QA Plan.

Working Blank Spike/Process Blank Spike: The process blank spike recovery was $100 \%$, well within the acceptance criteria of $80 \%$ to $120 \%$.

Matrix Spiked Sample: A matrix spike was prepared for the samples submitted under this ASR. Recovery of the matrix spike was $97 \%$, well within the acceptance criteria of $75 \%$ to $125 \%$.

Duplicate/replicates: The RSD was not calculated since all replicate results were less than $5 \times$ IDL.

Laboratory Control Sample (liquid): Sample recovery of mercury in SRM-1641d (certified by NIST to contain $1.60 \pm 0.018 \mu \mathrm{g} / \mathrm{ml}$ ) was recovered within acceptance criteria of $75 \%$ to $125 \%$.

System Blank/Processing Blanks: A system blank was processed during the analysis of the sample. The concentration measured was within about two times detection limit or less. Samples were about the same concentration as the process blank.

Quality Control Calibration Verification Check Standards: Six mid-range verification standards were analyzed throughout the analysis run. All were within the acceptance criteria of $80 \%$ to $120 \%$ recovery for the verification standard.

\section{Cyanide}

The AP-101 composite samples were distilled according to PNL-ALO-287 with the addition of sulfamic acid to minimize interference from high nitrates present in the sample. The distillates were analyzed for $\mathrm{CN}$ concentration according to PNL-ALO-289. The reporting limits were estimated to be approximately $0.25 \mu \mathrm{g} \mathrm{CN} / \mathrm{ml}$ based on the sample quantity distilled. No quality control or other measurement problems were encountered. 
An independent mid-range calibration check solution run at the beginning, middle, and end of the analysis batch gave an average recovery of $100 \%$. These calibration check standards ranged from $99 \%$ recovery to $100 \%$ recovery, which is within the $85 \%$ to $115 \%$ acceptance criteria of the governing QA plan.

The AP-101 composite was analyzed in triplicate. The RPD between the sample and duplicate was $4.4 \%$ and the RSD for the triplicates was $3.1 \%$. The measurement precision met the quality control criterion of $<15 \%$ RSD. The LCS (a distilled blank spike) recovery was $101 \%$, well within the quality control acceptance criteria. The spike recovery for the spiked AP-101 composite was $95 \%$, well within the acceptance criteria of $75 \%$ to $125 \%$.

\section{$\underline{\text { Ammonia }}$}

Ammonia was measured in triplicate sample aliquots of AP-101 composite using an ion selective electrode according to procedure PNL-ALO-226. The ammonia probe was calibrated using five standards spanning ammonia concentrations from $1.0 \mathrm{E}-2$ to $1.0 \mathrm{E}-6 \mathrm{M}$. The method of standard additions was used to determine the ammonia concentrations by first taking a direct reading and then adding a known standard to each sample. The triplicate concentrations were in good agreement with a RSD of $6 \%$. The method detection limit was estimated at $0.2 \mu \mathrm{g} / \mathrm{ml}$, well below the requested MRQ value of $140 \mu \mathrm{g} / \mathrm{ml}$.

\section{Hydroxide}

A sample of the AP-101 composite was analyzed in triplicate for the free hydroxide content following procedure PNL-ALO-228. Direct sample aliquots were analyzed using a Brinkman 636 AutoTitrator. A $0.1186 \mathrm{~N} \mathrm{NaOH}$ solution was prepared for use as a standard and sample spike and the titrant was a $0.2040 \mathrm{M} \mathrm{HCl}$ prepared solution. Triplicate determinations resulted in $\pm 3 \% \mathrm{RSD}$. The standard recoveries averaged $100 \%$ and the sample spike recovery was $88 \%$. Hydroxide was not detected in the reagent blank, demonstrating an MDL of $0.02 \mathrm{M} \mathrm{OH}$ or $340 \mu \mathrm{g} \mathrm{OH} / \mathrm{mL}$.

\section{Density}

The density of the AP-101 composite was calculated using the net sample mass in a $10-\mathrm{mL}$ volumetric flask at ambient temperature. The RSD of the measurements was $0.08 \%$. 
Table 4.1. 241-AP-101 Composite, ICP Metals QC Results

\begin{tabular}{|c|c|c|c|c|c|c|c|c|}
\hline $\begin{array}{r}\text { LabID } \\
\text { Sample ID } \\
\text { Units }\end{array}$ & $\begin{array}{l}\text { Average } \\
\mu \mathrm{g} / \mathrm{mL}\end{array}$ & RSD & $\begin{array}{l}\mathrm{MDL} \\
\mu \mathrm{g} / \mathrm{mL}\end{array}$ & $\begin{array}{l}\text { BNFL } \\
\text { MRQ } \\
\mu \mathrm{g} / \mathrm{mL}\end{array}$ & \% Recovery & $\begin{array}{l}\text { Matrix } \\
\text { Spike } \\
\% \text { Recovery }\end{array}$ & $\begin{array}{c}\text { Post } \\
\text { Matrix } \\
\text { Spike (A) } \\
\% \text { Recovery }\end{array}$ & $\begin{array}{c}\text { Post } \\
\text { Matrix } \\
\text { Spike (B) } \\
\% \text { Recovery }\end{array}$ \\
\hline Acceptance Criter & & $<15 \%^{(3)}$ & & & $80 \%-125 \%$ & $75 \%-125 \%$ & & \\
\hline \multicolumn{9}{|l|}{ Analyte ${ }^{(1)}$} \\
\hline $\mathrm{Ag}$ & $<0.63$ & & 0.63 & 17 & 69 & 35 & 96 & \\
\hline Al & 6,940 & 5.5 & 1.5 & 75 & & & 113 & \\
\hline $\mathrm{Ba}$ & {$[0.33]$} & 3.0 & 0.25 & 2.3 & 87 & 30 & 96 & \\
\hline $\mathrm{Bi}$ & $<2.5$ & & 2.5 & 170 & & & 95 & \\
\hline $\mathrm{Ca}$ & {$[7.7]$} & 2.0 & 6.3 & 150 & & & 97 & \\
\hline $\mathrm{Cd}$ & {$[2.0]$} & 2.9 & 0.38 & 7.5 & 92 & 87 & 97 & \\
\hline $\mathrm{Cr}$ & 143 & 8.9 & 0.51 & 15 & 93 & 94 & 103 & \\
\hline $\mathrm{Cu}$ & [1.6] & 7.4 & 0.63 & 17 & & & 97 & \\
\hline $\mathrm{Fe}$ & {$[2.5]$} & 14 & 0.63 & 75 & & & 97 & \\
\hline $\mathrm{K}$ & 31,200 & 2.1 & 51 & 750 & & & 115 & \\
\hline $\mathrm{La}$ & $<1.3$ & & 1.3 & 2.3 & & & & 100 \\
\hline $\mathrm{Mg}$ & $<2.5$ & & 2.5 & 170 & & & 102 & \\
\hline Mn & $<1.3$ & & 1.3 & 17 & & & 99 & \\
\hline $\mathrm{Na}$ & 129,000 & 2.9 & 3.8 & 170 & & & & \\
\hline $\mathrm{Nd}$ & $<2.5$ & & 2.5 & 170 & & & & 101 \\
\hline $\mathrm{Ni}$ & 7.9 & 7.6 & 0.76 & 30 & 88 & 85 & 99 & \\
\hline $\mathbf{P}$ & 314 & 16 & 2.5 & 330 & & & 98 & \\
\hline $\mathrm{Pb}$ & {$[15]$} & 0.0 & 2.5 & 300 & 101 & 65 & 107 & \\
\hline $\mathrm{Pd}$ & $<19$ & & 19 & 390 & & & & 53 \\
\hline $\mathrm{Rh}$ & $<7.6$ & & 7.6 & 18 & & & & 95 \\
\hline $\mathrm{Ru}$ & $<28$ & & 28 & 36 & & & & 96 \\
\hline $\mathrm{Si}$ & 137 & 4.0 & 13 & 90 & & & 147 & \\
\hline Sr & $<0.38$ & & 0.38 & 17 & & & 97 & \\
\hline $\mathrm{Ti}$ & $<0.63$ & & 0.63 & 17 & & & 95 & \\
\hline $\mathbf{U}$ & {$[62]$} & 9.7 & 51 & 780 & & & & 104 \\
\hline $\mathrm{U}(\mathrm{KPA})^{(2)}$ & 51.1 & 1.4 & 0.0002 & 780 & & & & \\
\hline $\mathrm{U}(\mathrm{ICP}-\mathrm{MS})^{(2)}$ & 55.3 & 5.7 & 0.02 & NP & & & 115 & \\
\hline $\mathrm{Zn}_{\mathrm{n}}$ & [5.6] & 3.7 & 1.3 & 17 & 89 & 92 & 96 & \\
\hline $\mathrm{Zr}$ & [1.4] & 4.2 & 1.3 & 17 & & & 100 & \\
\hline \multicolumn{9}{|c|}{ Additional analyte information } \\
\hline$A s^{*}$ & $<6.3$ & & & & 95 & [97] & 107 & \\
\hline $\mathrm{Be}^{*}$ & {$[1.0]$} & 5.6 & & & & & 97 & \\
\hline $\mathrm{B}^{*}$ & 15 & 2.6 & & & & & 97 & \\
\hline $\mathrm{Co}^{*}$ & $<1.3$ & & & & & & 97 & \\
\hline $\mathrm{Li}^{*}$ & $<0.76$ & & & & & & 95 & \\
\hline Mo* & [11] & 11 & & & & & 97 & \\
\hline $\mathrm{Se}^{*}$ & $<6.3$ & & & & 95 & {$[80]$} & 104 & \\
\hline $\mathrm{Sn}$ & $<38$ & & & & & & & 93 \\
\hline $\mathrm{T}^{*}$ & $<13$ & & & & 92 & [91] & 97 & \\
\hline $\mathrm{V}^{*}$ & $<1.3$ & & & & & & 97 & \\
\hline $\mathrm{W}^{*}$ & $<51$ & & & & & & & 95 \\
\hline $\mathrm{Y}$ & $<1.3$ & & & & & & 99 & \\
\hline
\end{tabular}

Shaded areas highlight non-compliances with BNFL acceptance criteria, see report for discussion.

(1) Overall error for reported results is estimated to be within $+1-15 \% 2-\sigma$; however results in brackets "[ ]" are less than the estimated quantitation level (i.e., 10-times MDL) and error is anticipated to exceed $+1-15 \%$.

(2) U (KPA) indicates $U$ determination by kinetic phosphorescence; U(ICP-MS) indicates U determination by ICP-MS. QC parameters for these techniques were not specified.

(3) RSD acceptance criteria for Na concentration is $<3.5 \%$. Analytes on ICP-MS Specification 7 list. 
Table 4.2. 241-AP-101 Composite, Radionuclide QC Results

\begin{tabular}{|c|c|c|c|c|c|c|c|c|c|}
\hline Unis & $\begin{array}{l}00-1701 \\
\text { Average } \\
\mu \mathrm{Ci} / \mathrm{mL}\end{array}$ & $\begin{array}{c}\% \text { Err } \\
1-\sigma\end{array}$ & $\begin{array}{c}\mathrm{RSD}^{(3)} \\
\% \\
\end{array}$ & $\begin{array}{c}\mathrm{MDL} \\
\mu \mathrm{Ci} / \mathrm{mL}\end{array}$ & $\begin{array}{l}\text { BNFL } \\
\text { MRQ } \\
\mu \mathrm{Ci} / \mathrm{mL}\end{array}$ & $\begin{array}{c}\text { Blank } \\
\text { Spike } \\
\text { \% Recovery }\end{array}$ & $\begin{array}{l}\text { Blank spike } \\
\text { Acceptance } \\
\text { Criteria } \\
\text { \% Recóvery }\end{array}$ & $\begin{array}{l}\text { Matrix } \\
\text { Spike } \\
\text { \% Recovery }\end{array}$ & $\begin{array}{c}\text { MS } \\
\text { Acceptance } \\
\text { Criteria } \\
\text { \% Recovery }\end{array}$ \\
\hline \multicolumn{10}{|l|}{ Radiochemical Analytes } \\
\hline${ }^{3} \mathrm{H}$ & $4.83 \mathrm{E}-3$ & 3 & 4.7 & $2.0 E-4$ & $2.1 \mathrm{E}-2$ & 96 & $80-120$ & & $N / A^{(s)}$ \\
\hline${ }^{14} \mathrm{C}$ & $2.63 E-4$ & 8 & 4.7 & $4.0 \mathrm{E}-5$ & $7.2 E-4$ & 97 & $80-120$ & 96 & $75-125$ \\
\hline${ }^{60} \mathrm{Co}(\mathrm{GEA}){ }^{(1)}$ & $3.29 \mathrm{E}-3$ & 7 & 3.0 & & $2.1 E-3$ & & $N P^{(t)}$ & & N/A \\
\hline${ }^{79} \mathrm{Se}$ & $5.82 \mathrm{E}-5$ & 5 & 18 & $3.0 \mathrm{E}-6$ & $9.0 \mathrm{E}-5$ & & $\mathrm{NP}$ & & N/A \\
\hline${ }^{90} \mathrm{Sr}$ & $8.74 \mathrm{E}-2$ & 3 & 0.3 & $2.0 \mathrm{E}-4$ & $3.0 \mathrm{E}-2$ & 92 & $75-125$ & 99 & N/A \\
\hline${ }^{99} \mathrm{Tc}(+7)$ & $4.72 \mathrm{E}-2$ & 4 & 8.1 & $2.0 \mathrm{E}-5$ & $1.5 \mathrm{E}-3$ & 99 & $80-120$ & 84 & $70-130$ \\
\hline${ }^{106} \mathrm{Ru} / \mathrm{Rh}(\mathrm{GEA}){ }^{(1)}$ & $<9 \mathrm{E}-2$ & & & $9.0 \mathrm{E}-2$ & & & NP & & N/A \\
\hline${ }^{125} \mathrm{Sb}(\mathrm{GEA})^{(1)}$ & $<6 \mathrm{E}-2$ & & & $6.0 \mathrm{E}-2$ & $1.7 E+0$ & & to be obtained & & N/A \\
\hline${ }^{134} \mathrm{Cs}(\mathrm{GEA}){ }^{(1)}$ & 4.73E-2 & 3 & 2.1 & & $3.9 \mathrm{E}-2$ & & $\mathrm{NP}$ & & N/A \\
\hline${ }^{137} \mathrm{Cs}(\mathrm{GEA}){ }^{(1)}$ & $1.44 \mathrm{E}+2$ & 2 & 0.4 & & $3.9 \mathrm{E}-1$ & & $\mathrm{NP}$ & & N/A \\
\hline${ }^{152} \mathrm{Eu}(\mathrm{GEA})\left({ }^{(1)}\right.$ & $<2 \mathrm{E}-3$ & & & $2.0 \mathrm{E}-3$ & & & $\mathrm{NP}$ & & N/A \\
\hline${ }^{15 s} \mathrm{Eu}(\mathrm{GEA})^{(\mathrm{l})}$ & $<2 \mathrm{E}-3$ & & & $2.0 \mathrm{E}-3$ & $2.0 \mathrm{E}-2$ & & $\mathrm{NP}$ & & $\mathrm{N} / \mathrm{A}$ \\
\hline${ }^{153} \mathrm{Eu}(\mathrm{GEA})^{(1)}$ & $<4 \mathrm{E}-2$ & & & $4.0 E-2$ & $9.0 \mathrm{E}-2$ & & NP & & N/A \\
\hline${ }^{238} \mathrm{Pu}$ & $1.47 \mathrm{E}-5$ & 6 & 5.2 & $2.0 \mathrm{E}-7$ & $1.0 \mathrm{E}-2$ & & NP & & N/A \\
\hline${ }^{239+240} \mathrm{Pu}$ & $1.26 \mathrm{E}-4$ & 4 & 1.6 & $2.0 \mathrm{E}-7$ & $1.0 \mathrm{E}-2$ & 98 & NP & 101 & $N / A$ \\
\hline${ }^{241} \mathrm{Am}(\mathrm{GEA})^{(1)}$ & $<4 E-2$ & & & $4.0 \mathrm{E}-2$ & $1.0 \mathrm{E}-2$ & & NP & & N/A \\
\hline${ }^{241} \mathrm{Am}$ & $1.69 \mathrm{E}-4$ & 5 & 2.4 & $5.0 \mathrm{E}-7$ & $3.0 \mathrm{E}-2$ & 94 & NP & 91 & N/A \\
\hline${ }^{242} \mathrm{Cm}$ & $<2 \mathrm{E}-7$ & & & $2.0 \mathrm{E}-7$ & $1.5 \mathrm{E}-1$ & & NP & & N/A \\
\hline${ }^{263+244} \mathrm{Cm}$ & $1.03 \mathrm{E}-6$ & 21 & 29 & $8.0 \mathrm{E}-8$ & $1.5 E-1$ & & NP & & N/A \\
\hline Total alpha & $2.47 \mathrm{E}-4$ & 14 & 9.1 & $7.0 \mathrm{E}-5$ & $2.3 \mathrm{E}-1$ & 99 & $70-130$ & 55 & $70-130$ \\
\hline Alpha sum ${ }^{(2)}$ & $3.11 \mathrm{E}-4$ & & 0.7 & & & & & & \\
\hline Total beta & $1.47 \mathrm{E}+2$ & 4 & 4.8 & $2.0 \mathrm{E}-1$ & & 100 & $70-130$ & 103 & $70-130$ \\
\hline \multicolumn{10}{|l|}{ ICP-MS Analytes } \\
\hline${ }^{99} \mathrm{Tc}$ (total) & $4.90 \mathrm{E}-2$ & $1-4$ & 4.3 & $2.6 \mathrm{E}-4$ & $1.5 \mathrm{E}-3$ & & $80-120$ & 101 & $70-130$ \\
\hline${ }^{126} \mathrm{Sn}$ & $<9 \mathrm{E}-4$ & & & $9.0 \mathrm{E}-4$ & $6.0 \mathrm{E}-3$ & & $80-120$ & & $70-130$ \\
\hline${ }^{129} \mathrm{I}$ & 8.05E-5 & $3-7$ & 7.1 & $6.7 \mathrm{E}-6$ & $1.8 \mathrm{E}-5$ & & NP & 99 & N/A \\
\hline${ }^{231} \mathrm{~Pa}$ & $<1 E-4$ & & & $1.1 E-4$ & $7.9 \mathrm{E}-5$ & & developed by lab & & developed by lab \\
\hline${ }^{233} \mathrm{U}$ & $5.30 \mathrm{E}-5$ & $7-11$ & 8.2 & $8.8 \mathrm{E}-6$ & $4.2 \mathrm{E}-4$ & & $90-110$ & & $75-125$ \\
\hline${ }^{234} \mathrm{U}$ & $2.40 \mathrm{E}-5$ & $\cdot 12-21$ & 12.5 & $5.7 \mathrm{E}-6$ & $1.2 \mathrm{E}-4$ & & $90-110$ & & $75-125$ \\
\hline${ }^{235} \mathrm{U}$ & $1.01 E-6$ & 0.3 & 4.2 & $6.8 \mathrm{E}-9$ & $4.5 \mathrm{E}-8$ & & $90-110$ & & $75-125$ \\
\hline${ }^{236} \mathrm{U}$ & $2.13 \mathrm{E}-6$ & $2-6$ & 4.2 & $5.8 \mathrm{E}-8$ & $1.4 \mathrm{E}-6$ & & $90-110$ & & $75-125$ \\
\hline${ }^{238} \mathrm{U}$ & $1.84 \mathrm{E}-5$ & 0.5 & 5.5 & $4.7 \mathrm{E}-8$ & $7.2 \mathrm{E}-8$ & & $80-120$ & & $70-130$ \\
\hline${ }^{237} \mathrm{~Np}$ & $<6 \mathrm{E}-6$ & & & $5.4 \mathrm{E}-6$ & $3.9 \mathrm{E}-5$ & & $90-110$ & 119 & $75-125$ \\
\hline${ }^{239} \mathrm{Pu}$ & $<2 \mathrm{E}-3$ & & & $1.2 \mathrm{E}-3$ & $3.0 \mathrm{E}-2$ & & not provided & 110 & not provided \\
\hline${ }^{210} \mathrm{Pu}$ & $<3 \mathrm{E}-3$ & & & $2.4 \mathrm{E}-3$ & $3.0 \mathrm{E}-2$ & & not provided & & not provided \\
\hline
\end{tabular}

Shaded areas highlight non-compliances with BNFL acceptance criteria, see report for discussion.

(1) Samples were run directly by GEA and did not require a preparation blank.

(2) Alpha sum refers to the summation of ${ }^{238} \mathrm{Pu},{ }^{239+240} \mathrm{Pu}$, ${ }^{241} \mathrm{Am}$, and ${ }^{243+244} \mathrm{Cm}$ alpha activities.

(3) In all cases the QC acceptance criteria for the RSD is $<15 \%$.

(4) NP: not performed, as stated in Quality Control Parameters for Liquid Analysis

(5) N/A: not applicable, as stated in Quality Control Parameters for Liquid Analysis 
Table 4.3. 241-AP-101 Composite, ICP-MS Stable Element QC Results

\begin{tabular}{|c|c|c|c|c|c|c|c|}
\hline Units & $\begin{array}{l}\text { Average } \\
1 \mathrm{~g} / \mathrm{mL}\end{array}$ & $\begin{array}{c}\mathrm{RSD} \\
\% \\
\end{array}$ & $\mu \mathrm{MDL}$ & $\begin{array}{l}\text { BNFL } \\
\text { MRQ } \\
\mu \mathrm{g} / \mathrm{mL}\end{array}$ & $\begin{array}{c}\text { LCS } \\
\% \text { recovered }\end{array}$ & $\begin{array}{c}\text { MS } \\
\% \text { recovered }\end{array}$ & $\begin{array}{l}\text { Post } \\
\text { Matrix } \\
\text { Spike } \\
\text { \% recoyered }\end{array}$ \\
\hline \multicolumn{2}{|c|}{ Acceptance Criteria } & $<15 \%$ & & & $80 \%-120 \%$ & $70 \%-130 \%$ & $70 \%-130 \%$ \\
\hline \multicolumn{8}{|l|}{ Analyte } \\
\hline As & 1.26 & 14 & 0.063 & 2.3 & 117 & 120 & 109 \\
\hline B & 16.0 & 6.5 & 0.16 & 2.3 & & & 105 \\
\hline $\mathrm{Be}$ & 1.32 & 2.7 & 0.004 & 2.3 & & & 105 \\
\hline $\mathrm{Ce}$ & $<0.077$ & & 0.077 & 2.3 & & & 117 \\
\hline Co & 0.352 & 5.5 & 0.012 & 2.3 & & & 108 \\
\hline${ }^{133} \mathrm{Cs}^{(1)}$ & 5.09 & 5.4 & 0.004 & 1.5 & & & 108 \\
\hline$E u^{(1)}$ & $<0.016$ & & 0.016 & 60 & & . & 115 \\
\hline${ }^{127} \mathrm{I}^{(1)}$ & 2.55 & 6.4 & 0.037 & $\mathrm{TBD}^{(2)}$ & & & 94 \\
\hline $\mathrm{Li}$ & 0.34 & 7.0 & 0.063 & 2.3 & & & 123 \\
\hline Mo & 14.5 & 8.9 & 0.013 & 2.3 & & & 105 \\
\hline $\mathrm{Pr}$ & $<0.018$ & & 0.018 & 2.3 & & & 118 \\
\hline $\mathrm{Rb}$ & 3.97 & 5.7 & 0.011 & 2.3 & & & 106 \\
\hline $\mathrm{Sb}$ & 0.042 & 7.2 & 0.014 & 2.3 & & & 94 \\
\hline $\mathrm{Se}$ & $<2.3$ & & 2.3 & 2.3 & 102 & 118 & \\
\hline $\mathrm{Ta}$ & $<0.089$ & & 0.089 & 2.3 & & & 89 \\
\hline $\mathrm{Te}$ & $<0.17$ & & 0.17 & 2.3 & & & 73 \\
\hline Th & $<0.011$ & & 0.011 & 2.3 & & & 122 \\
\hline $\mathrm{TI}$ & 0.0180 & 8.5 & 0.011 & 2.3 & & & 139 \\
\hline V & $<0.77$ & & 0.77 & 2.3 & & & 110 \\
\hline W & 28.6 & 0.9 & 0.23 & 2.3 & & & 124 \\
\hline${ }^{241} \mathrm{AMU}^{(1)}$ & $<0.011$ & & 0.011 & & & & \\
\hline${ }^{242} \mathrm{AMU}^{(1)}$ & $<0.010$ & & 0.010 & & & & \\
\hline${ }^{243} \mathrm{AMU}^{(1)}$ & $<0.0072$ & & 0.0072 & & & & \\
\hline
\end{tabular}

Shaded area highlights non-compliance with BNFL acceptance criteria, see report for discussion.

(1) QC acceptance criteria for LCS and matrix spike recoveries and precision were not specified.

(2) To be determined by method 
Table 4.4. 241-AP-101 Composite, IC QC Results

\begin{tabular}{|c|c|c|c|c|c|c|}
\hline Units & $\begin{array}{c}\text { Average } \\
\mu \mathrm{g} / \mathrm{mL}\end{array}$ & $\begin{array}{c}\text { RSD } \\
\% \\
\end{array}$ & $\begin{array}{r}\mathrm{MDL} \\
\mu \mathrm{g} / \mathrm{mL}\end{array}$ & $\begin{array}{l}\text { BNFL } \\
\text { MRQ } \\
\mu \mathrm{g} / \mathrm{mL} \\
\end{array}$ & $\begin{array}{c}\text { LCS } \\
\% \text { recov. }\end{array}$ & $\begin{array}{c}\text { Matrix } \\
\text { Spike } \\
\text { \% recoy. }\end{array}$ \\
\hline Acceptance Criteria. & & $<15 \%$ & & & $80 \%-120 \%$ & $75 \%-125 \%$ \\
\hline \multicolumn{7}{|l|}{ Inorganic Anions ${ }^{(1)}$} \\
\hline Fluoride ${ }^{(2)}$ & 2,900 & 1.2 & $1.3 E+2$ & $1.5 \mathrm{E}+2$ & 110 & 114 \\
\hline Chloride & 1,980 & 2.5 & $1.3 \mathrm{E}+2$ & $3.0 \mathrm{E}+2$ & 107 & 111 \\
\hline Nitrite & 41,900 & 1.8 & $2.5 E+2$ & $2.3 E+3$ & 105 & 119 \\
\hline Nitrate & 132,000 & 1.3 & $2.5 \mathrm{E}+2$ & $3.0 \mathrm{E}+3$ & 78 & 128 \\
\hline Phosphate & 1,020 & 2.0 & $2.5 \mathrm{E}+2$ & $2.3 \mathrm{E}+3$ & 104 & 119 \\
\hline Sulfate & 4,030 & 1.9 & $2.5 \mathrm{E}+2$ & $2.3 E+3$ & 106 & 108 \\
\hline \multicolumn{7}{|l|}{ Organic Anions ${ }^{(3)}$} \\
\hline Acetate $^{(4)}$ & 1,640 & 8.0 & $5.5 E+2$ & $\mathrm{TBD}^{(\xi)}$ & & $124^{(6)}$ \\
\hline Formate & 1,200 & 5.2 & $4.5 \mathrm{E}+2$ & $\mathrm{TBD}^{(5)}$ & 89.3 & $84^{(6)}$ \\
\hline Oxalate & 1,800 & 1.0 & $8.9 \mathrm{E}+2$ & $1.8 E+3$ & 103.8 & $114^{(6)}$ \\
\hline Citrate & $<890$ & & $8.9 \mathrm{E}+2$ & $\mathrm{TBD}^{(5)}$ & & \\
\hline \multicolumn{7}{|c|}{ Additional analyte information } \\
\hline Bromide & $<500$ & & & & 108 & 108 \\
\hline
\end{tabular}

Shaded areas highlight non-compliances with BNFL acceptance criteria, see report for discussion.

(1) Overall error for reported results is estimated to be within $+/-15 \%, 2-\sigma$.

(2) The fluoride results represents the summation of fluoride, acetate, and formate concentrations as these cannot be resolved on the IC column.

(3) Overall error for reported results is estimated to be within $+1-30 \%$ at $2-\sigma$.

(4) Acetate concentration represents the summation of acetate and glycolate concentrations.

(5) To be determined by the method

(6) Based on the average of 3 matrix spike recoveries. 
Table 4.5. 241-AP-101 Composite, Miscellaneous Analyte QC Results

\begin{tabular}{|c|c|c|c|c|c|c|}
\hline Units & $\begin{array}{l}\text { Average } \\
\mu \mathrm{g} / \mathrm{mL}\end{array}$ & $\begin{array}{c}\text { RSD } \\
\% \\
\end{array}$ & $\mu \mathrm{MDL}$ & $\begin{array}{l}\text { BNFL } \\
\mathrm{MRQ} \\
\mu \mathrm{g} / \mathrm{mL}\end{array}$ & $\begin{array}{c}\text { Blank } \\
\text { Spike } \\
\% \text { Recovery }\end{array}$ & $\begin{array}{c}\text { Matrix } \\
\text { Spike } \\
\% \text { Recovery }\end{array}$ \\
\hline Acceptance Criteria & & $<15$ & & & $80-120$ & $75-125$ \\
\hline Analyte & & & & & & \\
\hline \multicolumn{7}{|l|}{ Persulfate Method ${ }^{(1)}$} \\
\hline $\mathrm{TIC}$ & 6,460 & 1.2 & $4.0 \mathrm{E}+1$ & $1.5 \mathrm{E}+2$ & & 98.5 \\
\hline TOC & 1,960 & 4.5 & $8.0 \mathrm{E}+1$ & $1.5 \mathrm{E}+3$ & & 96.3 \\
\hline TC & 8,420 & 0.4 & $8.0 \mathrm{E}+1$ & & & 97.5 \\
\hline TC, Furnace Method & 8,610 & 0.8 & $1.7 \mathrm{E}+2$ & & & 97.5 \\
\hline Mercury & $<0.032$ & & $2.5 \mathrm{E}-2$ & $1.5 \mathrm{E}+0$ & 100 & 97 \\
\hline Cyanide & 5.70 & 2.2 & $2.5 \mathrm{E}-1$ & $4.5 \mathrm{E}+0$ & 101 & 95 \\
\hline Ammonia & 1.71 & 6.5 & $2.0 \mathrm{E}-1$ & $1.4 \mathrm{E}+2$ & & \\
\hline Total hydroxide & 41,300 & 4.2 & $3.4 \mathrm{E}+2$ & $7.5 E+4$ & 100 & 88 \\
\hline Units & $\mathrm{g} / \mathrm{mL}$ & $\%$ & $\mathrm{~g} / \mathrm{mL}$ & $\mathrm{g} / \mathrm{mL}$ & & \\
\hline Density $^{(2)}$ & 1.308 & 0.076 & & 0.9 & & \\
\hline
\end{tabular}

(1) Reporting units are $\mu \mathrm{gC} / \mathrm{mL}$ solution

(2).Acceptance criteria for precision was not specified. 


\subsection{References}

Sharma, A. K., S. A. Clauss, G. M. Mong, K. L. Wahl, J. A. Campbell. 1998. Analysis and Quantification of Organic Acids in Simulated Hanford Tank Waste and Hanford Tank Waste. Journal of Chromatography, 805, 101-107.

Camaioni, D. M., W. D. Samuels, J. C. Linehan, S. A. Clauss, A. K. Sharma, K. L. Wahl, J. A. Campbell. 1996. Organic Tanks Safety Program, FY 96 Waste Aging Studies, PNNL-11312, Pacific Northwest National Laboratory, Richland, Washington.

Ashby, E. C. et al. 1994. Synthetic Waste Chemical Mechanism Studies, WHC-EP-0823, Westinghouse Hanford Company, Richland, Washington.

Barney, G. L. 1996. Solubilities of Significant Organic Compounds in HLW Tank Supernate Solutions-FY 1996 Progress Report, WHC-EP-0899, Westinghouse Hanford Company, Richland, Washington. 


\section{Appendix A: Tank 241-AP-101 Grab Samples}


Mr. J. J. Short, Contracting Officer

Office of Procurement Services

U.S. Department of Energy

Office of River Protection

Post Office Box 450

Richland, Washington 99352-0450

Dear Mr. Short:

CONTRACT NUMBER DE-AC06-99RL14047; SAMPLE MANAGEMENT DOCUMENT PACKAGE FOR GRAB SAMPLES FROM TANK 241-AP-101

Reference: Letter, J. J. Short II, ORP, to M. P. DeLozier, CHG, "Contract No. DE-AC0699RL14047 - Direction to Provide Sample From Tank 241-AP-101 to BNFL Inc. (BNFL) and to Archive Sample at 222-S Laboratory," 00-OPD-0017/0000166, dated January 14, 2000.

As requested in the Reference (1), this letter transmits to the U.S. Department of Energy, Office of River Protection, three copies of a "sample management document package" for grab samples from tank 241-AP-101 on February 8, 2000. In accordance with Reference (1), five grab samples were delivered to the 325 Laboratory and five grab samples are archived at the 222-S Laboratory for use by BNFL Inc. Five samples were also archived at the 222-S Laboratory for use by the Waste Feed Delivery program. The attached sample management document package includes the following information regarding tank 241-AP-101 and the samples obtained: recent waste transfer history for tank 241-AP-101, past sampling and analysis of tank 241-AP-101 wastes, sample location selection, sampling information and chain-of-custody forms for the current sampling event.

If you have any questions, please contact Ms. C. DeFigh-Price, at 373-9596.

Very truly yours,

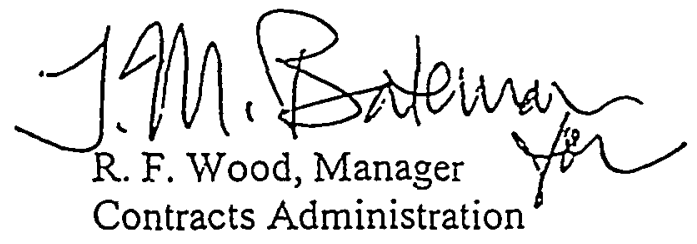

CH2M HILL Hanford Group, Inc.

ldf

Attachment 


\section{SECTION V: Sampling Information}

Waste in tank 241-AP-101 has been identified as potentially a suitable candidate LAW Envelope A feed. On February 8,2000 , ten 120 -mL grab samples were obtained from this tank and provided to BNFL Inc. (BNFL) for analysis and testing to evaluate the waste composition and ability to process the waste. An additional five samples were obtained for the Waste Feed Delivery Program.

Table 1 lists the fifteen grab samples and their locations. All samples were obtained on Febriary 8, 2000 from riser 002. At the time of sampling, all.samples were clear, yellow liquids with no solids. Five samples were shipped to the Pacific Northwest National Laboratory (PNNL) 325 Laboratory on February 8, 2000, and ten samples were shipped to the Fluor Hanford (FH) 222-S Laboratory on February 9 and 10, 2000. Chain-of-custody forms for the fifteen samples are provided in Section VI.

Table 1. Tank 241-AP-101 Sampling Information

\begin{tabular}{|c|c|c|c|}
\hline Sample Number & $\begin{array}{c}\text { Actual Sample } \\
\text { Elevation (inches) }\end{array}$ & $\begin{array}{l}\text { Receiving } \\
\text { Laboratory }\end{array}$ & Organization \\
\hline $1 \mathrm{AP}-00-1$ & 400 & 325 & BNFL \\
\hline $1 \mathrm{AP}-00-2$ & 400 & $222-\mathrm{S}$ & BNFL \\
\hline $1 \mathrm{AP}-00-3$ & 400 & $222-S$ & WFD \\
\hline $1 \mathrm{AP}-00-4$ & 290 & 325 & BNFL \\
\hline 1AP-00-5 & 290 & $222-S$ & BNFL \\
\hline $1 \mathrm{AP}-00-6$ & 290 & $222-S$ & WFD \\
\hline 1AP-00-7 & 190 & 325 & BNFL \\
\hline IAP-00-8 & 190 & $222-S$ & BNFL \\
\hline $1 \mathrm{AP}-00-9$ & 190 & $222-S$ & WFD \\
\hline 1AP- $00-10$ & 100 & 325 & BNFL \\
\hline $1 \mathrm{AP}-00-11$ & 100 & $222-S$ & BNFL \\
\hline $1 \mathrm{AP}-00-12$ & 100 & $222-S$ & WFD \\
\hline $1 \mathrm{AP}-00-13$ & 10 & 325 & $\mathrm{BNFL}$ \\
\hline $1 \mathrm{AP}-00-14$ & 10 & $222-S$ & BNFL \\
\hline $1 \mathrm{AP}-00-15$ & 10 & $222-S$ & WFD \\
\hline
\end{tabular}

Note:

'Sample elevation is the distance from the tank bottom to the mouth of the sample bottle. All samples were obtained at the requested sample elevations.

$B N F L=B N F L$ Inc.

WFD $=$ Waste Feed Delivery 


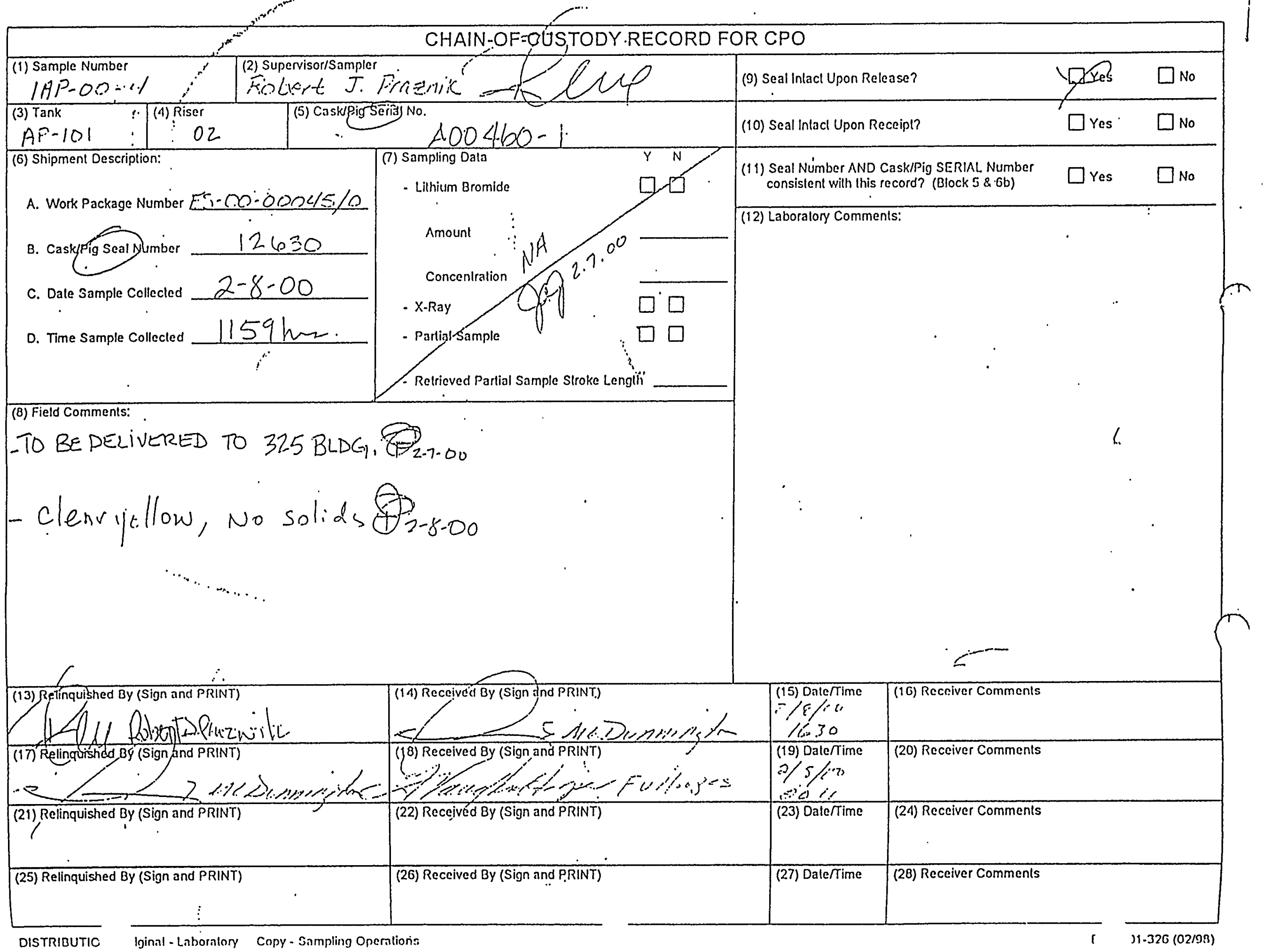




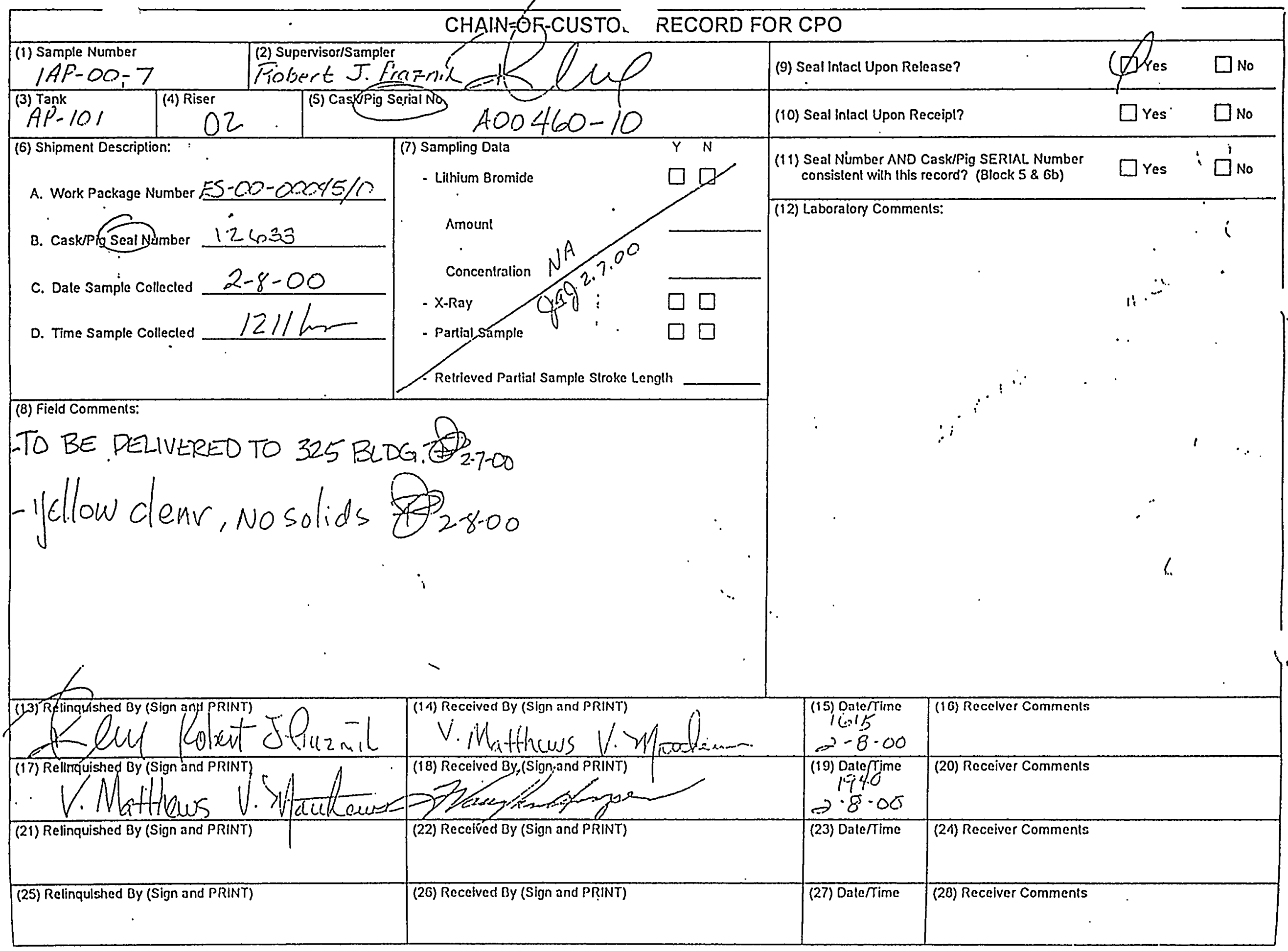




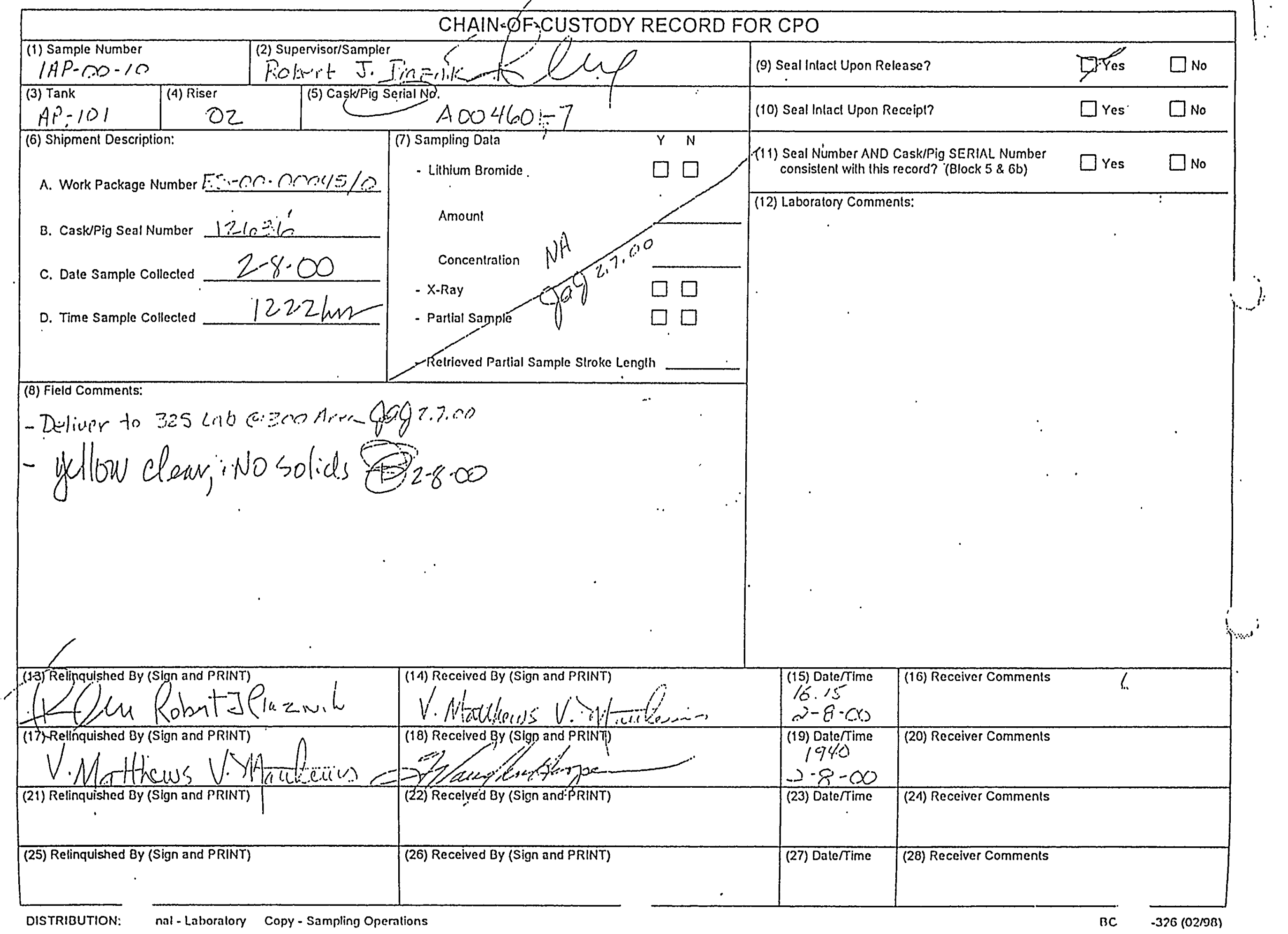




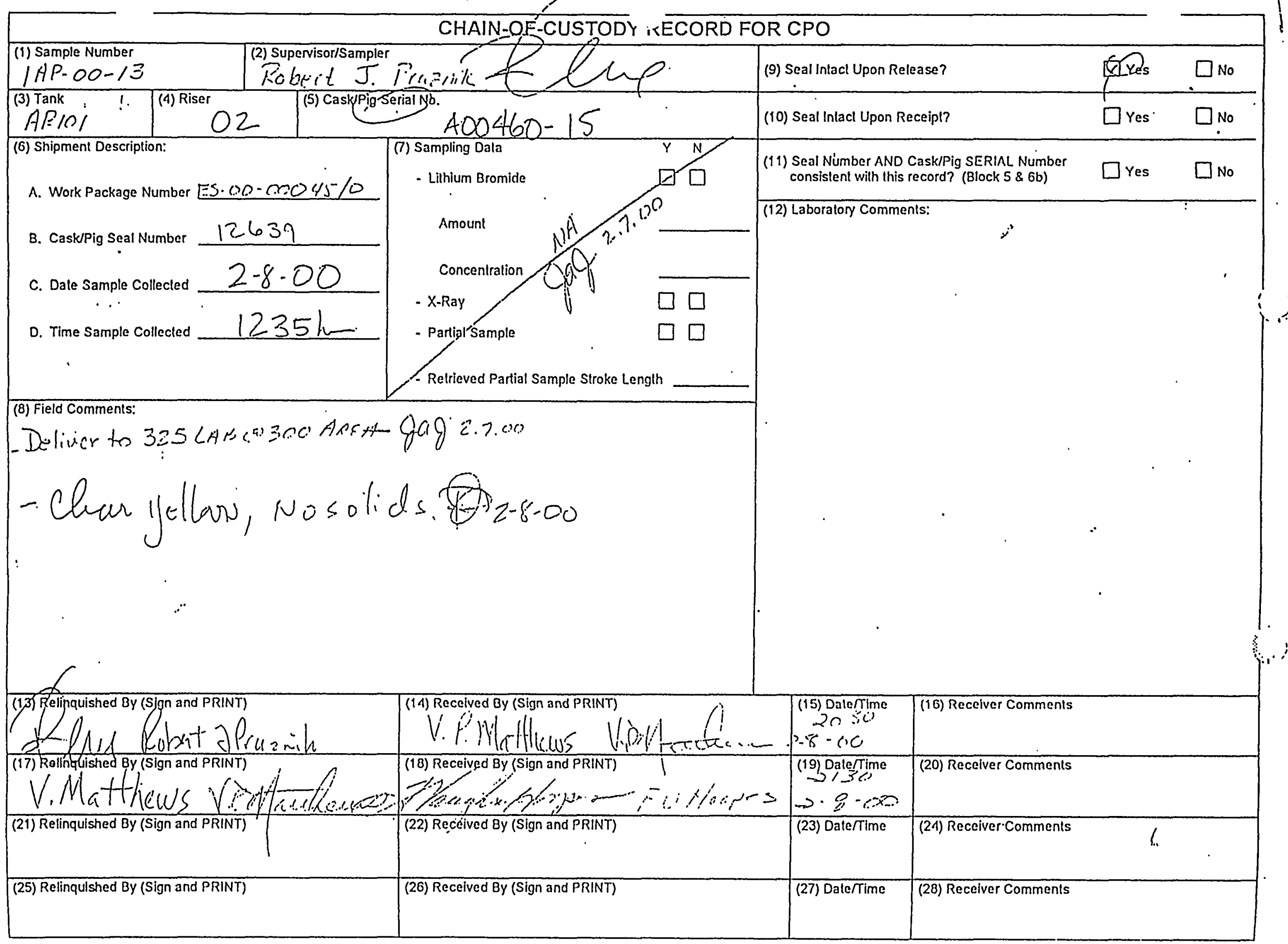


Appendix B: Test Instructions

B. 1 


\section{PNNL Test Instruction}

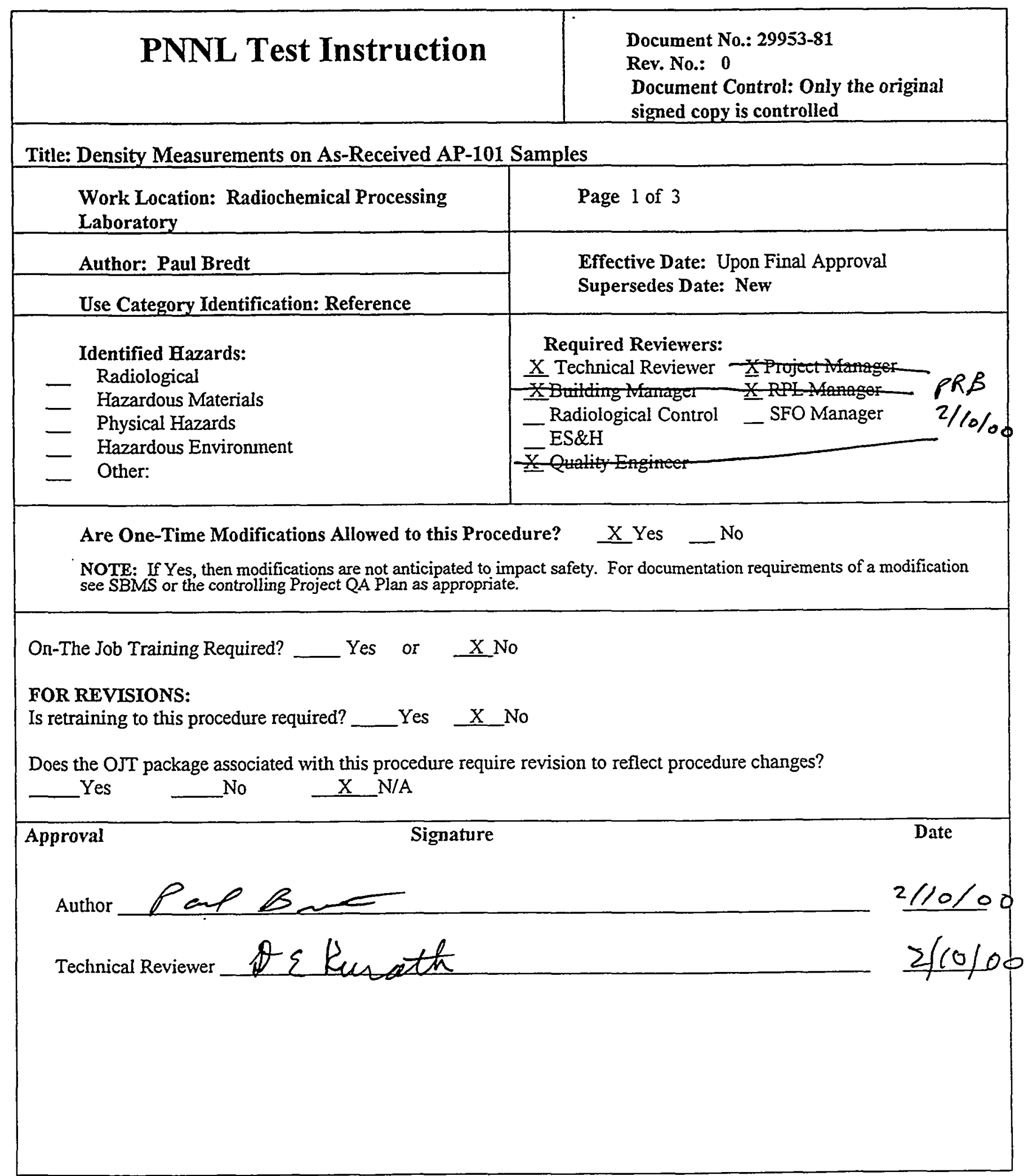




\section{Density Measurements on As-Received AP-101 Samples}

\section{Scope}

This test plan defines density measurements on samples of tank 241-AP-101 supernatant received from the Hanford tank farms on 2/8/00. These test instructions provides specific details to RPG staff regarding the implementation of Technical Procedure 29953-010, "Measurement of Physical and Rheological Properties of Solutions, Slurries and Sludges".

\section{Justification of Use Category}

This test instruction is reference use. Reference use was selected as the use category since this analysis is not a complex process and there are no safety impacts to the order of events. In addition, we may wish to modify the order of analyses or eliminate some analyses depending on the needs at the time of the operation.

\section{Applicability}

This test plan applies to RPL staff performing work on BNFL Privatization samples under Project 29953.

Work with actual samples is to be performed in the SAI hot cells by staff under the direction of a cognizant scientist.

\section{Prerequisites}

1) Keep the sample in a sealed glass container as much as possible to prevent it from drying and reduce the potential for organic contamination.

2) Cross-contamination between samples and contamination of samples from outside sources must be minimized at each step. Use new tools and bottles for each sample as much as possible. Those tools which are reused should be washed and rinsed prior to reuse.

3) Secondary containment is to be used whenever practical to minimize sample loss in the event of a spilled sample or broken sample bottle.

\section{Quality Control}

Quality control has been implemented in Technical Procedure 29953-010, "Measurement of Physical and Rheological Properties of Solutions, Slurries and Sludges". This work is to be conducted under the quality requirements of the Standards-Based Management System (SBMS).

\section{M\&TE List:}

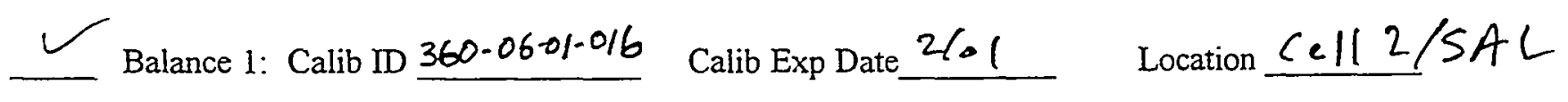


masses of 4 similar Jars to $1 A P$ saps from Julie vomaston of LMHC, payroll $=55327$

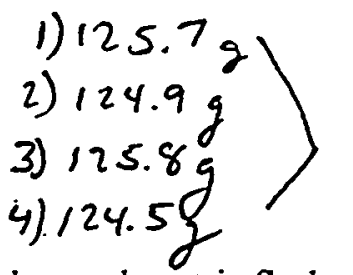

$$
\bar{x}=125.22 \mathrm{~g}
$$

Test Instruction 29953-081

PR Bredt $02 / 10 / 00$

4) $124.5 \mathrm{~g}$

Page 3 of 3

1) Weight five new clean volumetric flasks (between 5 and $25 \mathrm{ml}$ ) labeled as indicated below.

1AP-00-1

Tare $19.2593 \mathrm{~g}$

1AP-00-10

Tare $19.3396 \mathrm{~g}$
1AP-00-4

Tare $19.2709 \mathrm{~g}$

1AP-00-13

Tare $19.4298 \mathrm{~g}$
1AP-00-7

Tare 19.3125

2) Weigh samples 1AP-00-1, 1AP-00-4, 1AP-00-7, 1AP-00-10, and 1AP-00-13. Record the masses.

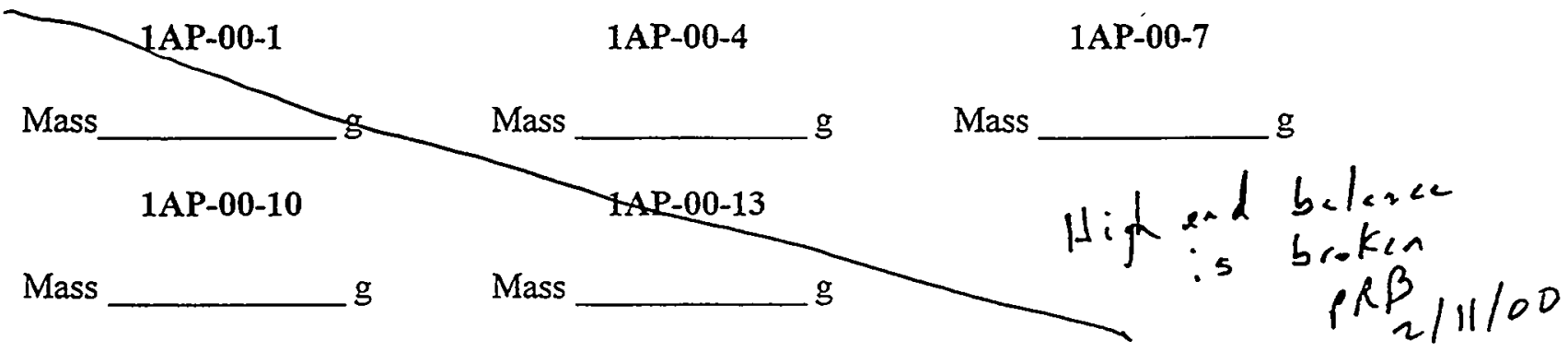

3) Fill the volumetric with supernatant for the respective jars. Record the new mass of the full volumetrics. used New glass transfer piper for eccl sample

1AP-00-1

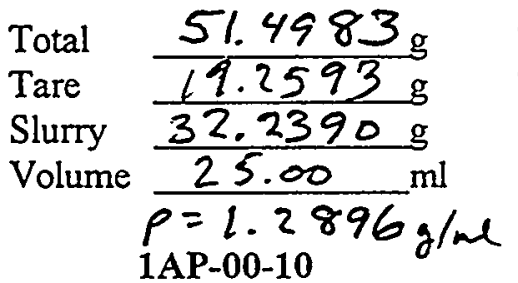

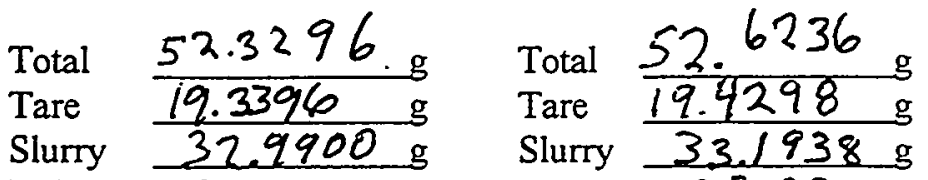

Volume $2500 \mathrm{ml}$ Volume $\frac{35.00 \mathrm{ml}}{25.0078}$ $p=1.3196 \mathrm{~g} / \mathrm{h} \quad p=1.3278 \mathrm{~g} / \mathrm{ml}$
1AP-00-4

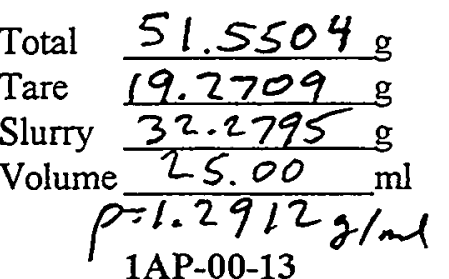

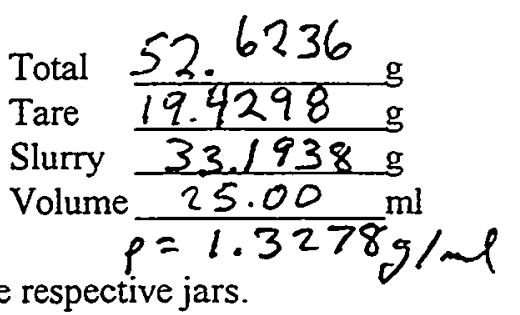

1AP-00-7

Total $\frac{51.5914 \mathrm{~g}}{19.3125 \mathrm{~g}}$

Tare $\frac{19.3125 \mathrm{~g}}{322789 \mathrm{~g}}$

Volume $25.00 \mathrm{ml}$

$\rho=1.29 / 2 \mathrm{~g} / \mathrm{al}$

5) Weigh samples 1AP-00-1, 1AP-00-4, 1AP-00-7, 1AP-00-10, and 1AP-00-13. Record the masses.

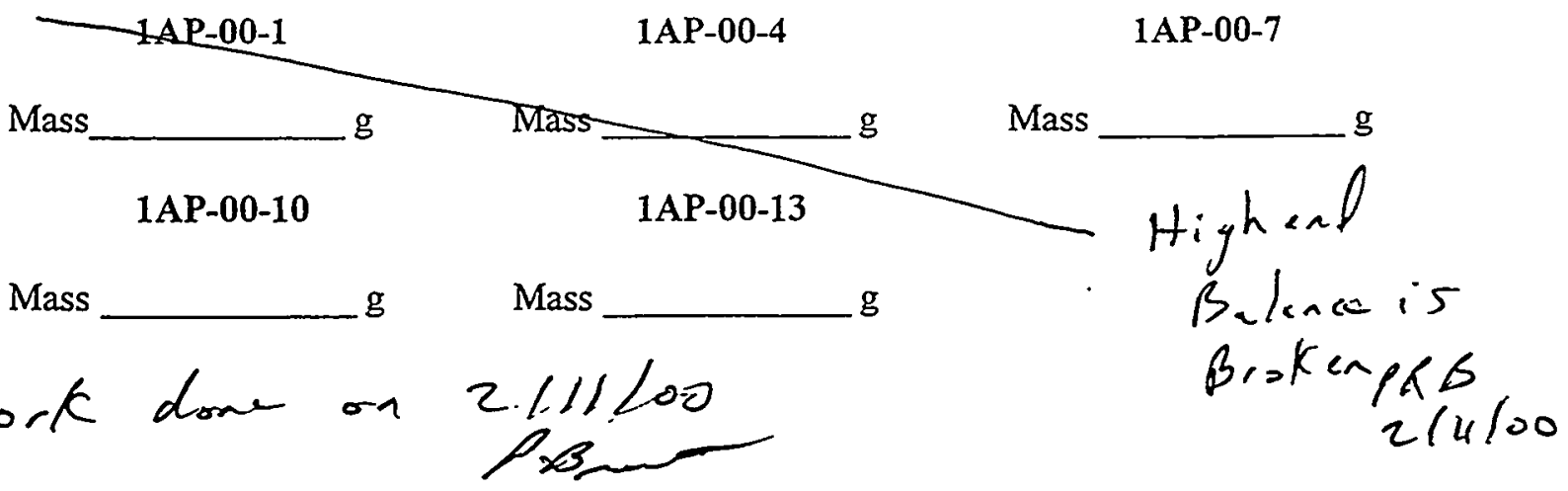




\section{PNNL Test Instruction}

Document No.: BNFL-TP-29953-83

Rev. No.: 0

Document Control: Only the original signed copy is controlled

Title: AP-101 Homogenization and Subsampling

Work Location: Shielded Analytical

Laboratory/Radiochemical Processing

Laboratory

Author: Paul Bredt

Use Category Identification: Reference

Identified Hazards:

Radiological

- Hazardous Materials

- Physical Hazards

- Hazardous Environment

- Other:
Page 1 of 5

Effective Date: Upon Final Approval

Supersedes Date: New

Required Reviewers:

$\underline{X}$ Technical Reviewer $\underline{X}$ Project Manager

Xuituling $x$ RPL Manager

- Radiological Control - SFO Manager

- ES\&H

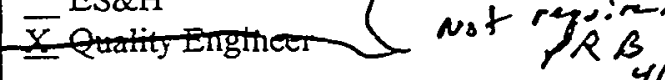

Are One-Time Modifications Allowed to this Procedure? $\quad \underline{X}$ Yes _ No

NOTE: If Yes, then modifications are not anticipated to impact safety. For documentation requirements of a modification see SBMS or the controlling Project QA Plan as appropriate.

On-The Job Training Required? __ Yes or $\mathrm{X}$ No

FOR REVISIONS:

Is retraining to this procedure required? ___ Yes $\mathrm{X}$ No

Does the OJT package associated with this procedure require revision to reflect procedure clianges?

Approval




\section{AP-101 Homogenization and Subsampling}

\section{Scope}

This test plan defines work to be conducted on five AP-101 liquid samples delivered to Battelle from the Hanford tank farms on 2/8/00. Under this Test Plan, the five samples will be combined into a single jar, stirred and then subsampled for other tasks.

\section{Applicability}

This test plan applies to RPL staff performing work on BNFL Privatization samples under Project 29953.

Work will be performed in the Shielded Analytical Laboratory (SAI) of the Radiochemical Processing Laboratory (RPL) by staff under the direction of a cognizant scientist.

\section{Prerequisites}

1) Keep the sample in a sealed glass container as much as possible to prevent it from drying and reduce the potential for organic contamination.

2) Cross-contamination between samples and contamination of samples from outside sources must be minimized at each step. Use new tools and bottles for each sample as much as possible. Those tools which are reused should be washed and rinsed prior to reuse.

3) Secondary containment is to be used whenever practical to minimize sample loss in the event of a spilled sample or broken sample bottle.

4) Since organic analyses will be performed on some of this material, staff are to avoid contacting the samples with plastics. The exception to this is Teflon which is already a sealing material already present in the sample lids.

5) This material may contain regulated levels of PCBs. Handle the samples and segregate all wastes accordingly.

6) If a balance is not available for this testing, skip the weighing steps.

\section{Quality Control:}

This work is to be conducted under the quality requirements of the Standards-Based Management System (SBMS). 
PR Bred

$03 / 31 / 00$
Test Plan: BNFL-TP-29953-083

Page 3 of 5

M\&TE List:

Balance 1:

Calif ID $360 \cdot 06-01-040$

Calif Exp Date $2 / 01$

Location 201

If a Category 1 balance is not available, conduct a performance check on an available balance. If needed, user calibrate an available balance and record calibration data below. Data from a user calibrated balance will be limited to information only use.

In Cell Balance is a sartorius max $424 \mathrm{~g}$

414100 used $100.003 \mathrm{~g}$ check weight, readizwas 100.004 


\section{Work Instructions:}

\section{Note:}

This is a very high visibility task within DOE-RL. Secondary containment should be used whenever and wherever possible to prevent inadvertent sample loss and/or hot cell contamination. Great care should be taken during sample transfers.

1) Weigh a clean 1L jar labeled "AP-101 COMP".

$$
\text { Tare } 535 \quad \begin{array}{r}
\text { AP-101 COMP } \\
360-06-01-043 \\
\text { ex } 8 / 2000
\end{array}
$$

2) Weigh a clean Teflon stir bar.

$$
\text { Tare } \begin{gathered}
\text { Stirbar } \\
\text { T.0498 } \leftarrow \text { usig Bulance } \\
360-0601-040
\end{gathered}
$$

3) Add the Teflon stir bar to "AP-101 COMP".

4) Weigh the sample jars listed below. Transfer all material from the jars to "AP-101 COMP". Reweigh the empty jars and record the masses in the space provided.

\begin{tabular}{|l|l|l|l|}
\hline Sample Label & Mass (Full) & Mass (Empty) & Mass Transferred \\
\hline $1 \mathrm{AP}-00-1$ & 300.308 & 125.973 & \\
\hline $1 \mathrm{AP}-00-4$ & 296.724 & 126.494 & \\
\hline $1 \mathrm{AP}-00-7$ & 294.544 & 124.805 & \\
\hline $1 \mathrm{AP}-00-10$ & 299.031 & 125.430 & \\
\hline IAP-00-13 & 298.009 & 125.777 & \\
\hline
\end{tabular}

5) Set up secondary containment such that if the primary sample jar (AP-101 COMP) breaks during stirring then the sample material can be easily and cleanly recovered. It is preferred that this be done by placing "AP-101 COMP" in a secondary container that will still allow for proper operation of the stir bar. If this is not possible, then the magnetic stir plate can be placed in secondary containment. 
PR Bred

03/31/00
Test Plan: BNFL-TP-29953-083

Page 5 of 5

6) Securely replace the lid on "AP-101 COMP" and stir the material in "AP-101 COMP" for a minimum of 30 minutes using the magnetic stirrer. Consult with the cognizant scientist on the appropriate stir rate. start stirrighe 9:3/ ar 414100 stopped e 10:25 am

7) Weigh a volume graduated $120 \mathrm{ml}$ glass jar labeled "AP-101 GL".

$$
\begin{aligned}
& \text { AP-101 GL }
\end{aligned}
$$

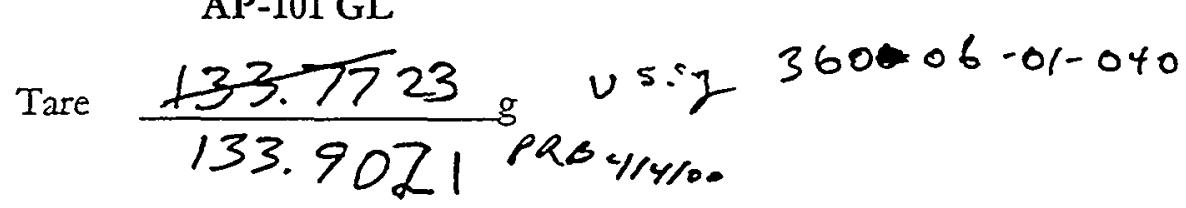

8) Transfer $100 \mathrm{ml}$ ( $\pm 10 \mathrm{ml})$ of supernatant from "AP-101 COMP" to "AP-101 GL". Securely replace the lid on "AP-101 COMP", and "AP-101 GL". Record the mass and volume of material in "AP-101 GL".

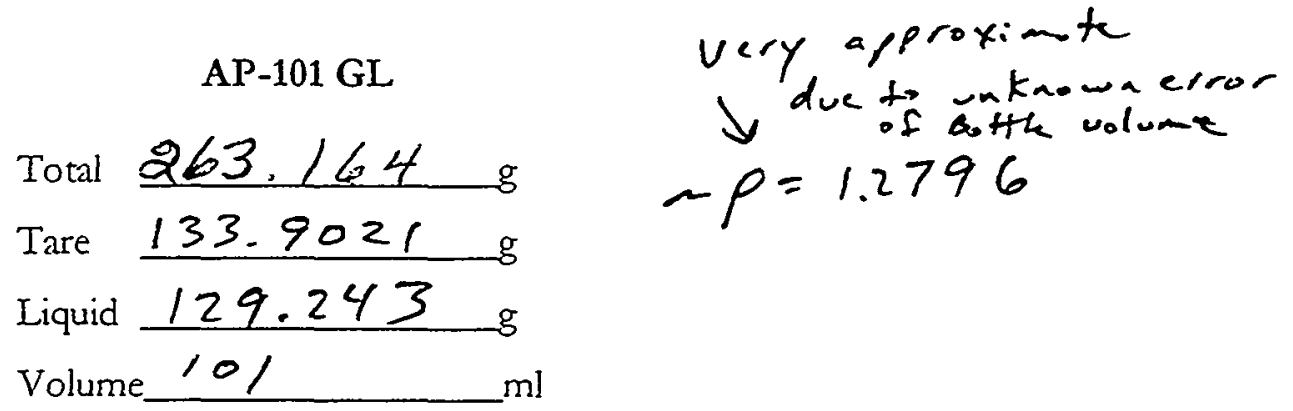

9) Store both "AP-101 COMP", and "AP-101 GL" in secondary containment in a location where they are unlikely to be disturbed.

all work completed during

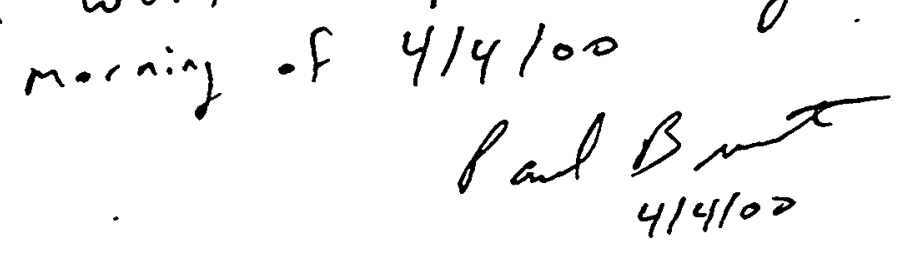


Requestor -.- Complete all fields on this COVER PAGE, unless specified as optional or ASR is a revision

Requestor:

Signature

Print Name

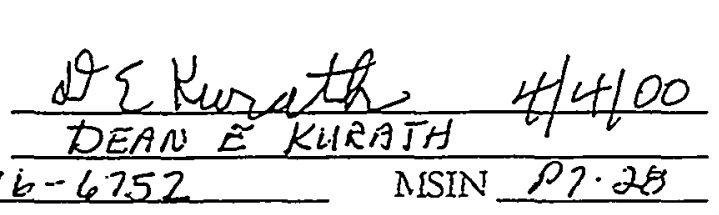

PNNL Project \#:

29953

Phone $37 \dot{i}-6752$

Matrix Type Information

\begin{tabular}{|c|c|c|c|}
\hline $\begin{array}{l}\text { + Liquids: } \\
\text { + Solids: }\end{array}$ & $\begin{array}{l}\angle \text { Aqueous } \\
\text { Soil } \\
\text { Glass } \\
\text { Smear }\end{array}$ & $\begin{array}{l}\text { Organic } \\
\text { Sludge } \\
\text { Filter } \\
\text { Organic }\end{array}$ & $\begin{array}{l}\text { Multi-phase } \\
\text { Sediment } \\
\text { Metal } \\
\text { Other }\end{array}$ \\
\hline - Other: & $\begin{array}{l}\text { Solid/Liqu } \\
\text { Gas }\end{array}$ & $\begin{array}{r}\text { uid M Fixture, SI } \\
\text { Biologic }\end{array}$ & $\begin{array}{l}\text { urry } \\
\text { al Specimen }\end{array}$ \\
\hline
\end{tabular}

If sample matrices varg; specify on Request Page

Disposal Information

- Disposition of Virgin Samples:

Virgin samples are returned to requestor unless archiving provisions are made with receiving group!

If archiving, provide:

Archiring Reference Doc \#

1 Disposition of Trezted Samples:

Dispose $V$ Arter 40 dzyReturn

Charge Code:

$\frac{29953}{-5-12-00}$

Date Required:

QA/Special Requirements

- QA Plan:

SBMS

HASQARD (CAWSRP)

- Additional QA Requirements? No or Reference DOC \# SEE TABLE \& ATInCHMLX)/Z

- Field COC? inDivis S ALS

- Lab COC Required? No ᄂ $\longleftarrow$ Yes

- Hold Time: None

$$
\begin{aligned}
& \text { or RCRA Other, Specify CERCLA } \\
& \text { \& Date Sampled } \\
& \text { Time Sampled }
\end{aligned}
$$

- Special Storage Requirements:

None $\_$Refrigerate $\left(4^{\circ} \mathrm{C}\right)$

or Other, specify:

- Data Quality Review Required? No _ Yes _

Waste Designation Information

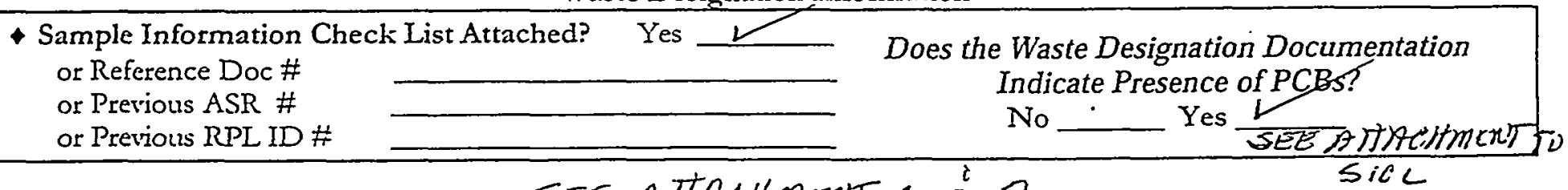

Additional or Special Instructions SEE A THACHMENT $1 \varepsilon_{c}^{i} 2$

Send Report To D.E. KURATAt Phone $376-6752$

Preliminary results requested, as available? No __ Yes

Receiving and Login Information (to be completed by Jaboratory staff)

Date Delivered: RESIDENT IN SAL Received By:

Delivered By (optional)

Time Delirered (optional)

Group ID (opional)

CMIC IVaste Sample?

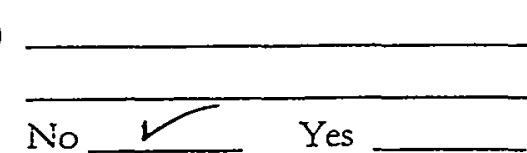

ASR Number: $\frac{00-0170 / \delta}{5778}$

Dost Estimate, if requested: $\mathrm{S}$

RPG/CMC Work Accepted By:

Pfw Thee signature/Date:

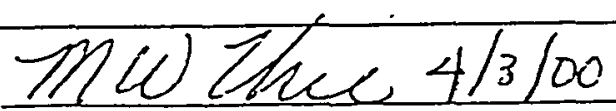

ASR FYY2(X) - RPCiI.due 
Analytical Service Request (ASR)

(REQUEST PAGE -.--- Information Specific to Individual Samples)

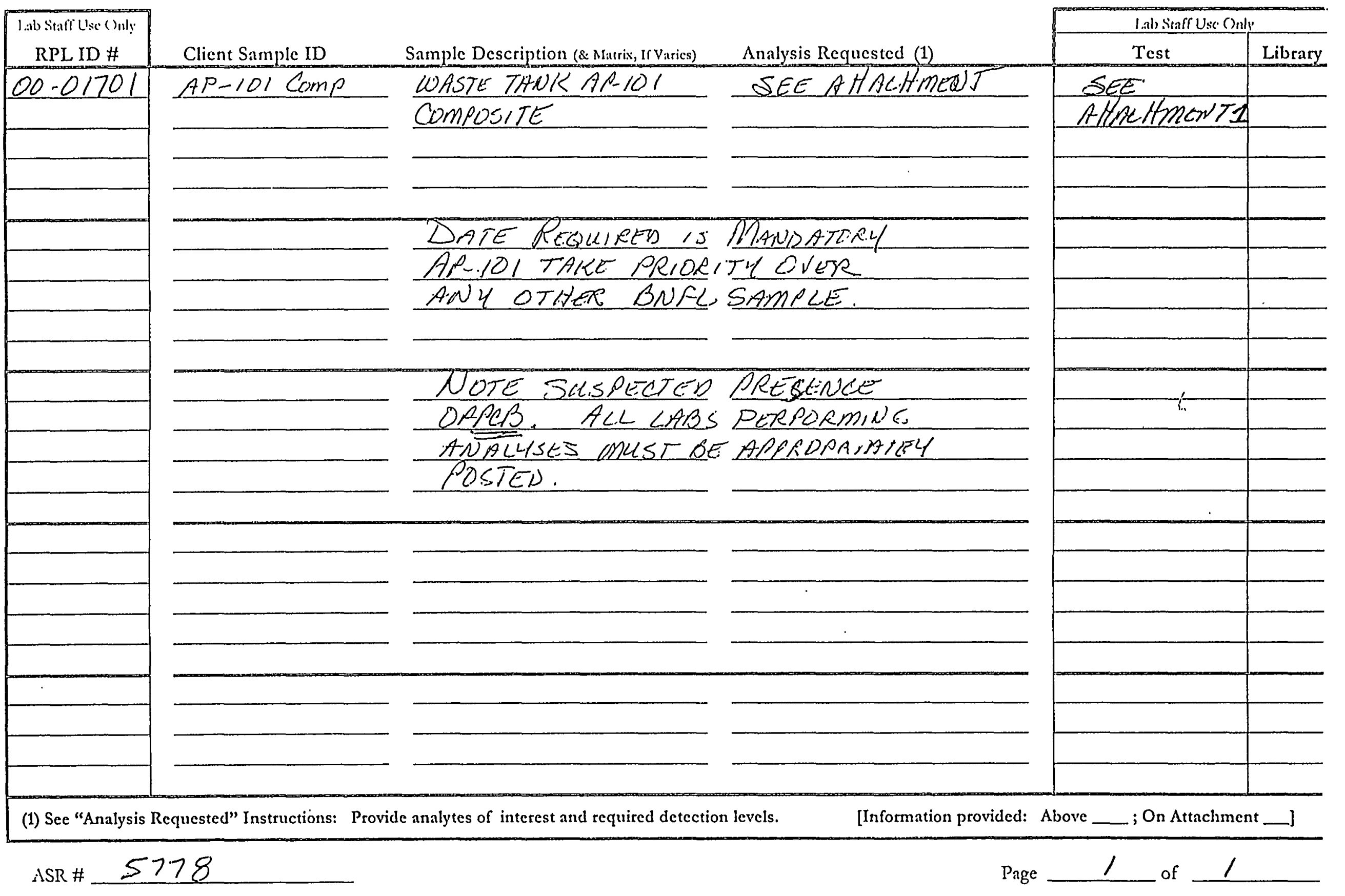




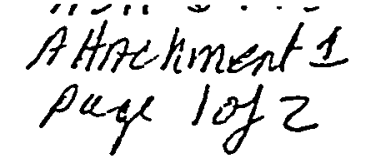

\begin{tabular}{|c|c|c|}
\hline 0.01 & ASR 5778 & \\
\hline 00-01701 $\& 704$ Supernatant Com & & $\cdots$ \\
\hline Digestion-128 & SAL & -- Use W54906 \\
\hline ICP-211-CMC & LAB & -- Use CMC WP Number \\
\hline ICP/MS & ADV INORG & -- Use W54906 \\
\hline GEA-381/474-CMC & RAD & - Use CMC WP Number \\
\hline Alpha/Gross-4001/408-CMC & RAD & -- Use CMC WP Number \\
\hline Beta/Gross-4001/408-CMC & RAD & -- Use CMC WP Number \\
\hline $\mathrm{Am}, \mathrm{Cm} / \mathrm{AEA}-417 / 422-\mathrm{CMC}$ & RAD & -- Use CMC WP Number \\
\hline $\mathrm{Pu} / \mathrm{AEA}-417 / 422-\mathrm{CMC}$ & RAD & -- Use CMC WP Number \\
\hline U/KPA-4014-CMC & RAD & -- Use CMC WP Number \\
\hline Sr-90-476/408-CMC & RAD & -- Use CMC WP Number \\
\hline Se79-440/474-CMC & RAD & -- Use CMC WP Number \\
\hline Tc99-432/408-CMC & RAD & -- Use CMC WP Number \\
\hline Direct Sub-Sample & & \\
\hline Density/Solution & SAL & -- Use W54906 \\
\hline IC-212-CMC & LAB & -- Use CMC IVP Number \\
\hline TOC/TIC-381-CMC & LAB & -- Use CMC WWP Number \\
\hline TOC/TIC-380-CMC & LAB & -- Use CMC WP Number \\
\hline NH3-ISE & LAB & -- Use W54906 \\
\hline CN/Total & LAB & - Use W54906 \\
\hline H3-418/474-CMC & RAD & -- Use CMC WP Number \\
\hline $\mathrm{C} 14-381 / 474-\mathrm{CMC}$ & RAD & -- Use CMC WP Number \\
\hline $\mathrm{Hg}-131 / 201-\mathrm{CMC}$ & LAB & -- Use CMC WP Number \\
\hline OH-/Titration-228-CMC & LAB & -- Use CMS WP Number \\
\hline IC-Organic & ORG & -- Use W54906 \\
\hline Ext-Solvent (PCB/Prep) & SAL & -- Hold (Use W54906) \\
\hline PCB/Pesticide (PCB only) & ORG & -- Hold (Use W54906) \\
\hline
\end{tabular}

\section{Special Instructions}

See Attacthed Table 2, Table 3 and Table 4 for analyte list, MRQs, and QC Parameters

All analyses are to be done in Triplicate.

Results are to be reported in $\mathrm{ug} / \mathrm{ml}$ or $\mathrm{uCi} / \mathrm{ml}$, as applicable

$\mathrm{QC}$ is to include process blank, matrix spike, and LCS (or blank spike)

Method detection limit is to be reported for all analytes.

Digestion:

Prepare one set of triplicate digestions using the sample quantity defined by the procedure (i.e., total of $60 \mathrm{ml}$ ). This set of digestions (without further dilutions) will be distributed for all radiochemistry. Additional dilutions may be required due to dose. No MS prepared, where required by method the radionuclides are to be postspiked.

Prepare a second set of triplicate digestions using $5 \mathrm{ml}$ sample sizes and additional MS (i.e., total $20 \mathrm{ml}$ ). This set of digestions will be distributed for ICP ( $10 \mathrm{ml}$ each) and ICP/MS ( $15 \mathrm{ml}$ each) analyses. Additional dilutions may be required due to dose. The MS is to include only TCLP metals, all other analytes are to be post-spiked.

Estimated Subsample quanities: (Total ml. including MS) May need to be diluted due to dose

Density/Solution (perform in volumetrics and reuse sample for other analyses)

IC-212-CMC $(5 \mathrm{ml})$

TOC/TIC-381-CMC (3 ml)

NH3-ISE (4 ml) - No subsample for MS required

H3-418/474-CMC (5 ml)

$\mathrm{Hg}-131 / 201-\mathrm{CMC}(1 \mathrm{ml})$
IC-Organic $(5 \mathrm{ml})$

TOC/TIC-380-CMC (3 ml)

$\mathrm{CN} /$ Total $(8 \mathrm{ml})$

Cl4-381/474-CMC (3 ml)

$\mathrm{OH}-/$ Titration-228-CMC $(5 \mathrm{ml})$

Page 1 of 2 
PCB Extraction/Analysis: Hold until authorization to proceed has been obtained-îtom D.E. Kurath.

\section{Hot Cell Instructions for Preparation of PCB Organic Samples}

1) Transfer 100-ml aliquot (40-ml aliquot for MS and MSD) of the AP-101 Comp into a separatory funnel. (Note: if $300 \mathrm{mls}$ are available after all other subsamples have been taken, then use $50-\mathrm{ml}$ aliquots for MS and MS duplicate)

2) Add the surrogate spiking solution to all samples (including blank) and the target compound spiking solution to the MS and MSD. Use the entire contents of the vial(s) provided for spiking. After transferring the contents of the spiking vial to the sample, add approximately $0.2 \mathrm{~mL}$ of methylene chloride to the vial(s) and transfer this rinsate to the sample. (Note: surrogate and spiking solutions are to be supplied by E. W. Hoppe)

3) Perform three sequential separatory funnel shakeout extractions of the supematant using, $=50$-mL portions of methylene chloride. Collect and combine the three extracts in a $250-\mathrm{mL}$ amber bottle labeled AP-101-PCB-X

Where $\mathrm{X}=\mathrm{S}$ for sample, $\mathrm{D}$ for duplicate, MS for matrix spike and MSD for matrix spike duplicate.

4) Dry extracts with anhydrous sodium sulfate. Volume reduction will be performed outside the hot cells.

For further guidance and questions, contact Eric W. Hoppe, (509) 376-2126. 
Table 2

Supernate Analyses Required by Contract Specification 7 and Opportunistic Arsalytes

\begin{tabular}{|c|c|c|}
\hline Analute & Minimum Reportable Quantiv & Anzlusis Mfethod \\
\hline & póml & \multirow{12}{*}{ ICP-AES } \\
\hline Al & $7.5 \pm \div 01$ & \\
\hline $\mathrm{B} 2$ & $2.3 \bar{E}+00$ & \\
\hline $\mathrm{Ca}$ & $1.5 E+02$ & \\
\hline $\mathrm{Cd}$ & $7.5 E \div 00$ & \\
\hline $\mathrm{CI}_{\mathrm{I}}$ & $1.5 \mathrm{E}+01$ & \\
\hline $\mathrm{Fe}$ & $7.5 E \div 01$ & \\
\hline $\mathrm{K}$ & $7.5 E+02$ & \\
\hline $\mathrm{L}_{2}$ & $2.3 \bar{E} \div 00$ & \\
\hline$N_{2}$ & $.7 E \div 02$ & \\
\hline $\mathrm{Ni}$ & $3.0 E \div 01$ & \\
\hline$\frac{P b}{U}$ & $\frac{3.0 \Xi+02}{7.85 \div 02}$ & \\
\hline$U$ & $\frac{7.8 \mathrm{E} \div 02}{7.8 \mathrm{E}+02}$ & Kin. Fhosphorescence \\
\hline sq & $1.7 \mathrm{E}+01$ & \multirow{15}{*}{$\begin{array}{c}\text { ICP-AES } \\
\text { (Opporturistic) }\end{array}$} \\
\hline $\mathrm{Bi}$ & $1.7 E+02$ & \\
\hline $\mathrm{Cu}$ & $1.7 \mathrm{E} \div 01$ & \\
\hline Mg & $1.7 \mathrm{E}+02$ & \\
\hline Min & $1.7 E \div 01$ & \\
\hline nid & $1.7 E \div 02$ & \\
\hline$P$ & $33 E \div 02$ & \\
\hline Pd & $3.9 \mathrm{E} \div 02$ & \\
\hline $\mathrm{Rh}$ & $1.8 \mathrm{E}+01$ & \\
\hline Ru & $3.6 \mathrm{E} \div 01$ & \\
\hline $\mathrm{Si}$ & $9.0 E \div 01$ & \\
\hline St & $1 . T E+01$ & \\
\hline $\mathrm{Ii}$ & $1 . T E+01$ & \\
\hline$Z_{n}$ & $1.7 E \div 01$ & \\
\hline $\mathrm{Zr}$ & $1.7 \mathrm{E}+01$ & \\
\hline IIC & $1.5 E \div 02$ & \multirow[b]{2}{*}{ Funace Oxidation } \\
\hline IOC & $1.5 E+03$ & \\
\hline TOC & $1.5 \mathrm{E} \div 03$ & $\begin{array}{l}\text { Silver catalyze gersulfate ard } \\
\text { furnzec oxjdatior methad }\end{array}$ \\
\hline TIC & $1.5 E+02$ & $\begin{array}{l}\text { Silver caislyze persulfaie ajd } \\
\text { furrace oxidajoz matiod }\end{array}$ \\
\hline HE & $1.5 E \div 00$ & Cold Vazor Ad \\
\hline $\mathrm{Cl}$ & $3.0 \Xi+02$ & \multirow{6}{*}{ 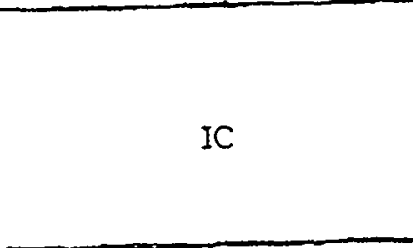 } \\
\hline$F$ & $1.5 \mathrm{E} \div 02$ & \\
\hline $\mathrm{NO}_{2}$ & $2.3 \mathrm{E} \div 03$ & \\
\hline $\mathrm{NO}_{3}$ & $3.0 E+03$ & \\
\hline $\mathrm{PO}_{3}$ & $2.3 E+03$ & \\
\hline $\mathrm{SO}_{1}$ & $2.3 E+03$ & \\
\hline Formate & Io be ceiermined by method & \multirow{4}{*}{$\begin{array}{c}\text { IC } \\
\text { (Opportunistic) }\end{array}$} \\
\hline Oxalate & $1.8 \mathrm{E}+03$ & \\
\hline Acetate & Io be deterrained by method & \\
\hline Citrate & To be decerminad by method & \\
\hline
\end{tabular}




\begin{tabular}{|c|c|c|}
\hline \multicolumn{3}{|c|}{$\begin{array}{c}\text { Table } 2 \\
\text { Supernate analyses Required by Contract Specification } 7 \\
\text { and Opportunistic Analytes }\end{array}$} \\
\hline Analyte & MIinimum Report3ble Quantity & Analysis MIethod \\
\hline & $\mathrm{LCi} / \mathrm{ml}$ & \\
\hline${ }^{21 p}$ & $3.9 E \cdot 05$ & \multirow{4}{*}{$I C P-\lambda I S$} \\
\hline${ }^{27} \mathrm{Pu}$ & $3.0 E-02$ & \\
\hline${ }^{30} \mathrm{pL}$ & $3.0 \bar{E}-02$ & \\
\hline Sic & $1.5 \mathrm{E}-03$ & \\
\hline & $\mu g^{\prime} \mathrm{m}^{\prime}$ & \multirow{7}{*}{$\begin{array}{c}\text { XCP-MIS } \\
\text { (Opportunistic) }\end{array}$} \\
\hline As & $2.3 E \div 00$ & \\
\hline$B$ & $2.3 E \div 00$ & \\
\hline $\mathrm{Be}$ & $2.3 E \div 00$ & \\
\hline $\mathrm{Ce}_{e}$ & $2.3 E \div \div 00$ & \\
\hline $\mathrm{Co}$ & $2.3 E \div 60$ & \\
\hline Cs (total) & $1.5 E+00$ & \\
\hline Eu (total) & $6.0 \mathrm{E}+01$ & \multirow[t]{26}{*}{$\cdots$} \\
\hline I (natural (1: $^{2}$ ) & Io be determined by method & \\
\hline $\mathrm{Li}_{\mathrm{i}}$ & $2.3 E \div 00$ & \\
\hline 310 & $2.3 E+00$ & \\
\hline $\mathrm{Pr}$ & $2.3 E+00$ & \\
\hline$\overline{R b}$ & $2.3 E+00$ & \\
\hline$S b$ & $2.3 E \div 00$ & \\
\hline $\mathrm{Se}$ & $2.3 E \div 00$ & \\
\hline$I_{2}$ & $23 E+00$ & \\
\hline $\mathrm{Ie}$ & $2.3 E \div 00$ & \\
\hline Ih & $2.3 E \div 00$ & \\
\hline II & $2.3 E \div 00$ & \\
\hline$v^{\prime}$ & $23 E+00$ & \\
\hline \multirow[t]{2}{*}{$x$} & $23 E \div 00$ & \\
\hline & $\mu \mathrm{Ci} / \mathrm{ml}$ & \\
\hline${ }_{i=1}^{E N I U}$ & To be detarminad by method & \\
\hline $A \mathrm{ADXO}$ & To be ceiermined by method & \\
\hline${ }^{2+3} A, 110$ & Io be determined by method & \\
\hline${ }^{21 !} \mathrm{Pa}_{2}$ & $7.9 E-05$ & \\
\hline${ }^{25} \mathrm{U}$ & $4.2 \mathrm{E}-07$ & \\
\hline 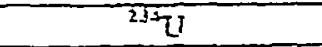 & $1.2 E-04$ & \\
\hline एบบ & $4.5 E-08$ & \\
\hline$\sqrt{2} \mathrm{U}$ & 1.4E-06 & \\
\hline${ }^{23} \mathrm{U}$ & $7.2 E-0 \delta$ & \\
\hline${ }^{13} \mathrm{SD}$ & $6.0 E-03$ & \\
\hline I (or GEA method) & $1.8 \mathrm{E}-05$ & \\
\hline $\sin ^{2}=$ & $3.0 \mathrm{E}-02$ & Separajons / Iiquid Scintillarion \\
\hline STC & $1.5 E-03$ & $\begin{array}{c}\text { Separations / Liquid } \\
\text { Scintillation (Opportunistic) }\end{array}$ \\
\hline${ }^{250}$ & $1.0 \mathrm{E}-02$ & \multirow{6}{*}{ Sepz:zions/AEA } \\
\hline$M P_{L}$ & $1.0 E \cdot 02$ & \\
\hline${ }^{2-1} \mathrm{Pu}_{\mathrm{u}}$ & $5.1 \bar{E} \cdot 02$ & \\
\hline $\mathrm{Am}$ & $3.0 E \cdot 02$ & \\
\hline$=\mathrm{Cm}$ & $1.5 E \cdot 01$ & \\
\hline$\sqrt{25 . .+7} \mathrm{Cm}$ & $1.5 \equiv .01$ & \\
\hline
\end{tabular}


Table 2

Supernate Analyses Regulred by Contract Specirlcation 7

and Opportunistic Analytes

\begin{tabular}{|c|c|c|}
\hline Analyte & Minimum Reportable Quantity & Analisis ilethod \\
\hline & $\mathrm{LCi} / \mathrm{ml}$ & \\
\hline TH+EU & 2.CE-02 & \multirow{4}{*}{ Exrnged Countiag Tins GEA } \\
\hline TSE & $9.0 E-02$ & \\
\hline${ }^{60} \mathrm{Co}$ & $2.1 E-05$ & \\
\hline \multirow[t]{2}{*}{${ }^{\mathrm{T}} \mathrm{Cs}$} & $3.9 E-01$ & \\
\hline & $\mu \mathrm{Ci} / \mathrm{ml}$ & \\
\hline${ }^{10 S} \mathrm{Re} / \mathrm{Rh}$ & Io be detarmined by method & \multirow{6}{*}{$\begin{array}{c}\text { Exterded Counting Time GEA } \\
\text { (Opportunistic) }\end{array}$} \\
\hline${ }^{12 j} \mathrm{sb}$ & $1.7 E+00$ & \\
\hline${ }^{14} \mathrm{Cs}_{5}$ & $3.9 E-02$ & \\
\hline${ }^{135} \mathrm{Cs}$ & $3.9 \mathrm{E}-02$ & \\
\hline${ }^{\mathrm{St}} \mathrm{Eu}$ & To be datinnined by method & \\
\hline $\mathrm{Am}$ & $1.0 \mathrm{E}-02$ & \\
\hline rota! and free $\mathrm{OH}$ & $\left.7.5 E \div 04 \mu g^{\prime} \mathrm{n}\right]$ & Iiuation \\
\hline 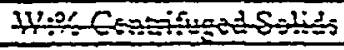 & $\theta .5+1$ & $E$ \\
\hline 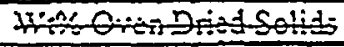 & $6.25-19$ & E:-نim \\
\hline Separare Oiganic Phase & $N / A$ & Visual Oosiciation \\
\hline Density & $0.9 \mathrm{gm} / \mathrm{ml}^{2}$ & \\
\hline
\end{tabular}

Table 3

Additional Supernate Analyzes Required by Waste Feed Staging DQO and LANV/ HIL IF Feed Processing DQO (PNTL-12163)

\begin{tabular}{|c|c|c|}
\hline Analyte & MIinimum Reportable Quantity & Analysis Method \\
\hline & $\mu \mathrm{g} / \mathrm{ml}$ & \\
\hline$\hat{N H} \cap \mathrm{NH}_{4}$ & $1.4 E+02$ & ISE \\
\hline$C \pi^{\circ}$ & $4.5 E \div 00$ & Dissillajon/Colosimesic \\
\hline To:al Alphs & $2.5 E-01+\mathrm{Ci} / \mathrm{ml}$ & Alpha Counging \\
\hline 3 & $2.1 \mathrm{E} .02 \mathrm{\mu g} / \mathrm{ml}$ & Separacicas / Liquid Scirobllation \\
\hline${ }^{\mathrm{T}} \mathrm{C}$ & $7.2 \mathrm{E}-04 \mu \mathrm{Ci} / \mathrm{m}^{\mathrm{J}}$ & Separations / I iquid Scintillarion \\
\hline${ }^{7} \mathrm{~S} E$ & $9.0 \equiv-051: \mathrm{Ci}^{\prime} \mathrm{m}$ & Separations / Liquid Scintillation \\
\hline Total B>la & To bs daciminsd (LCi/ml) & Beia Couning \\
\hline SLim of Alpha & Io becis=tsmined $(\mu \mathrm{C} / \mathrm{mnl})$ & 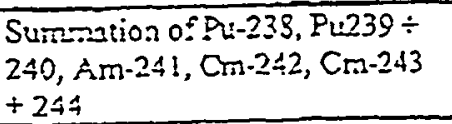 \\
\hline
\end{tabular}


Table 4. Quality Control Parameie:s for Liquid Analysis

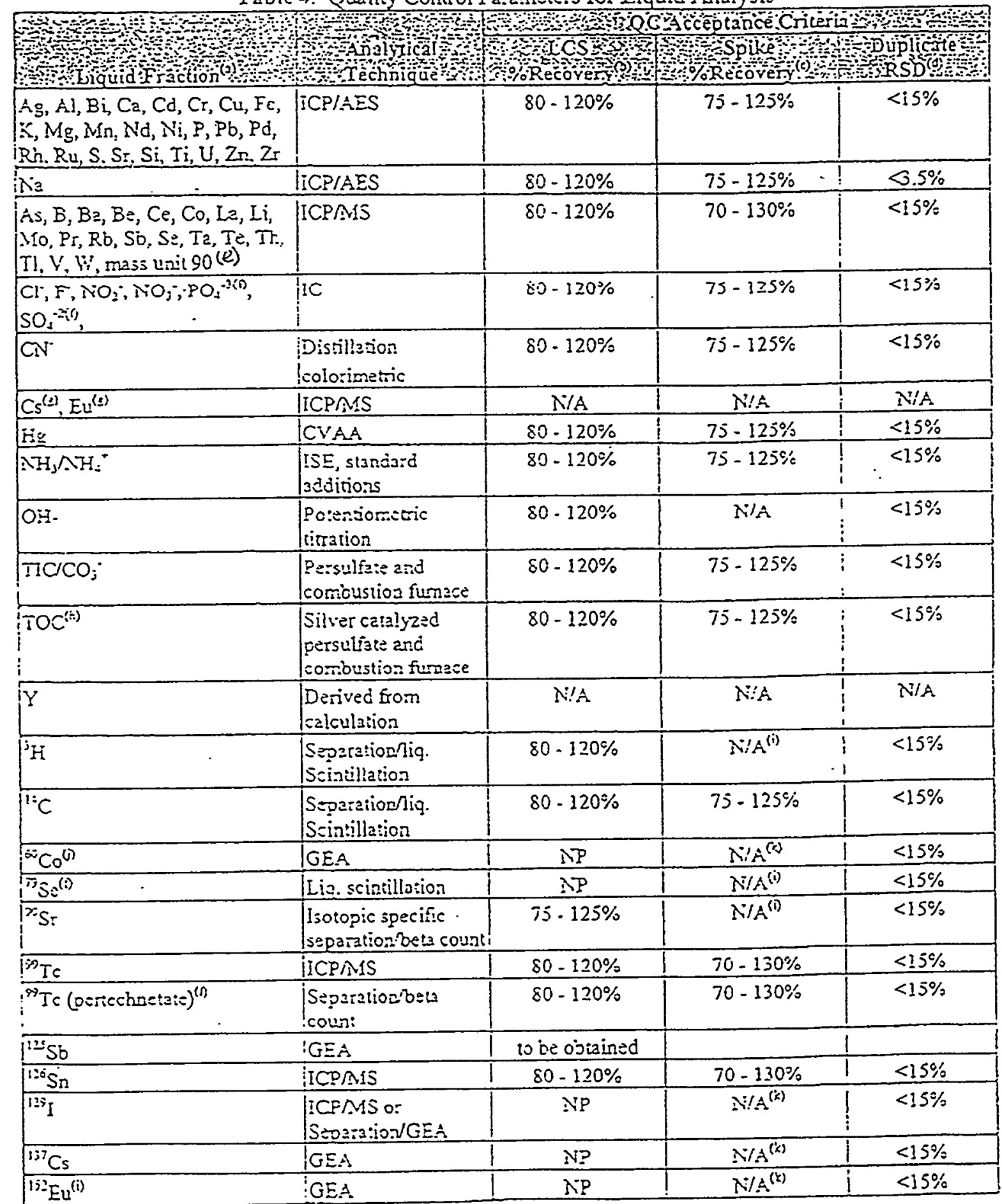




\section{$10 \geqslant 01,10$

Table 4. Quality Control Parameters for Liquid Analysis (contd)

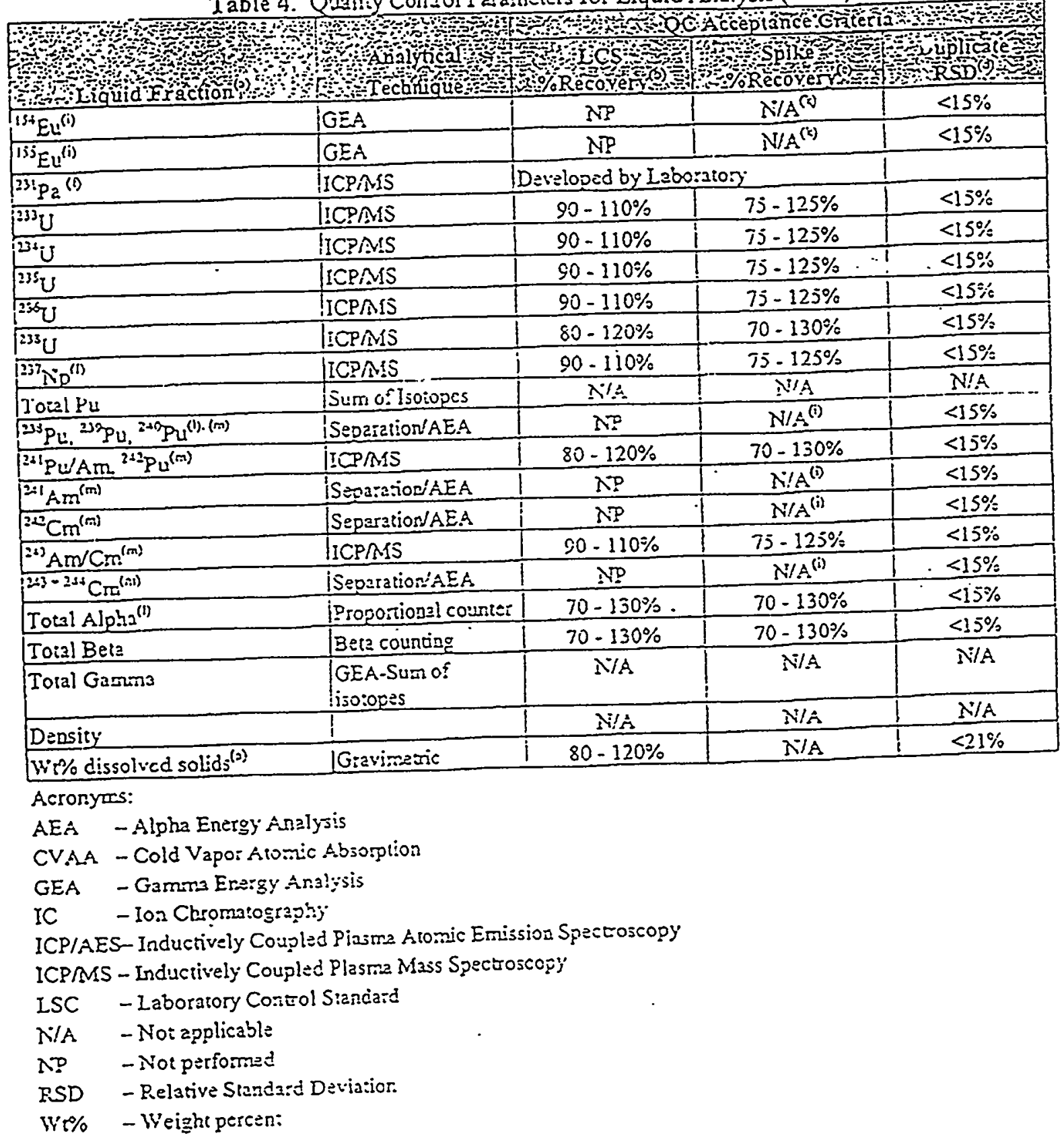




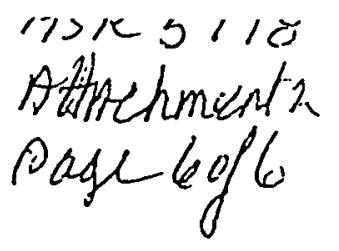

Table 4. Quality Control Parametcrs for Licuiò Analysis (con:d)

\section{Llquids footnotes}

(a) Analytes for the Solubility Screening Test a-a a subse: of this azelyta list. Refer to Section 7.6.3.

(b) LCS = Laboraiory Control Standard. This standarc is caried through the entire metrod. The aecuraey of a method is ustially expressed as the percen recorery of the LCS. Tre LCS is a matrix witi known concentration of analytes processed with each prepara:ion and analyses ba:ch. It is expressed as percent recoven; i.e., the amocni measured, divided by tie known concentration, times 100.

(c) For some metiods, bie sample accuracy is expressed as the fercen: recoverj of a ma nix spike sample. It is expiessed as perceni recovery; i.e., the amoure meejured less the amount in the samgle, divided by tha spike added, tims 100. One matrix spike is performed pe: analytical baice. 'S moles aze batched uith similar matices. Fo: other analytes, the accuracy is deternined basej on use of serial dilutions as described in Saction 7.7.2.2.

(d) RSD = Relative S:ancard Deviation between the samples. Sample precision is es:inated by analyzing replieates iaken separately through preparation and analysis. Accepiable sample paceision is usually < $<5 \%$ RSD if tha sample result is at leasi 10 tirces ine instumener detectica limit. RSD - (stendard devizion c? the menn'mean) $\times 100$

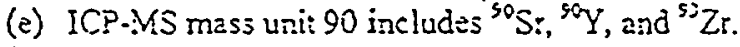

(i) Aczlysis required for only liquid fraction.

(g) Toinl $C_{5}$ and Eu a:e sums of all iso:opes, therefore spiking asd LCS does rot app?y.

(h.) Analys is for cxalate rozy be required as described in Section 7.S.

(i) Mlatix spike analyses are not required for this mschod because a taces is used to correct for analyte loss during sarap!e p:eparation and analysis. The result generated using tbe tacer accourit for any inaccuracy of the method on the ratrix. The reponed resulis refiect this correction

(j) Ar. extended counting time in the presence of high ${ }^{137} \mathrm{Cs}$ accivity may be required to ashieve the minimum reportabic quadicy for ${ }^{60} \mathrm{Co} 2 \mathrm{~d}^{152} \mathrm{Eu},{ }^{155} \mathrm{Eu}$.

(k) The measurement is a direct readirg of the erergy and the analysis is no: affected by the sample matrix; therefcre, a matrix spike is nor recuired.

(1) TLe sum of ${ }^{233} \mathrm{Pu}, 3{ }^{35} \mathrm{Pu},{ }^{2 * \mathrm{PL}}$, and ${ }^{211} \mathrm{Am}$ activities will be used as a measu-ement of aloba-emitting TRU when to:al alpha measurement in the liquic fraction is equal to or exceeds $6.0 \mathrm{E}-05 \mathrm{Ci} / \mathrm{L}$ for Envelopes $\mathrm{A}$ and $B$ and 4.0E-04 $\mathrm{Ci} /$ for Envelope $C$. Tos selecred nigger values corsespond to $70 \%$ of the LAW enveloge limits for IRU. Tr.e selected isotopes accoval fo: greater tran 95\% of the alpa-emitinz IRU activisy based or p:evious anzlysis of Phase I candidate tark waste (Esch 19973, 19970, 1997c). Adjitional isotopes wicich

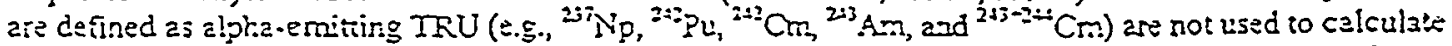
to:a! IRU acrivity because tre $M D$ As for these iso:opes are lage in comparison with tha envelope liraits and

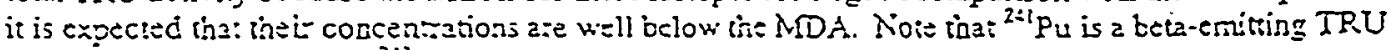
whose anelysis, along with ${ }^{2+2} \mathrm{Cm}$ is required specifically for class $\mathrm{C}$ w'aste cetermizatioc.

(m) Analysis for these a.zalytes is required only if the to:al alpha measuremect is equal to or exceeds $6.0 \mathrm{E}-05 \mathrm{Ci} / \mathrm{L}$ for Envlope $A$ and $B$ feed and $4.0 \equiv .04 \mathrm{Ci} / \mathrm{L}$ for Envelope $C$. These values correspord to $70 \%$ of the envelope limit for TRU. Based or the previous anzlysis resuls fo: Prase I tanks, ai: total aloha values less than specified, the values for these analytes are less then the MDA. Toerefore, if the toial alpha values are less tizan epecified, tia MDA for the individuz! analyze uill be tsed to fulfill the dista reeds for this DQO.

(n) Feigh: percent cissolved solids method is deseribed in Section 7.j.s. 


\section{RPL Sample Information Checklist}

(Please have client or sample owner complete to the best of their knowledge or provide the information obtained from the client.)

CLIENT

Name: D. E KuRATH

Phone: $376-6,252$

Employer:
CHECKLIST PREPARED BY:

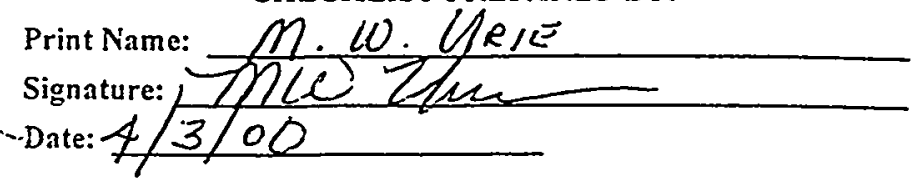

(To be complete by Battelle research or laboratory stam

RPL Unique Identifier(s)

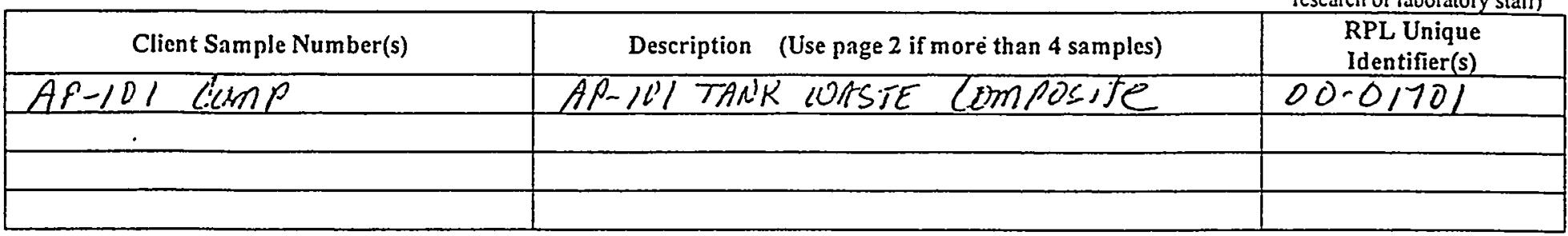

1. Is the sample from a commercial chemical product, manufacturing chemical intermediate, or off-specification commercial chemical product (i.e., P or U Listed)? (See 40 CFR 261.33) $\square$ Yes

If $y e s$, what chemicals or waste codes?

2. Is the sample from an $F$ or $K$ listed source? (See 40 CFR 261.31 and 261.32). QYes $\square$ No

If $y$ 'es, what is the source and waste code? HAN FORD TANK WUASTE

3. Mark any of the following physical and chemical characteristics or constituents (and associated waste code) you suspect to be present:

$\begin{array}{ll}\square \text { Explosive (D003) } & \square \text { Pyrophoric (D003) } \\ \square \text { Oxidizer (D001) } & \square \text { Asbestos } \\ \square \text { Sulfides (D003) } & \square \text { Cyanides (D003) } \\ \square \text { Water Reactive (D003) } & \square \text { Air Reactive (D003) } \\ \square \text { Corrosive (D002); } \mathrm{pH}=\quad 12.5 \text { or Les5 }\end{array}$

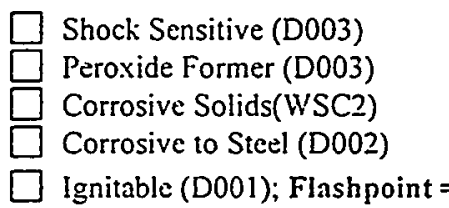
Generates Toxic Gases in Water (D003)
$\square$ Halogenated Hydrocarbons (WPO1 or WPO2)
Polycyclic Aromatic Hydrocarbons (WP03)

V) Corrosive (D002); $\mathrm{pH}=12.5$ or Less

Ignitable (D001); Flashpoint $=$

${ }^{\circ} \mathrm{F}$ or

${ }^{\circ} \mathrm{C}$

4. Mark any of the following constituents (and associated waste code) you suspect to be present (40 CFR 261.24):

\section{Arsenic (D004)}

$\downarrow$ Barium (D005)

$\square$ Cadmium (D006)

V. Chromium D007)

11 Lead (D008)

$\square$ Mercury (D009)

$\square$ Selenium (D010)

Silver (DOII)

$\square$ Benzene (D018)
Carbon tetrachloride (D019)
Chlordane (D020)
Chlorobenzene (D021)
Chloroform (D022)
Cresol, o-, m-, or p- (D023-D025)
$\square$ 2,4.D (D016)
$\square$ 1.4-Dichlorobenzene (D027)
1,2-Dichloroethane (D028)
1,1-Dichloroethylene (D029)

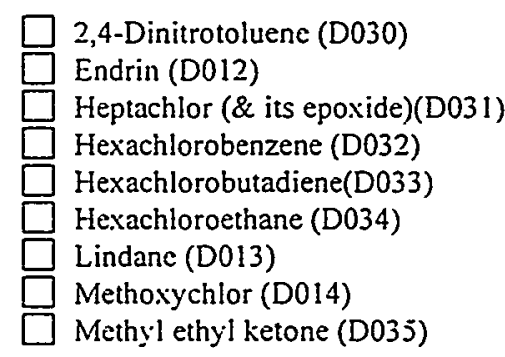

$\square$ Nitrobenzene (D036)
$\square$ Pentachlorophenol (D037)
$\square$ Pyridine (D038)
$\square$ Tetrachloroethylene (D039)
$\square$ Toxaphene (D015)
$\square$ Trichloroethylene (D040)
$\square$ 2,4,5-Trichlorophenol (D041)
$\square$ 2,4,6-Trichlorophenol (D042)
$\square$ 2,4,5-TP (Silvex) (D017)
$\square$ Vinyl chloride (D043)

5. List any known RCRA Underlying Hazardous Constituents:

6. Are there any state hazardous waste codes associated with the sample? $\square$ Yes $\triangle$ No

If yes, please list:

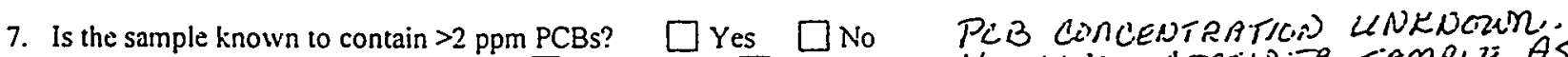

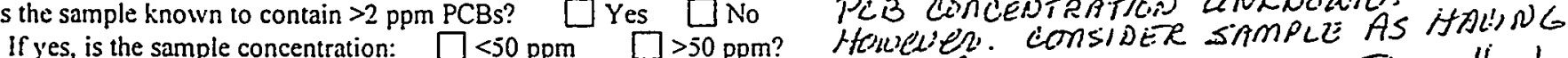

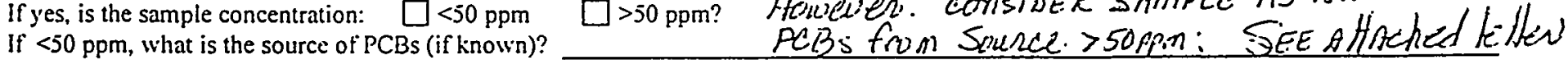

8. Is the sample radioactive? If yes. list any known isotopes, activities, or dose rates associated with the sample:

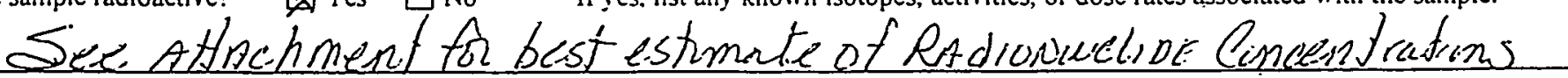

(To be completed by Battelle research or laboratory staff)

Battelle Project \#:

Charge Code H:

dnature:
Date:

\begin{tabular}{|l|}
\hline \\
No Anomalies Found \\
\hline Anomalies Found. RPL POC Notified \\
\hline
\end{tabular}




\section{Best TWINS estimate of contents of AP-101 for use with SICL}

\begin{tabular}{|l|l|r|}
\hline Analyce & Uñits: & AP-101 \\
\hline $\mathrm{Al}$ & $\mathrm{g} / \mathrm{L}$ & $9.66 \mathrm{E}+00$ \\
\hline $\mathrm{Bi}$ & $\mathrm{g} / \mathrm{L}$ & $0.00 \mathrm{E}+00$ \\
\hline $\mathrm{Ca}$ & $\mathrm{g} / \mathrm{L}$ & $3.87 \mathrm{E}-02$ \\
\hline $\mathrm{Cl}$ & $\mathrm{g} / \mathrm{L}$ & $1.32 \mathrm{E}+00$ \\
\hline $\mathrm{TIC}$ as CO3 & $\mathrm{g} / \mathrm{L}$ & $1.40 \mathrm{E}+01$ \\
\hline $\mathrm{Cr}$ & $\mathrm{g} / \mathrm{L}$ & $1.08 \mathrm{E}-01$ \\
\hline $\mathrm{F}$ & $\mathrm{g} / \mathrm{L}$ & $2.29 \mathrm{E}+00$ \\
\hline $\mathrm{Fe}$ & $\mathrm{g} / \mathrm{L}$ & $3.87 \mathrm{E}-03$ \\
\hline $\mathrm{Hg}$ & $\mathrm{g} / \mathrm{L}$ & $0.00 \mathrm{E}+00$ \\
\hline $\mathrm{K}$ & $\mathrm{g} / \mathrm{L}$ & $1.79 \mathrm{E}+01$ \\
\hline $\mathrm{La}$ & $\mathrm{g} / \mathrm{L}$ & $0.00 \mathrm{E}+00$ \\
\hline $\mathrm{Mn}$ & $\mathrm{g} / \mathrm{L}$ & $0.00 \mathrm{E}+00$ \\
\hline $\mathrm{Na}$ & $\mathrm{g} / \mathrm{L}$ & $1.46 \mathrm{E}+02$ \\
\hline $\mathrm{Ni}$ & $\mathrm{g} / \mathrm{L}$ & $6.30 \mathrm{E}-03$ \\
\hline $\mathrm{NO} 2$ & $\mathrm{~g} / \mathrm{L}$ & $4.03 \mathrm{E}+01$ \\
\hline $\mathrm{NO} 3$ & $\mathrm{~g} / \mathrm{L}$ & $1.31 \mathrm{E}+02$ \\
\hline $\mathrm{OHTOTAL}$ & $\mathrm{g} / \mathrm{L}$ & $6.95 \mathrm{E}+01$ \\
\hline $\mathrm{Pb}$ & $\mathrm{g} / \mathrm{L}$ & $3.13 \mathrm{E}-03$ \\
\hline $\mathrm{PO} 4$ & $\mathrm{~g} / \mathrm{L}$ & $9.94 \mathrm{E}-01$ \\
\hline $\mathrm{Si}$ & $\mathrm{g} / \mathrm{L}$ & $8.39 \mathrm{E}-02$ \\
\hline $\mathrm{SO} 4$ & $\mathrm{~g} / \mathrm{L}$ & $3.43 \mathrm{E}+00$ \\
\hline $\mathrm{Sr}$ & $\mathrm{g} / \mathrm{L}$ & $3.29 \mathrm{E}-06$ \\
\hline $\mathrm{TOC}$ & $\mathrm{g} / \mathrm{L}$ & $3.15 \mathrm{E}+00$ \\
\hline $\mathrm{UTOTAL}$ & $\mathrm{g} / \mathrm{L}$ & $2.53 \mathrm{E}-02$ \\
\hline $\mathrm{Zr}$ & $\mathrm{g} / \mathrm{L}$ & $1.74 \mathrm{E}-02$ \\
\hline
\end{tabular}

\begin{tabular}{|l|l|r|}
\hline Analyte & $\mathrm{Units}$ & $\mathrm{AP}-101 \mathrm{E}$ \\
\hline $3 \mathrm{H}$ & $\mathrm{mCi} . / \mathrm{L}$ & $1.38 \mathrm{E}-02$ \\
\hline $14 \mathrm{C}$ & $\mathrm{mCi} . / \mathrm{L}$ & $1.77 \mathrm{E}-04$ \\
\hline $59 \mathrm{Ni}$ & $\mathrm{mCi} . / \mathrm{L}$ & $3.29 \mathrm{E}-04$ \\
\hline $60 \mathrm{Co}$ & $\mathrm{mCi} . / \mathrm{L}$ & $3.29 \mathrm{E}-03$ \\
\hline $63 \mathrm{Ni}$ & $\mathrm{mCi} . / \mathrm{L}$ & $3.29 \mathrm{E}-02$ \\
\hline $79 \mathrm{Se}$ & $\mathrm{mCi} . / \mathrm{L}$ & $3.87 \mathrm{E}-04$ \\
\hline $90 \mathrm{Sr}$ & $\mathrm{mCi} . / \mathrm{L}$ & $1.35 \mathrm{E}-01$ \\
\hline $90 \mathrm{Y}$ & $\mathrm{mCi} . / \mathrm{L}$ & $1.35 \mathrm{E}-01$ \\
\hline $93 \mathrm{Zr}$ & $\mathrm{mCi} . / \mathrm{L}$ & $2.90 \mathrm{E}-03$ \\
\hline $93 \mathrm{mNb}$ & $\mathrm{mCi} . / \mathrm{L}$ & $2.10 \mathrm{E}-03$ \\
\hline $99 \mathrm{Tc}$ & $\mathrm{mCi} . / \mathrm{L}$ & $5.12 \mathrm{E}-02$ \\
\hline $106 \mathrm{Ru}$ & $\mathrm{mCi} . / \mathrm{L}$ & $7.92 \mathrm{E}-06$ \\
\hline $113 \mathrm{mCd}$ & $\mathrm{mCi} . / \mathrm{L}$ & $1.52 \mathrm{E}-02$ \\
\hline $125 \mathrm{Sb}$ & $\mathrm{mCi} . / \mathrm{L}$ & $2.55 \mathrm{E}-02$ \\
\hline $126 \mathrm{Sn}$ & $\mathrm{mCi} . / \mathrm{L}$ & $1.25 \mathrm{E}-02$ \\
\hline $129 \mathrm{I}$ & $\mathrm{mCi} . / \mathrm{L}$ & $5.56 \mathrm{E}-05$ \\
\hline $134 \mathrm{Cs}$ & $\mathrm{mCi} . / \mathrm{L}$ & $2.55 \mathrm{E}-03$ \\
\hline $137 \mathrm{Cs}$ & $\mathrm{mCi} . / \mathrm{L}$ & $1.73 \mathrm{E}+02$ \\
\hline $137 \mathrm{mBa}$ & $\mathrm{mCi} . / \mathrm{L}$ & $1.64 \mathrm{E}+02$ \\
\hline $151 \mathrm{Sm}$ & $\mathrm{mCi} . / \mathrm{L}$ & $2.08 \mathrm{E}+00$ \\
\hline $152 \mathrm{Eu}$ & $\mathrm{mCi} . / \mathrm{L}$ & $7.74 \mathrm{E}-04$ \\
\hline $154 \mathrm{Eu}$ & $\mathrm{mCi} . / \mathrm{L}$ & $7.32 \mathrm{E}-02$ \\
\hline $155 \mathrm{Eu}$ & $\mathrm{mCi} . / \mathrm{L}$ & $4.05 \mathrm{E}-02$ \\
\hline $226 \mathrm{Ra}$ & $\mathrm{mCi} . / \mathrm{I}$ & $7.60 \mathrm{E}-08$ \\
\hline $227 \mathrm{Ac}$ & $\mathrm{mCi} . / \mathrm{L}$ & $1.48 \mathrm{E}-07$ \\
\hline $228 \mathrm{Ra}$ & $\mathrm{mCi} . / \mathrm{L}$ & $4.42 \mathrm{E}-05$ \\
\hline $229 \mathrm{Th}$ & $\mathrm{mCi} . / \mathrm{L}$ & $1.04 \mathrm{E}-06$ \\
\hline $231 \mathrm{~Pa}$ & $\mathrm{mCi} . / \mathrm{L}$ & $6.65 \mathrm{E}-07$ \\
\hline $232 \mathrm{Th}$ & $\mathrm{mCi} . / \mathrm{L}$ & $6.00 \mathrm{E}-06$ \\
\hline $232 \mathrm{U}$ & $\mathrm{mCi} . / \mathrm{L}$ & $3.64 \mathrm{E}-06$ \\
\hline $233 \mathrm{U}$ & $\mathrm{mCi} . / \mathrm{L}$ & $1.40 \mathrm{E}-05$ \\
\hline $234 \mathrm{U}$ & $\mathrm{mCi} . / \mathrm{L}$ & $1.15 \mathrm{E}-05$ \\
\hline $235 \mathrm{U}$ & $\mathrm{mCi} . / \mathrm{L}$ & $4.42 \mathrm{E}-07$ \\
\hline $236 \mathrm{U}$ & $\mathrm{mCi} . / \mathrm{L}$ & $8.27 \mathrm{E}-07$ \\
\hline $237 \mathrm{~Np}$ & $\mathrm{mCi} . / \mathrm{L}$ & $1.82 \mathrm{E}-04$ \\
\hline $238 \mathrm{Pu}$ & $\mathrm{mCi} . / \mathrm{L}$ & $1.07 \mathrm{E}-05$ \\
\hline $238 \mathrm{U}$ & $\mathrm{mCi} . / \mathrm{L}$ & $8.39 \mathrm{E}-06$ \\
\hline $239 \mathrm{Pu}$ & $\mathrm{mCi} . / \mathrm{L}$ & $1.44 \mathrm{E}-04$ \\
\hline $240 \mathrm{Pu}$ & $\mathrm{mCi} . / \mathrm{L}$ & $3.43 \mathrm{E}-05$ \\
\hline $241 \mathrm{Am}$ & $\mathrm{mCi} . / \mathrm{L}$ & $1.95 \mathrm{E}-04$ \\
\hline $241 \mathrm{Pu}$ & $\mathrm{mCi} . / \mathrm{L}$ & $9.96 \mathrm{E}-04$ \\
\hline $242 \mathrm{Cm}$ & $\mathrm{mCi} . / \mathrm{L}$ & $3.20 \mathrm{E}-07$ \\
\hline $244 \mathrm{Cu}$ & $\mathrm{mCi} . / \mathrm{L}$ & $4.15 \mathrm{E}-09$ \\
\hline $\mathrm{mCi} . / \mathrm{L}$ & $1.80 \mathrm{E}-08$ \\
\hline $\mathrm{mCi} . / \mathrm{L}$ & $1.62 \mathrm{E}-05$ \\
\hline $\mathrm{mCi} . / \mathrm{L}$ & $3.54 \mathrm{E}-04$ \\
\hline
\end{tabular}


Kathleen Whelan

Direct tel: $\quad 509-375-4312$

MSIN K9-84

Direct fax: $\quad 509-372-4334$

Battelle Memorial Institute

Pacific Northwest National Laboratory

CCN栗: 012259

902 Battelle Boulevard

P.O. Box 999

Richland, Washington 99352

March 17.2000

Dear Kathy:

Contract NOO. DE-ACOG-96RY13308 - W375-SC-98-4168-REQUEST FORPROPOSAL TO CONDUCT PCB ANALYSIS OF TANK 241-AP-10I SANIPLE

References: 1. CCN 012160, Letter M. E. Johnson, BNFL Inc., to Eugene Morrey, Battelle, "Request for Proposal to Conduct Revised Analysis of Tank 241-AP-101 Samples", dated March 15, 2000.

BNFL inc. received verbal notification on March 15, 2000 from Dr. N. R. Brown, U.S. Department of Energy Office of River Protection (DOE-ORP), the tank 241-AP-101 sample currently at Battelle facilities may have in part originated from a waste source that contained greater than 50ppm polychlorinated biphenyl (PCB) compounds. Battelle personnel should conduct appropriate handling practices for this waste sample, consistent with Battelle procedures. .

BNFL Inc. is requesting Battelle to prepare a proposal for conducting analysis of the tank $241-$ AP-101 sample to determine the concentration of PCB compounds following EPA. Test Methods for Evaluation of Solid Waste Physical / Chemical Methods, SW-846. The requested $\mathrm{PCB}$ analysis of the tank 241-AP-101 sample is to be conducted in addition to the analyses already requested by BNFL Inc. in correspondence number 012160 (ref.). 
Please indicate in your proposal the volume of additional tank 241-AP-101 sample (if necessary) for conducting the PCB analyses. Please submit your proposal to MS Anne Thompson by March 24, 2000. Please contact Michael Johnson, if you have technical inquiries relating to this request for proposal

Sincerely,

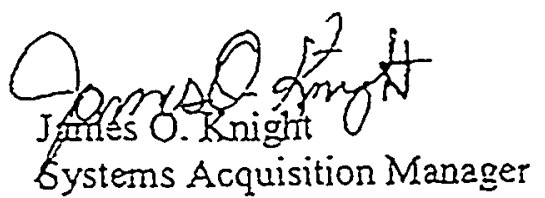

ANT/vle

cc:

D. Blumenluanz

J. R. Cook

M. E. Johnson

Contracts File

Contracts Correspondence File

PDC

Neil R. Brown

Karyn Wiemers
ENTL Inc. BNFI Inc.

BNFL Inc.

BNEL Inc.

BNFL Inc.

BNFL Ine.

DOE-O

DOE-O
ETC-1/P-122

ETC-1/P113

B-267

H6-60

$\mathrm{H} 6-60$ 


\section{Test Instruction}

Unique Numerical Designation: TI-29953-086

Revision number: 0

Effective Date: April 17, 2000

Controlling Procedure No: N/A
Author Approval: Ary 1. funct 4/17/00 Technical Reviewer: \&L Kunath 4 /n/ 00

BNFL Reviewer: $N / A$

\section{TITLE: AP-101 Precipitation/Crystallization Versus}

\section{Temperature}

1. Set bath temperature to $10^{\circ} \mathrm{C}$

2. Inspect the AP-101 sample (sample ID: AP-101 GL) for precipitates

$$
\begin{aligned}
& \text { Notes: Appeans to he some silids floatin around in the AP, } 10162 \text { samply. } \\
& \text { Will cilter, then tromsken filtate to cleam glass botth } \\
& \rightarrow \text { "AP-101 OL Filter" }
\end{aligned}
$$

3. If the sample has solids, filter through a $0.45-\mu \mathrm{m}$ nylon membrane. If there are no solids, proceed directly to step 4 .

4. Place the sample in the cooling bath at $10^{\circ} \mathrm{C}$ PLACEO $10406 / 8 / 00 \mathrm{~cm} R$

5. Inspect the sample for solids each day (excluding weekends) for a period of seven days; note observations below

Date Time Observations

6-9-00 1040 NO UPSABILITY CHAEES

$6-12-\infty 1230$ NO VISAISL CHANGES

6-i3-001530 NO lisibility changes

6-14-00- NOTHAKEA'

6rt5-000930 visibe changes

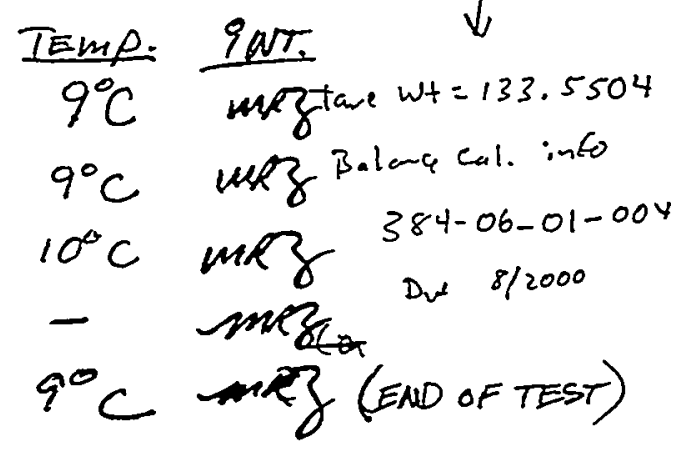


Note

If no solids have formed after seven days, proceed to step 17.

6. Label a 120-mL glass jar as AP101-10 - - Liquid

7. Weigh vial AP101-10-Liquid

Wt. AP101-10-Liquid $=$ g

Note balance calibration information:

Calibration ID:

Calibration Date:

Due Date:

\section{Note}

During steps 8 through 11 , keep AP-101 GL in the $10^{\circ} \mathrm{C}$ water bath to the extent possible to avoid warming the sample

8. Using a pipette transfer the liquid from AP-101 GL to AP101-10-Liquid; take care not to transfer any solids during this process

9. Weigh vial AP101-10-Liquid

$$
\begin{aligned}
& \text { Wt. AP101-10'-Liquid }=\_\mathrm{g} \\
& \mathrm{Wt.} \text { liquid }=9 \mathrm{a}-7 \mathrm{a}=
\end{aligned}
$$

10. Place a piece of filter paper into AP-101 GL and tip the jar so that the excess liquid wicks up the filter paper; take care not to remove any solids during this process

11. Remove the filter paper

12. Weigh vial AP-101 GL with the damp solids

$$
\text { Wt. AP-101 GL = }
$$

13. Calculate the weight of the damp solids

Wt. wet solids $=12 \mathrm{a}-133.9021=$

Note: The tare weight of AP-101 GL is $133.9021 \mathrm{~g}$ 
14. Dry the solids in AP-101 GL to a constant weight at $105^{\circ} \mathrm{C}$ Notes:

15. Weigh vial AP-101 GL with the dry solids

$$
\text { Wt. AP-101 GL = }
$$

16. Calculate the weight of the dry solids

$$
\text { Wt. solids }=15 \mathrm{a}-133.9021=
$$

17. End of Test 


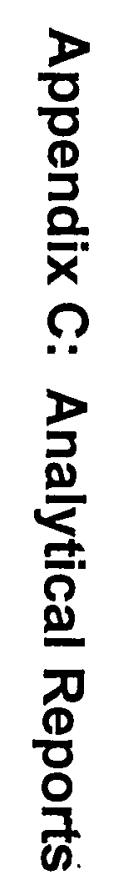


Radiochemical Processing Laboratory

Shielded Facility Operations Team

\section{Shielded Analytical Laboratory} Bench Sheet

lient: MW URIE N

TI\#/ASR: ASR $\cdot 5778$

WP Number: W54906

Procedure: Bench Instruction

\section{AP101 DENSITIES \\ SAMPLE IDENTIFICATION}

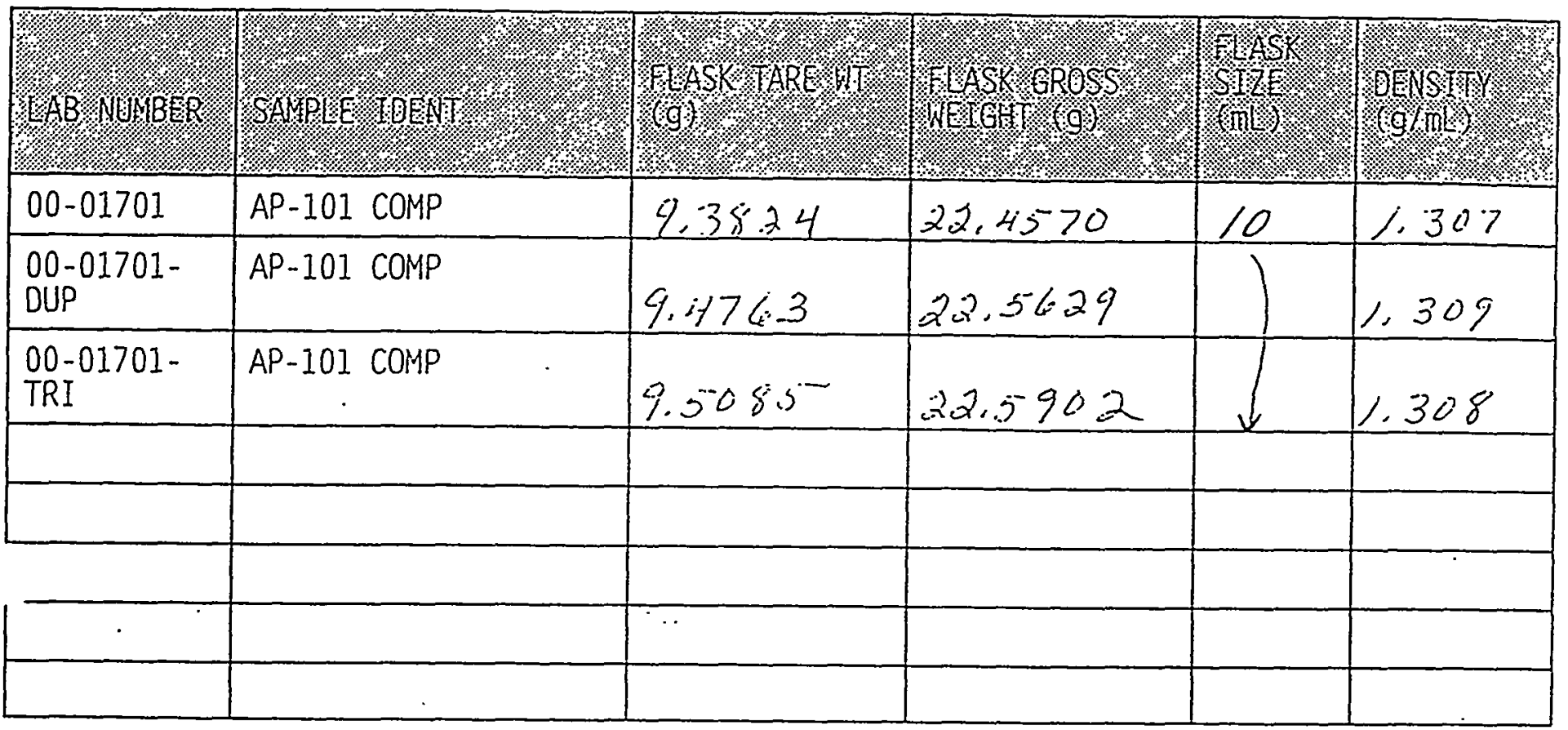

DENSITY $=\frac{\text { FLASK GROSS }(q)-\text { FLASK TARE }(q)}{\text { FLASK SIZE }(\mathrm{mL})}$

M\&TE: $X$ Ce17 2 (360-06-01-016) Mettler AE160 Balance Other Cel1 5. (360-06-01-019) Sartorius LP4200S Balance Bench (510-06-01-014) Mettler AT201 Balance Bench (360-06-01-040) Denver A160 Balance

Ainzlyst:

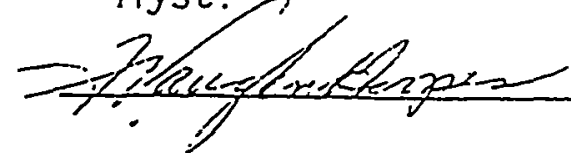

Date:

$4-5-00$
Reviewer:

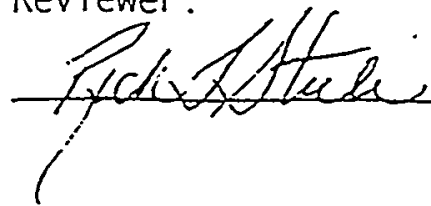

Date:

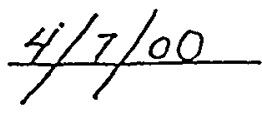




\section{Battelle PNNL/RPG/Inorganic Analysis ... \\ ICPAES Data Report}

Project:

Client:

29953 / W54906

D. Kurath

ACL Number(s): 00-01701
Client ID: “AP-101-COMP”
ASR Number: 5778
Total Sample: 1

Procedure: PNL-ALO-211, "Determination of Elements by Inductively Coupled Argon Plasma Atomic Emission Spectrometry" (ICP-AES).

Analyst: $\quad$ D.R. Sanders

Analysis Date (Filename): 04-11-00 (A0595) [ALO-128 SAU/vh]

See Chemical Measurement Center 98620: ICP-325-405-1 File for Calibration and Maintenance Records.

M\&TE Number:

ICPAES instrument -- WB73520

Mettler AT400 Balance -- Ser.No. 360-06-01-029
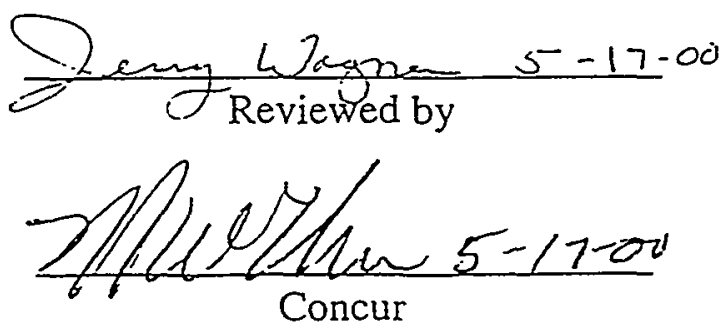


\section{Battelle PNNL/RPG/Inorganic Analysis ... ICPAES Data Report}

\section{ASR-5778}

Sample AP-101-COMP (RPL\# 00-01701) was prepared in triplicate by the Shielded Analytic Lab (SAL) using ALO-128 acid digestion of liquids procedure. A process blank, blank-spike and matrix-spike were also prepared similarly at the same time as the samples. Approximately 6.6 grams of liquid (density $1.308 \mathrm{~g} / \mathrm{ml}$ ) or about $5 \mathrm{ml}$, was processed and diluted to a final volume of about $25 \mathrm{ml}$ (final solution volume was weighed and density corrected to a volume). Some insoluble precipitate remained after processing requiring filtration before analysis could be performed. Analytical dilution prior to ICPAES analysis required 5, 10 and 50-fold dilution in order to quantify all analytes of interest. Measurement results are reported in $\mu \mathrm{g} / \mathrm{ml}$ corrected for sample density, processing and analytical dilution. Volumes and weights have been recorded on bench sheets and included with this report.

Quality control objectives were met for the majority of analytes of interest listed in ASR-5778 attachment 2: page 1 of 6 (Table 2 ...MRQ's) and page 4 of 6 (Table 4 ...QC Acceptance Criteria).

Objectives missed:

a) Sulfur is not available on the ICPAES instrument used for this work.

b) MRQ's required for "...Contract Specification $7 . .$. " for barium $(2.3 \mu \mathrm{g} / \mathrm{ml})$ and lanthanum $(2.3 \mu \mathrm{g} / \mathrm{ml})$ were below $\mathrm{EQL}(2.5$ and $12.7 \mu \mathrm{g} / \mathrm{ml}$ respectively).

c) Also, MRQ's for "...Opportunistic Analytes" for rhodium (18), ruthenium (36), and' . silicon (90) were below EQL $(76,278$, and $126 \mu \mathrm{g} / \mathrm{ml}$ respectively).

d) LCS for silver (69\%R) was below "QC Acceptance Criteria" (80\%-120\%R).

e) Spike Recovery for silver (35\%R), barium (30\%R), and lead (65\%R) was below " $Q C$ Acceptance Criteria" (75\% - 125\%R).

f) Duplicate \%RPD (average) for phosphorous (15.8\%RPD) was below "QC Acceptance Criteria" ( $<15 \%$ RPD).

See attachment 1 and 2 to this report.

Quality control check-standard results met tolerance requirements for all analytes except as noted below. Following is a list of quality control measurement results relative to ICPAES analysis tolerance requirements. Please note that $M R Q$ is equivalent to $E Q L$ in this report.

Five fold serial dilution:

(liquid samples)

Results were within tolerance limit of $\leq 10 \%$ for all analytes tested after correcting for dilution. 


\section{Battelle PNNL/RPG/Inorganic Analysis ... ICPAES Data Report}

\section{Duplicate RPD (Relative Percent Difference):}

(liquid samples)

All analytes of interest were recovered within tolerance limit of $\leq 15 \%$ relative percent difference (RPD) except as follows. RPD for phosphorous in the three sample replicates ranged from about $15 \%$ to $28 \%$ RPD. Average RPD for phosphorous within the three replicates was $15.8 \%$. Chromium in the three sample replicates ranged from about $1 \%$ RPD to about $16 \%$ RPD. Average RPD for chromium within the three replicates was about $8.9 \%$.

Post-Spiked Samples (Group A):

(liquid samples)

All analytes of interest were recovered within tolerance of $75 \%$ to $125 \%$ except silicon. Silicon recovery (147\%) exceeded tolerance limit. All other analytes of interest above EQL were within tolerance.

Post-Spiked Samples (Group B):

(liquid samples)

All analytes of interest were recovered within tolerance of $75 \%$ to $125 \%$ except palladium. Palladium recovery (53\%) exceeded tolerance limit. All other analytes of interest above EQL were within tolerance. Palladium was found low in the group B spike. Single element palladium at $2 \mu \mathrm{g} / \mathrm{ml}$ measured at the beginning, middle and end of the run $(2.00 \pm 0.04 \mu \mathrm{g} / \mathrm{ml})$ were well within tolerance limit. No palladium was detected in the sample.

Blank Spike: (liquid samples)

All analytes of interest were recovered within tolerance limit of $80 \%$ to $120 \%$ recoveries except silver. Low recovery of silver in the blank spike (about 69\%) was probably due to the small amount of hydrochloric acid used during sample preparation resulting in some silver precipitating from solution.

Matrix Spiked Sample: (liquid samples)

All analytes of interest were recovered within tolerance limit of $75 \%$ to $125 \%$ recoveries except silver, barium and lead. Silver recovery (about 35\%), barium recovery (about 30\%) and lead recovery (about $65 \%$ ) were all low and may be related to the presence of sulfate and/or carbonate present in the sample. Low silver recovery is probably, in part, due to the small amount of hydrochloric acid used during sample processing. All sample aliquots had a small amount of precipitate remaining after processing requiring filtration. 


\section{Battelle PNNL/RPG/Inorganic Analysis ... ICPAES Data Report}

Quality Control Check Standards (solid and liquid samples):

Concentrations of all analytes were within tolerance limit of $\pm 10 \%$ accuracy in standards (except palladium): QC_MCVA, QC_MCVB, and QC_SSTMCV. Calibration Blank (ICP98.0) concentration is acceptable, less than two times DL. Palladium in QC check standard MCVB was low (about $42 \%$ to $48 \%$ ) however, a single element standard of palladium at $2.0 \mu \mathrm{g} / \mathrm{ml}$ measured at the beginning, middle and end of the ICP run was well within tolerance limit indicating acceptable palladium accuracy. No palladium was detected in the sample aliquots.

High Calibration Standard Check (solid and liquid samples):

Verification of the high-end calibration for all analytes measured is within tolerance limits of $\pm 5 \%$ accuracy.

Process Blank:

(liquid samples)

All analytes of interest were within tolerance limit of $\leq \mathrm{EQL}$ or $<5 \%$ of sample concentration in the prepared samples.

Laboratory Control Standard (LCS):

(liquid samples) The blank-spike and matrix-spike were prepared and measured as an LCS control (See results described above)

Please note bracketed values listed in the data report are within ten times instrument detection limit and have a potential uncertainty much greater than $15 \%$.

Comments:

1) "Final Results" have been corrected for all laboratory dilution performed on the sample during processing and analysis unless specifically noted.

2) Detection limits.(DL) shown are for acidified water. Detection limits for other matrices may be determined if requested.

3) Routine precision and bias is typically $\pm 15 \%$ or better for samples in dilute, acidified water (e.g. $2 \% \mathrm{v} / \mathrm{v} \mathrm{HNO}_{3}$ or less) at analyte concentrations greater than ten times detection limit up to the upper calibration level. This also presumes that the total dissolved solids concentration in the sample is less than $5000 \mu \mathrm{g} / \mathrm{mL}$ ( 0.5 per cent by weight).

4) Absolute precision, bias and detection limits may be determined on each sample if required by the client.

5) The maximum number of significant figures for all ICP measurements is 2. 
Battelle PNNL/RPG/Inorganic Analysis ... ICPAES Data Report Page 1 of 1

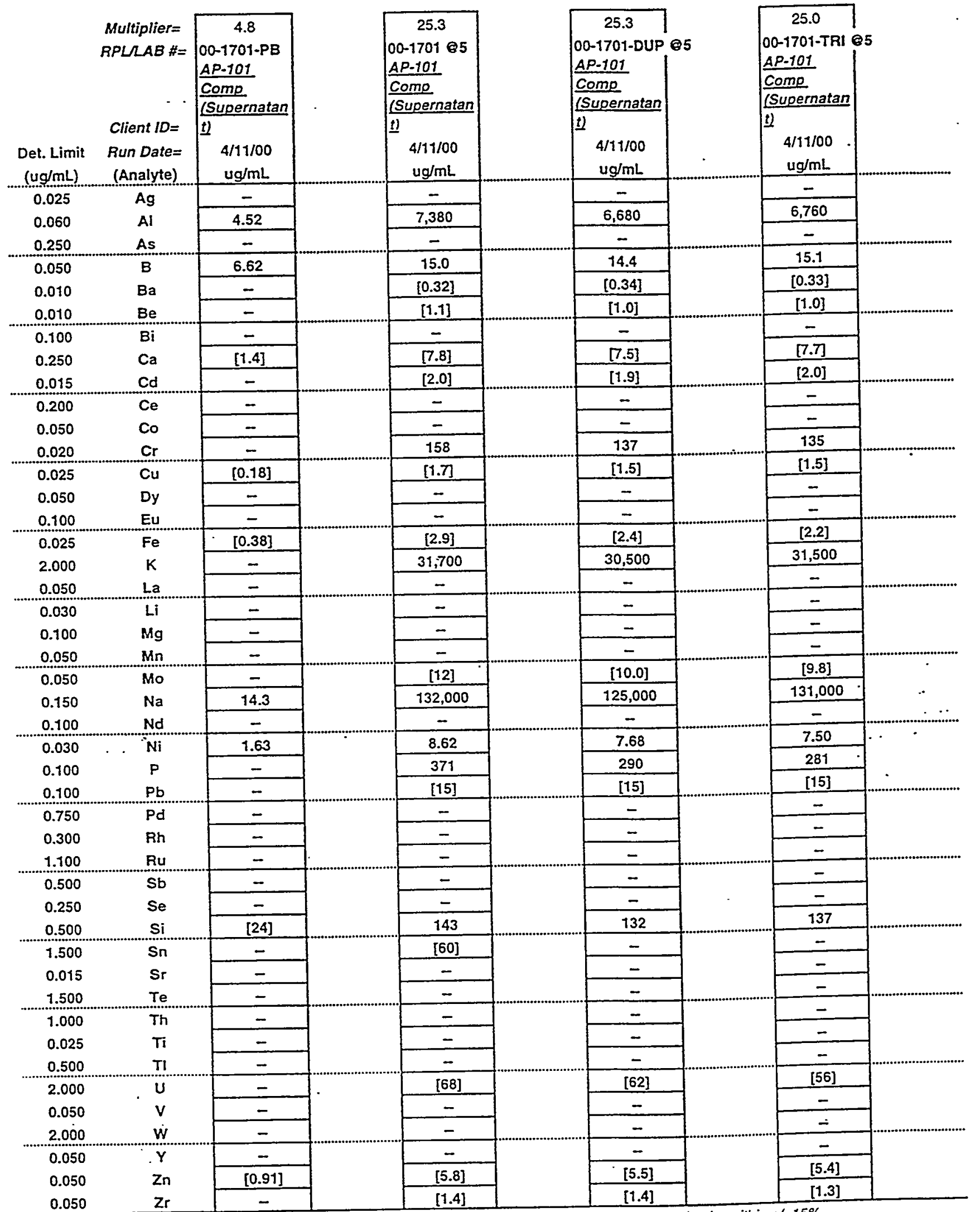

Note: 1) Overall error greater than 10-times delection limit is estimated to be within $+1-15 \%$.

2) Values in brackets $D$ are within 10 -times detection limit with errors likely to exceed $15 \%$.

3) ...- indicate measurement is below detection. Sample detection limit may be found by

multiplying "det. limit" (far left column) by "multiplier" (top of each column).

Data (1) from 'A0595 D.Kurath ASR-5778 AP-101 Comp (ALO-128) Supernatant ICP98 hi.XLS 4/12/00 1:02 PM 
ASR-5778 "ICPAES Measurement Results -- Data"

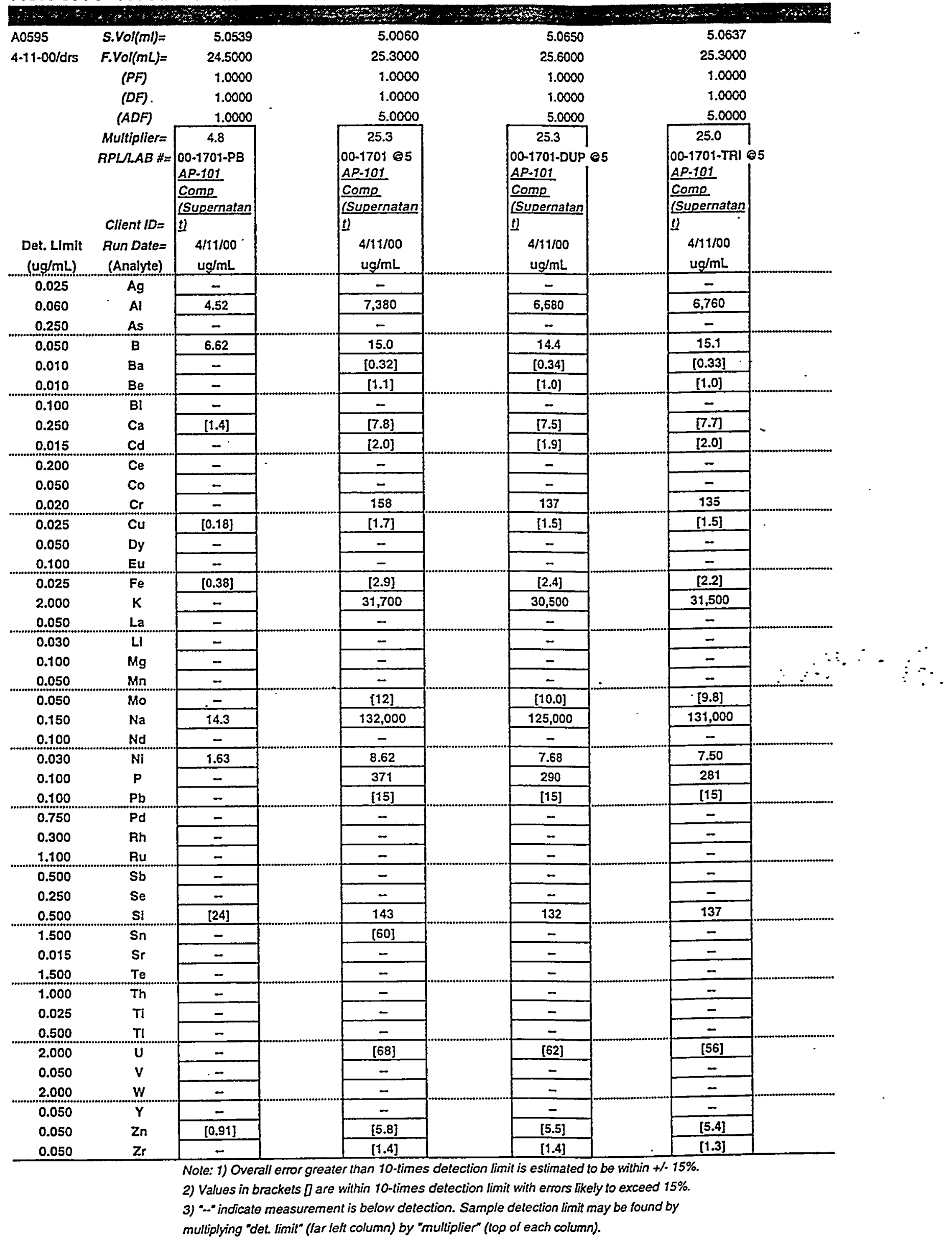


Attachment No. 1 of 2, ASR-5778 "ICPAES Measurement Results -- Statistical Summary"

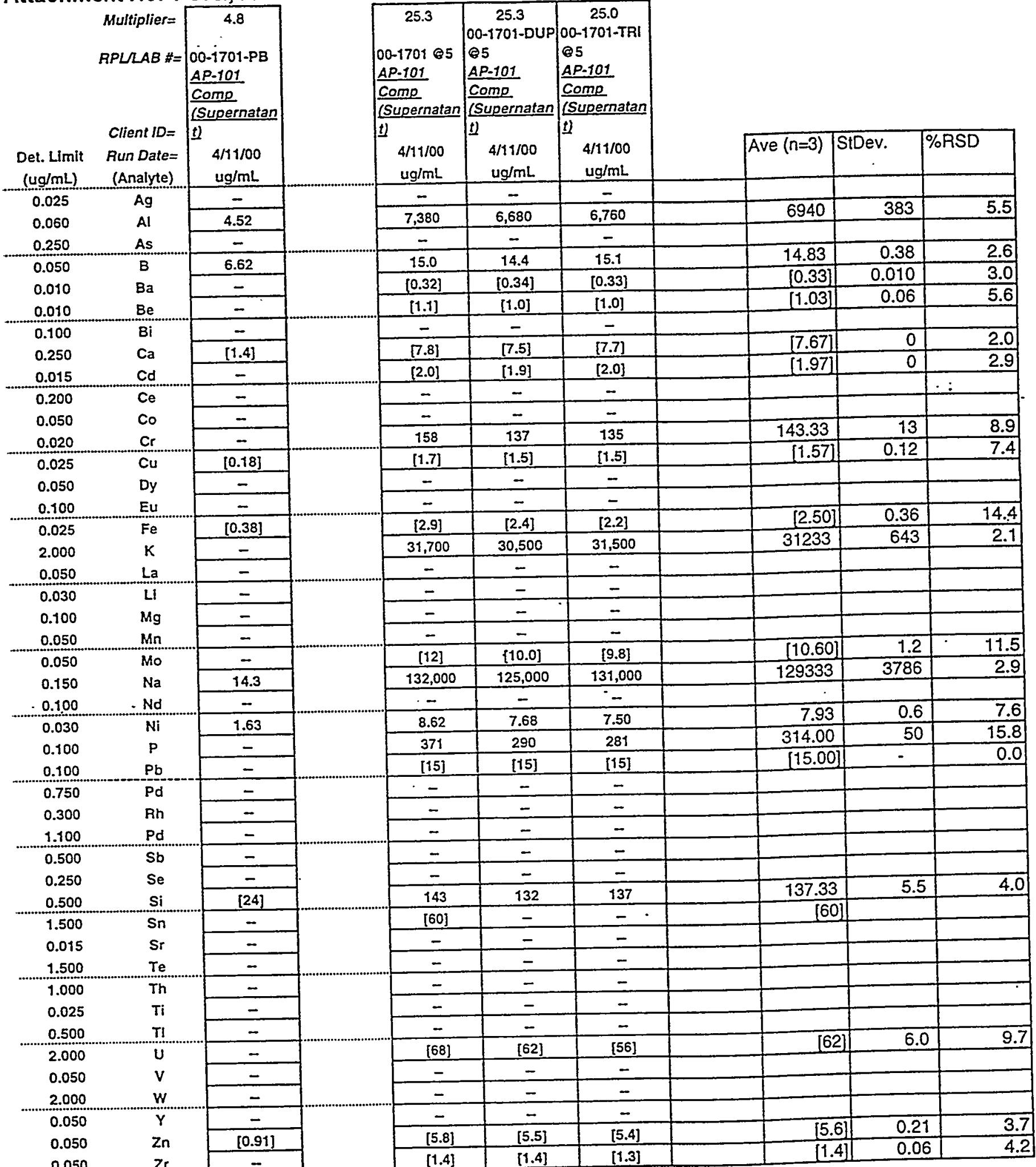

Note: 1) Overall error greater than 10-times detection limit is estimated to be within $+1-15 \%$.

2) Values in brackets $\square$ are within 10-times detection limit with errors likely to exceed $15 \%$.

3) :--- indicale measurement is below detection. Sample detection limit may be found by

multiplying "det. limit" (far left column) by "multiplier" (top of each column).

ASR-5778 Statistics from ASR-5778 D.Kurath ICPAES e-report (5-2-00 jjw).xls 


\section{Attachment No. 2 of 2, ASR-5778 "ICPAES Measurement Results -- Quality Control Parameters"}

\begin{tabular}{|c|c|c|c|c|c|c|c|}
\hline \multirow{2}{*}{\multicolumn{3}{|c|}{ ASR-5778 D. Kurath }} & \multicolumn{2}{|c|}{ A0595 4/11/00 } & \multirow[t]{2}{*}{ RPL\#: 00-1701 } & \multirow{2}{*}{\multicolumn{2}{|c|}{ Client ID: "AP-101 COMP" }} \\
\hline & & & $\mathrm{PF}=$ & 25.3 & & & \\
\hline & Analvite & $\frac{\mathrm{MRQ}}{(\mathrm{ug} / \mathrm{ml})}$ & $\frac{\text { IDL(ICPAES) }}{(\mathrm{ug} / \mathrm{ml})}$ & $\frac{E Q L}{(u \mathrm{ug} / \mathrm{ml})}$ & {$\left[\begin{array}{c}80 \%-120 \%] \\
\frac{\text { LCS }}{(\% R)}\end{array}\right.$} & $\begin{array}{l}{[75 \%-125 \%]} \\
\frac{\text { Spike Rec'y }}{(\% R)}\end{array}$ & $\begin{array}{c}{[<15 \%]} \\
\text { Dup \%RSD } \\
\text { (\%RSD) }\end{array}$ \\
\hline 1[ & $\overline{A g}$ & 17 & 0.025 & 6.3 & 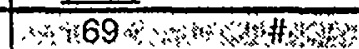 & A & - \\
\hline 2 & Al & 75 & 0.06 & 15.2 & & & 5.5 \\
\hline 3 & Batsong & 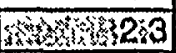 & YAE & 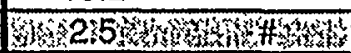 & 87 & 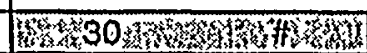 & [3] \\
\hline 4 & $\mathrm{Bi}$ & 170 & 0.1 & 25.3 & & & - \\
\hline 5 & $\overline{\mathrm{Ca}}$ & 150 & 0.25 & 63.3 & & & [2] \\
\hline 6 & $\mathrm{Cd}$ & 7.5 & 0.015 & 3.8 & 92 & 87 & [2.9] \\
\hline 7 & $\mathrm{Cr}$ & 15 & 0.02 & 5.1 & 93 & 94 & 8.9 \\
\hline 8 & $\mathrm{Cu}$ & 17 & 0.025 & 6.3 & & & [7.4] \\
\hline 9 & $\mathrm{Fe}$ & 75 & 0.025 & 6.3 & & & {$[14]$} \\
\hline 10 & $\mathrm{~K}$ & 750 & 2 & $506.0^{\circ}$ & & & 2.1 \\
\hline 11 & 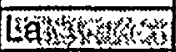 & 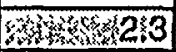 & 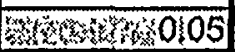 & 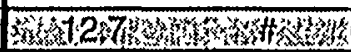 & & & -- \\
\hline 12 & $\mathrm{Mg}$ & 170 & 0.1 & 25.3 & & & -- \\
\hline 13 & $\mathrm{Mn}$ & 17 & 0.05 & 12.7 & & & $\cdots$ \\
\hline 14 & $\mathrm{Na}$ & 170 & 0.15 & 38.0 & & & 2.9 \\
\hline 15[ & $\mathrm{Nd}$ & 170 & 0.1 & 25.3 & & . & -- \\
\hline 16[ & $\mathrm{Ni}$ & 30 & 0.03 & 7.6 & 88 & 85 & 7.6 \\
\hline 17 & $P$ & 330 & 0.1 & 25.3 & & & 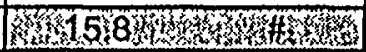 \\
\hline 18[ & $\mathrm{Pb}$ & 300 & 0.1 & 25.3 & 101 & W & {$[0]$} \\
\hline 19 & $\overline{P d}$ & 390 & 0.75 & 189.8 & & & $\ldots$ \\
\hline 20 & 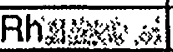 & 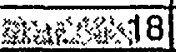 & Muly & 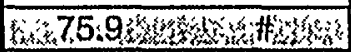 & & & -- \\
\hline 21 & 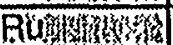 & 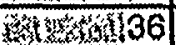 & 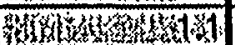 & 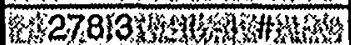 & & & -. \\
\hline 22 & 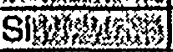 & 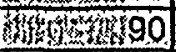 & 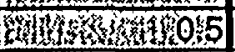 & 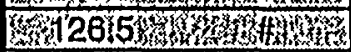 & & & $\overline{4}$ \\
\hline 23 & $\mathrm{Sr}$ & 17 & 0.015 & 3.8 & & & -- \\
\hline 24[ & $\mathrm{Ti}$ & 17 & 0.025 & 6.3 & & & -- \\
\hline 25 & $\mathrm{U}$ & 780 & 2 & 506.0 & & & {$[9.7]$} \\
\hline 26 & $\mathrm{Zn}$ & 17 & 0.05 & 12.7 & 89 & 92 & [3.7] \\
\hline 27 & $\mathrm{Zr}$ & 17 & 0.05 & 12.7 & & & {$[4.2]$} \\
\hline
\end{tabular}

Note: Gray areas indicate quality results outside of control limits of Table 2, "Supernate Analyses Required by Contract Specification 7 and Opportunistic Analytes" and Table 4, "Quality Control Parameters for Liquid Analysis" (reference: See ASR-5778 Attachment 2 page 1 of 6 , and page 4 of 6) 


\title{
Battelle PNNL/RPG/Inorganic Analysis --- IC Report
}

\author{
REVISION 1 (June 13, 2000)
}

$\begin{array}{lllr}\text { Client: } & \text { D Kurath } & \text { Charge Code/Project: } & \text { W54906/29953 } \\ \text { RPL Numbers: } & \text { 00-1701 (triplicate) } & \text { ASR Number: } & 5778 \\ \text { Analyst: } & \text { MJ Steele } & \text { Analysis Date: } & \text { April 23-24, 2000 }\end{array}$

Procedure: PNL-ALO-212, "Determination of Inorganic Anions by Ion Chromatography" M\&TE: IC system (WD25214); Balance (360-06-01-031) --- See Chemical Measurement Center 98620 RIDS IC File for Calibration, Standards Preparations, and Maintenance Records.

\section{Final Results:}

The AP-101 composite sample (00-1701) was analyzed in triplicate by ion chromatography (IC) for inorganic anions as specified in the governing ASR. The final results are presented in Table 1 below. All analytical samples were diluted 2000 to 5000 fold at the IC workstation to ensure that all anions reported were measured within the calibration range. Per the ASR the samples were analyzed in triplicate and the relative standard deviation between the measurements is reported. The minimum reportable quantity (MRQ) for each anion was defined by the ASR, and all MRQ were met at the dilutions analyzed. From recoveries demonstrated on some of the verifications standards analyzed, the AP-101 sample matrix has an adverse effect on the IC column and some reported results may be $10 \%$ to $20 \%$ low. By further diluting the sample, this effect could be minimized, but at the expense of meeting the MRQs (particularly phosphate, sulfate, and oxalate).

For IC column and parameters used, the IC system can not separate fluoride, acetate, and formate; the IC system quantifies and reports all as fluoride. It is unlikely that the levels of fluoride quantified are present in the tank waste, and since acetate and formate could be present in the AP-101 sample, the fluoride results should be used with reservation.

\begin{tabular}{|c|c|c|c|c|c|c|c|c|c|}
\hline $43, y, y$ & orable 1 & $(\mathrm{H}(\mathrm{t})$ & ens & $=N^{2}$ & $\mathrm{Br}^{1}$ & $\mathrm{NO}_{3}$ & 20 & $\mathrm{SO}_{4}$ & 3204 \\
\hline RPI Uimber & 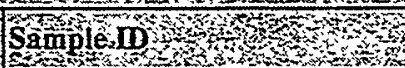 & ing & 10. & vig/ming & ofin & igm & Tht & ughn & igg/mI \\
\hline Ptots & 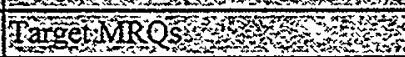 & M150 & 300 & 28300 & mingas & 3,000 & $300 \%$ & 2300 & 1800 \\
\hline $00-1701$ & AP-101 Composite & 2,880 & 2,000 & 42,200 & $<500$ & 133,000 & 1,040 & 4,070 & 1,100 \\
\hline 00-1701 Dup & AP-101 Composite Duplicate & 2,880 & 1,920 & 41,000 & $<500$ & 130,000 & 1,000 & 3,940 & 1,060 \\
\hline 00-1701 Trip & AP-101 Composite Triplicate & 2,940 & 2,010 & 42,400 & $<500$ & 133,000 & 1,020 & 4,080 & 1,100 \\
\hline & Rel Std Dev (\%) & $1.2 \%$ & $2.5 \%$ & $1.8 \%$ & $\mathrm{n} / \mathrm{a}$ & $1.3 \%$ & $2.0 \%$ & $1.9 \%$ & $2.1 \%$ \\
\hline 00-1701 MS & AP-101 Composite MS \%Rec & $114 \%$ & $111 \%$ & $119 \%$ & $108 \%$ & $128 \%$ & $119 \%$ & $108 \%$ & $121 \%$ \\
\hline & Blank Spike \%Rec & $110 \%$ & $107 \%$ & $105 \%$ & $108 \%$ & $78 \%$ & $104 \%$ & $106 \%$ & $107 \%$ \\
\hline
\end{tabular}

Rel Std Dev (5) = Relative Standard Deviation - Sample, Duplicate, Triplicate MS \%Rec = Matrix Spike Standard \% Recovery, BS \%Rec = Blank Spike Standard \% Recovery

$\left({ }^{*}\right)$ Use fluoride results with reservation; IC system can not resolve fluoride, acetate, and formate. 


\section{Battelle PNNL/RPG/Inorganic Analysis --- IC Report}

\section{Q.C. Comments}

Duplicates/Replicates: The ASR requested that the analyses be performed in triplicate and therefore the relative standard deviation was calculated for the three analyses. The Quality Control parameters defined in Table 4 attached to the ASR states acceptance criteria of $<15 \%$ relative percent difference (RSD). Table 1 presents the RSD based on comparison of the triplicate analysis. The RSD meets the acceptance criteria for all anion.

Matrix Spike: The matrix spike recoveries for all anions, except nitrate, were within the spiking acceptance criteria of $75 \%$ to $125 \%$ as established by ASR attachment Table 4 . The high nitrate concentration of the sample relative to the nitrate spiking level (i.e., sample concentration was 10 times greater than the spike concentration) significantly impacts the ability to measure the nitrate spike. No attempt was made to spike the samples at additional spiking level.

Blank Spike: The blank spike recoveries for all anions, except nitrate, were within the Laboratory Control Samples (LCS) acceptance criteria of $80 \%$ to $120 \%$ as established by the ASR attachment Table 4. Nitrate recovered slightly low at $78 \%$. It should be noted that the blanks spike nitrate recovery is not consistent with other control standards analyzed during the analysis run (e.g., Verification Check Standards).

System Blank/Processing Blanks: A dozen system blanks were process during the analysis of the slurry samples. No anions were detected in the system blanks above the method detection limit.

Quality Control Calibration Verification Check Standards: Over twenty mid-range verification standards were analyzed throughout the analysis runs. Numerous verification standards analyzed just after the analysis of some of the AP-101 samples demonstrated low recoveries (i.e., recoveries ranging from $80 \%$ to $90 \%$ ). Failure of the verification standard was only observed in those standards analyzed just after the AP-101 samples that had were prepared with the least dilution. Numerous reruns were performed alternating the AP-101 (at various dilutions) and the verification standard to obtain valid data.

\section{General Comments:}

- The reported "Final Results" have been corrected for all dilution performed on the sample during processing or analysis.

- The low calibration standards are defined as the estimated quantitation limit (EQL) for the reported results and assume non-complex aqueous matrices. Actual detection limits or quantitation limits for specific sample matrices may be determined, if requested.

- Routine precision and bias are typically $\pm 15 \%$ or better for non-complex aqueous samples that are free of interference and haye smilar concentrations as the measured anions.

Approval: 2200 Date $6-13-00$

Archive Information:

Files: ASR 5778 Kurath Rev 1.doc

ASR 5729 5764-68 5778.xls 


\section{Instrumentation}

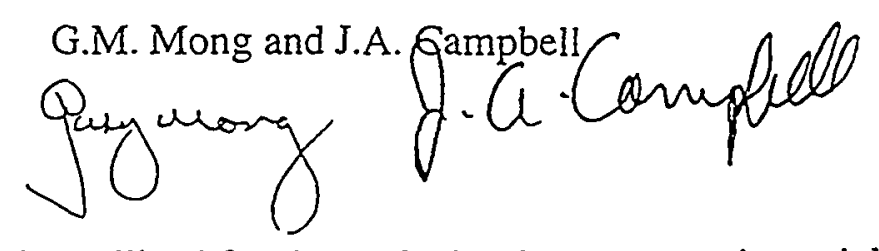

The analytical instrumentation utilized for the analysis of low-molecular weight organic acids consisted of an ion chromatography unit equipped with a conductivity detector. A Dionex AS-11 column and AG-11 guard column were used at ambient temperature with a $25-\mu \mathrm{L}$ sample loop. An anion suppressor was used. The flow rate of the mobile phase was $2.0 \mathrm{~mL} / \mathrm{min}$. A description of the IC system is provided in Table 1.a.

Table 1.a Ion Chromatography Instrumentation

\begin{tabular}{|l|l|c|c|}
\hline System/Instrument & Manufacturer & Model Number & M\&TE (1) Number \\
\hline Ion Chromatograph & Dionex & 500 DX & WD 24293 \\
\hline Conductivity Detector & Dionex & CD20 & WD 24295 \\
\hline
\end{tabular}

(1) Measuring and Test Equipment

The IC gradient conditions were: (a) $0.0 \mathrm{~min} 0 \% 100 \mathrm{mM} \mathrm{NaOH}, 98.1 \%$ deionized water and $1.9 \% 5 \mathrm{mM} \mathrm{NaOH}$, (b) $6.4 \mathrm{~min} 0 \% 100 \mathrm{mM} \mathrm{NaOH}, 0 \%$ deionized water and $100 \%$ $5 \mathrm{mM} \mathrm{NaOH}$, and (c) $18.4 \mathrm{~min} 35 \% 100 \mathrm{mM} \mathrm{NaOH}, 0 \%$ deionized water and $65 \% 5$ $\mathrm{mM} \mathrm{NaOH}$. The mobile phase contained a gradient of deonized water and a weak solution of $\mathrm{NaOH}$.

\section{Analysis Results}

Samples were analyzed using PNNL operating procedure AOAM-1 (Method for the Analysis and Quantification of Organic Acids in Simulated and Actual Hanford Tank Wastes by Ion Chromatography ). Sample AP-101 was done in triplicate at a dilution found to give acceptable total ion loading to the column (Dionex AS-11 anion exchange media). This dilution was calculated to be a 2242 times the sample weight as delivered to the 325 shielded laboratory.

Although acetate is reported, acetate coelutes with glycolate and requires the use of an alternate column for separation from glycolate. Without additional separation, one can not unequivocally state that the acetate/glycolate peak contains only acetate, only glycolate, a combination of both analytes, or a possible contaminant. From tank waste and solubility studies, the results are tank waste type dependent. In other words, for one tank waste the component may be entirely acetate. For another tank with a different fill history, the analytical results may indicate the component may be primarily glycolate or a combination of both analytes (Sharma et al. 1998, Camaioni et al. 1998, Barney 199, Ashby et al. 1994). 
The results are shown below for quantity (in micrograms) of acetate, formate, and oxalate found per milliliter of sample., based on a measured density of $1.308 \mathrm{~g} / \mathrm{mL}$. Citrate was below detectability in each sample using this dilution scheme.

\begin{tabular}{|ccrcc|}
\hline Sample & $\begin{array}{c}\mu \mathrm{g} \\
\text { acet/mL }\end{array}$ & $\mu \mathrm{g}$ & $\mu \mathrm{g}$ oxal $/ \mathrm{mL}$ & $\mu \mathrm{g}$ \\
form $/ \mathrm{mL}$ & & & citrate $/ \mathrm{mL}$ \\
$\# 1$ & 1543 & 1131 & 1799 & ND \\
$\# 2$ & 1793 & 1256 & 1781 & ND \\
$\# 3$ & 1601 & 1196 & 1817 & ND \\
& & & & \\
Average & 1645 & 1194 & 1800 & ND \\
\hline
\end{tabular}

The detection limits for acetate, formate, oxalate, and citrate are estimated to be 550 $\mu \mathrm{g} / \mathrm{mL}, 450 \mu \mathrm{g} / \mathrm{mL}, 890 \mu \mathrm{g} / \mathrm{ml}$, and $890 \mu \mathrm{g} / \mathrm{mL}$, respectively, based on the dilution factors.

\section{QC Evaluation}

Matrix spiking was done at a level approximately 1.5 times the level of analyte in the final diluted samples. This level of spiking is at a challenging level for accurate quantitation; the reported levels are near the lowest calibration point for each analyte. These results are summarized below:

\begin{tabular}{|llcccc|}
\hline MS spike & & $\mathrm{ms}$ & $\mathrm{msd}-1$ & $\mathrm{msd}-2$ & average \\
recovery & Acetate & $175 \%$ & $105 \%$ & $91 \%$ & $124 \%$ \\
& Formate & $71 \%$ & $104 \%$ & $79 \%$ & $84 \%$ \\
& Oxalate & $122 \%$ & $92 \%$ & $129 \%$ & $114 \%$ \\
& & & & \\
\hline
\end{tabular}

The value for acetate in the matrix spike sample should be considered suspect, as the peak quantitation had to be done by estimation (since the peak size was so small). The other data represent quantitation which was extracted directly from electronic integration data. Overall, the average data for MS and MSD is within acceptable limits. The LCS consisted of a mixture of formate and oxalate. The per cent recoveries obtained were 89.3 and $103.8 \%$, respectively.

\section{References}

1. Sharma, A.K., S.A. Clauss, G.M. Mong, K.L. Wahl, J.A. Campbell. 1998. Analysis and quantification of organic acids in simulated Hanford tank waste and Hanford tank waste. J. of Chromatogr, 805, 101-107.

2. Camaioni, D.M., W.D. Samuels, J.C. Linehan, S.A. Clauss, A.K. Sharma, K.L. Wahl, J.A. Campbell. 1996. Organic Tanks Safety Program, FY 96 Waste Aging Studies, PNNL11312, Pacific Northwest National Laboratory, Richland, Wa. 
3. Ashby, E.C. et al. 1994. Synthetic Waste Chemical Mechanism Sudies, WHC-EP-082̉3, Westinghouse Hanford Company, Richland, Wa.

4. Barney, GL. 1996. Solubilities of Significant Organic Compounds in HLWV Tank Supernate Solutions-FY 1996 Progress Report, WHC-EP-0899, Westinghouse Hanford Company, Richland, Wa. 
Client: $\quad$ D. Kurath

ACL Numbers: 00-1701

Analyst:

MJ Steele
Charge Code/Project: W54906/29953

ASR Number:

5778

Analysis Date: May 12 and April 13-14, 2000

Procedure: PNL-ALO-381, "Direct Determination of TC, TOC, and TIC in Radioactive Sludges and Liquids by Hot Persulfate Method"

PNL-ALO-380, "Determination of Carbon in Solids Using the Coulometric Carbon Dioxide Coulometer"

M\&TE: Carbon Analysis System (WA92040); Balance (360-06-01-023).

Final Results:

\begin{tabular}{|c|c|c|c|c|c|c|c|c|c|}
\hline & : & & HO & ERSULF & E MET & & & FURNACE & ETHOD \\
\hline RPL Number & Sample ID & $\begin{array}{c}\mathrm{TIC} \\
(\mu \mathrm{g} C / \mathrm{ml})\end{array}$ & $\begin{array}{l}\text { TIC } \\
\text { RPD }\end{array}$ & $\begin{array}{c}\text { TOC } \\
(\mu \mathrm{gC} / \mathrm{ml})\end{array}$ & $\begin{array}{l}\text { TOC } \\
\text { RPD }\end{array}$ & $\begin{array}{c}\mathrm{TC} \\
(\mu \mathrm{gC} / \mathrm{ml})\end{array}$ & $\begin{array}{c}\mathrm{TC} \\
\mathrm{RPD}\end{array}$ & $\begin{array}{c}\mathrm{TC} \\
(\mu \mathrm{gC} / \mathrm{ml})\end{array}$ & $\begin{array}{c}\text { TC } \\
\text { RPD }\end{array}$ \\
\hline 00-01701 & AP-101 COMPOSITE & 6,550 & & 1,860 & & 8,410 & & 8,530 & \\
\hline $00-01701$ & AP-10I COMPOSITE & 6,400 & $2 \%$ & 1,980 & $6 \%$ & 8,390 & $0 \%$ & 8,670 & $2 \&$ \\
\hline 00.01701 & AP-101 COMPOSITE & 6,430 & & 2,030 & & 8.460 & & 8.620 & \\
\hline & RSD & $1.2 \%$ & & $4.5 \%$ & & $0.4 \%$ & & $0.8 \%$ & \\
\hline $00-01701 \mathrm{MIS}$ & MS Recovery & $98.5 \%$ & & $96.3 \%$ & . & $97.5 \%$ & & $97.5 \%$ & \\
\hline & MDL & 40 & & 80 & & 80 & & 170 & \\
\hline
\end{tabular}

RPD = Relative Percent Difference

$\mathrm{RSD}=$ Relative Standard Deviation

The analysis of the liquid sample submitted under ASR 5778 was performed by the hot persulfate wet oxidation method and by the furnace oxidation method. The hot persulfate method uses acid decomposition for $\mathrm{TIC}$ and acidic potassium persulfate oxidation at $92-95^{\circ} \mathrm{C}$ for $\mathrm{TOC}$, all on the same sample, with TC being the sum of the TIC and TOC. "The furnace oxidation method determines TC by oxidizing all forms of carbon (i.e., inorganic and organic) in oxygen at $1000^{\circ} \mathrm{C}$. Although the ASR requested TOC and TIC by the furnace method, the method is considered reliable only for TC. For the sample matrix analyzed the furnace method and hot persulfate method should provide equivalent TC results, and this was confirmed by the results, with the average hot persulfate TC.being $8420 \mu \mathrm{g} / \mathrm{ml}$ and the furnace TC being $8610 \mu \mathrm{g} / \mathrm{ml}$; an RPD of about $2 \%$.

The table above shows the results, rounded to two to three significant figures. The raw data bench sheets and calculation work sheets showing all calculations are attached. All sample results are corrected for average percent recovery of system calibration standards and are also corrected for contribution from the blank. 


\section{Battelle PNNL/RPG/Inorganic Analysis --. TOC/TIC Report}

\section{Q.C. Comments:}

The TIC standard is calcium carbonate and TOC/TC standard is $\alpha$-Glucose (the certificates of purity are attached). The standard materials were used in solid form for system calibration check standards as well as matrix spikes. The QC for the methods involves calibration blanks, system calibration standards, sample duplicates, and one matrix spike per matrix type.

Calibration Standards: The QC system calibration check standards were all within acceptance criteria of $90 \%$ to $110 \%$, with the average recovery being about $99 \%$ for TIC and $99 \%$ for TOC over the two days that the hot persulfate analyses were performed and about $100 \%$ for TC for the furnace analyses.

Calibration Blanks: The calibration blanks run at the beginning, middle, and end of the analysis run were acceptable and the standard deviations for the TIC and TOC blanks are near the historical pooled standard deviation used to establish the method detection limits. On the May $12^{\text {th }}$ run, the TOC blanks were about 2 to 3 times higher than normal; however, the blanks were quite consistent and the high blanks should have no effect on the reported data.

Duplicates: No actual sample duplicates were identified on the ASR. However, the relative percent difference (RPD) between replicates (i.e., a sample and duplicate analysis) was less than $10 \%$ for TIC, TOC, and TC. Besides the RPD, the relative standard deviation (RSD) for the triplicate analyses was calculated, and all RSDs are less than $5 \%$, indicate very good precision between for all measurements. The RSD met the ASR Table 4 RSD acceptance criterion of $<15 \%$.

Matrix Spike: The accuracy of the carbon measurements can be estimated by the recovery results from the matrix spike. The matrix spike for both the hot persulfate and furnace method demonstrated recoveries of about $96 \%$ to $99 \%$ for TIC, TOC, and TC; well within the acceptance criteria of $75 \%$ to $125 \%$ recovery.

Laboratory Control Sample: No LCS is included in the carbon analysis procedure.

\section{General Comments:}

- The reported "Final Results" have been corrected for all dilution performed on the sample during processing or analysis.

- Routine precision and bias are typically $\doteq 15 \%$ or better for non-complex samples that are free of interferences.

- The estimated quantitation limit (EQL) is defined as 5 times the MDL. Resulis less than 5 times the MDL have higher uncertainties, and RPDs are not calculated for any results less than 5 times the MDL.

- Some results may be reported as less than ("<") values. These less than values represent the sample MDL (method detection limit). which is the system MDL adjusted for the volume of sample used for the analysis. The system MDL is based on the attached pooled historical blank data. The evaluation and calculation of the system MiDL is included in the data package.

Report Prepared by:

Review/Approval by:

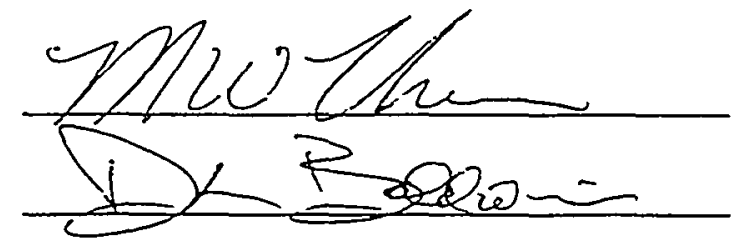

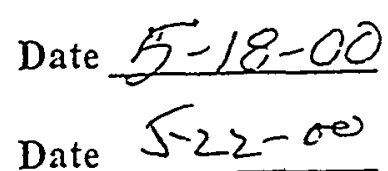

Archive Information:

Files: ASR 5778 Kurath.doc

ASR 5668R 5778 Kurath.xls 


\section{ริำ Baltelle}

... Putting Technology To Work

Date $\quad$ May $1 \dot{7}, 2000$

To $\quad$ K. E. Kurath

From

S. K. Fiskum Uk. Fiokur
Project 29953

No.

Internal Distribution

File/LB

Subject Hydroxide Analyses for AP101 Composite ASR 5778, Rev. 1

A sample of the composite from tank AP101 (00-1701) was analyzed in triplicate for the hydroxide content following procedure PNL-ALO-228. Direct sample aliquots were analyzed using a Brinkman 636 Auto-Titrator. A $0.1186 \mathrm{~N} \mathrm{NaOH}$ solution was prepared for use as a standard and sample spike and the titrant was a $0.2040 \mathrm{M} \mathrm{HCl}$ prepared solution. Triplicate resilts $(2.49,2.42$, and $2.38 \mathrm{M} \mathrm{OH})$ gave an average $\mathrm{OH}$ molarity of 2.43 with a relative standard deviation of $\pm 3 \%$. The standard recoveries averaged $100 \%$ and the sample spike recovered at $88 \%$. Hydroxide was not detected in the reagent blank, demonstrating an $\mathrm{MDC}$ of $0.02 \mathrm{M} \mathrm{OH}$ or $3.4 \mathrm{E}+2 \mu \mathrm{g} \mathrm{OH} / \mathrm{mL}$. A second titration inflection point was determined at an average $\mathrm{pH}$ of 7.5 and a third inflection point at an average $\mathrm{pH}$ of 4.9. The titration curves are attached.

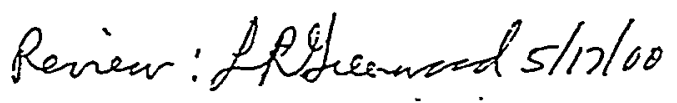




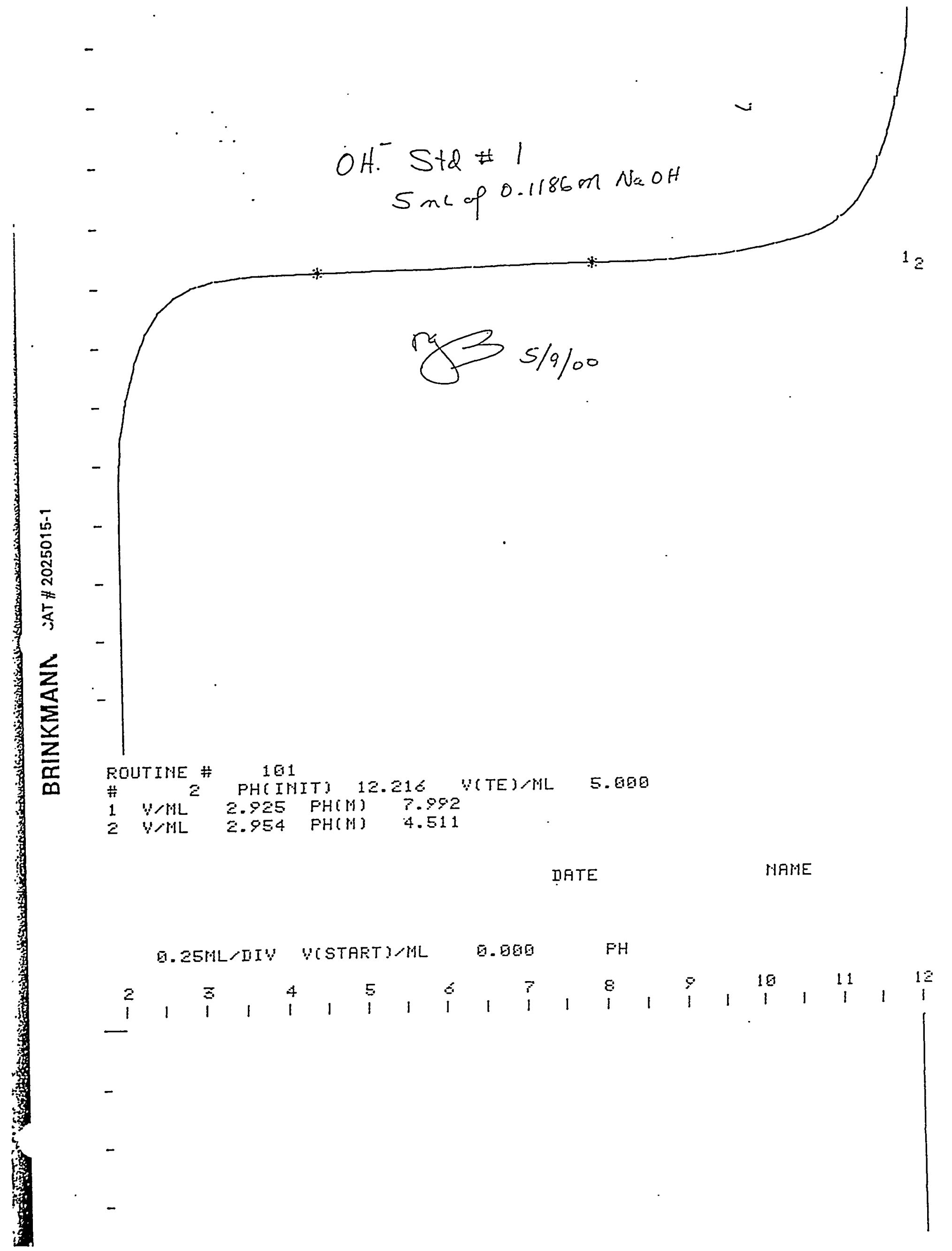




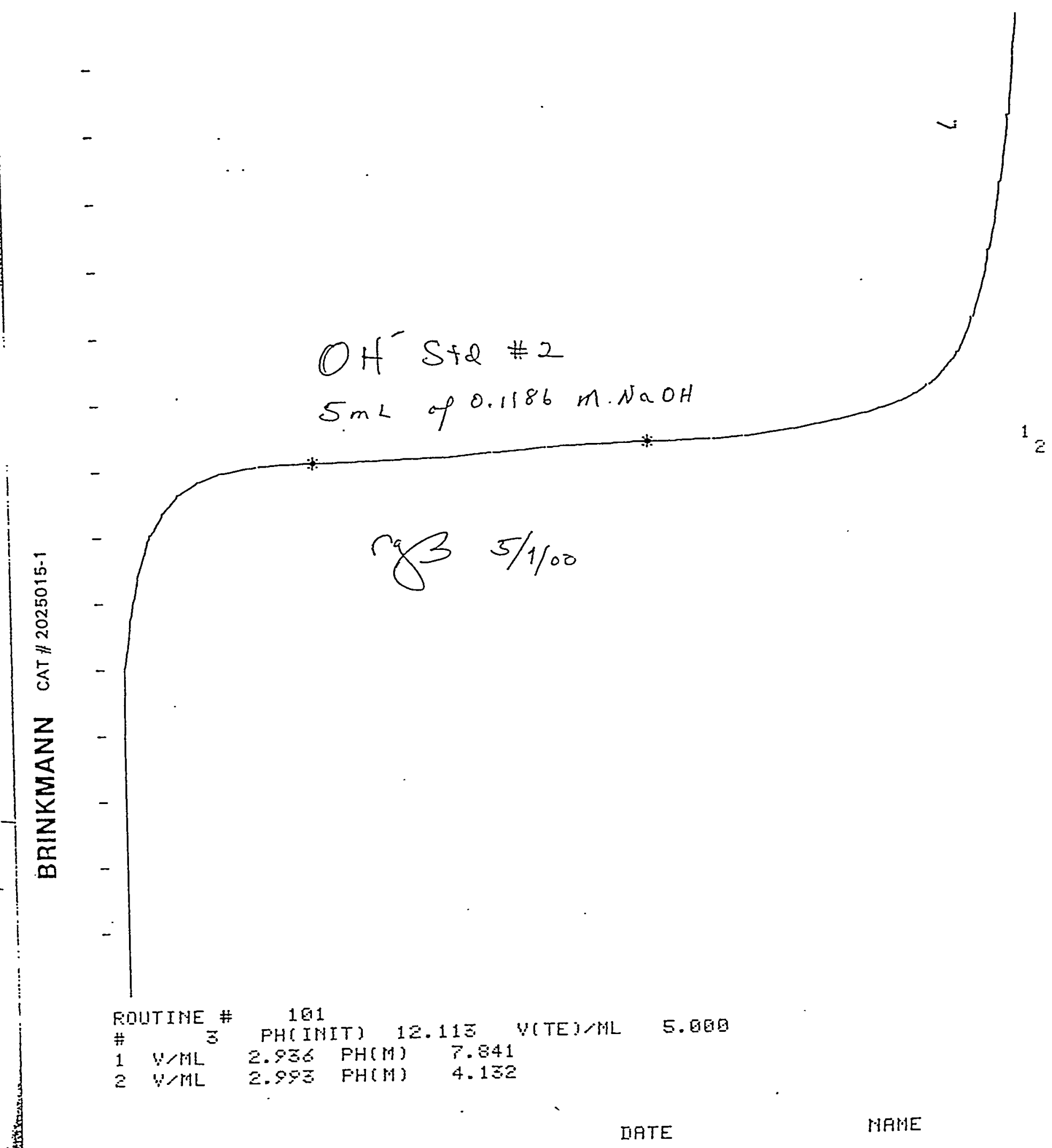

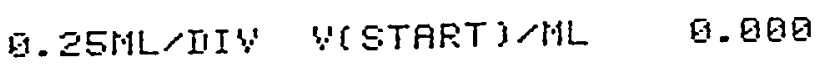

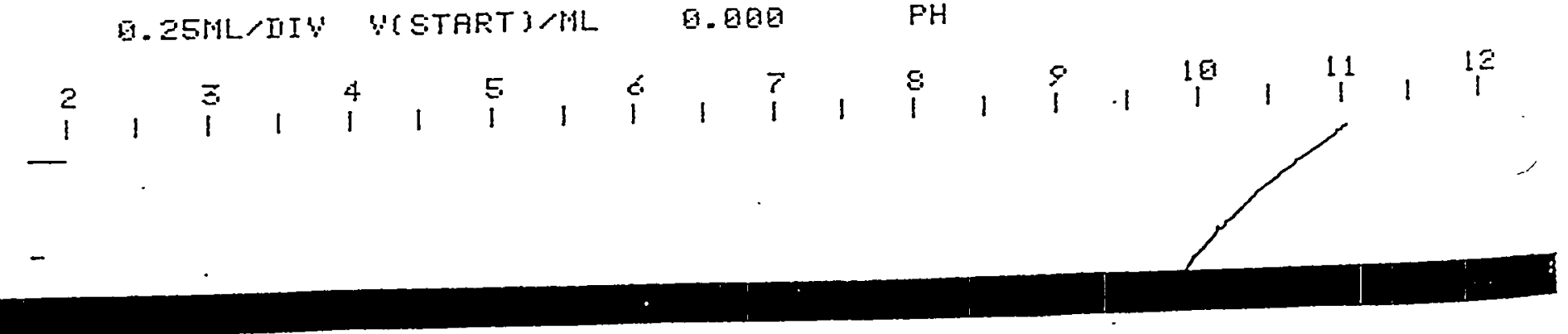




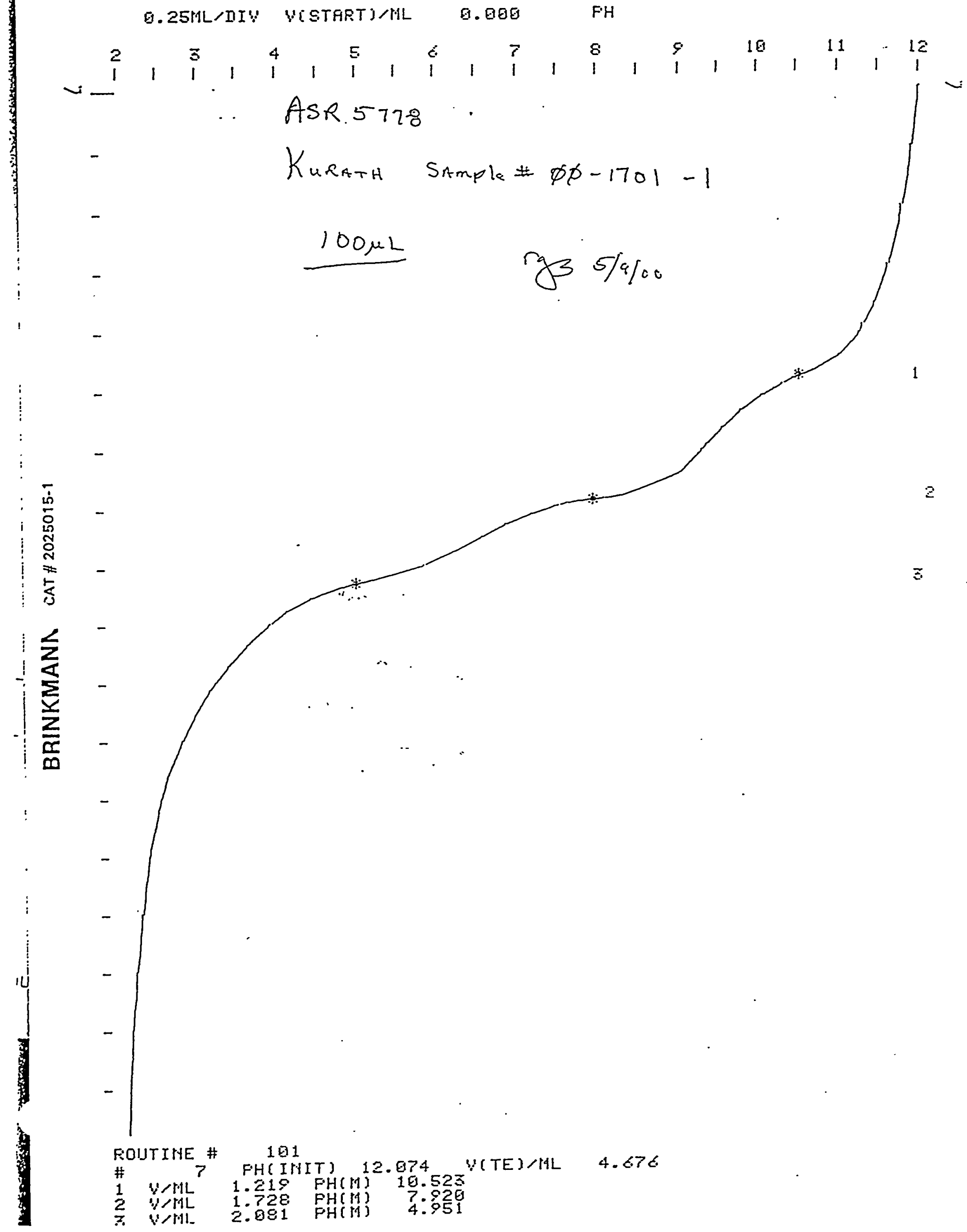




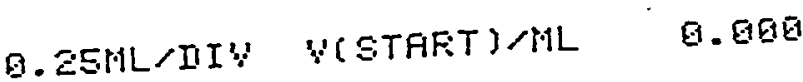

PH

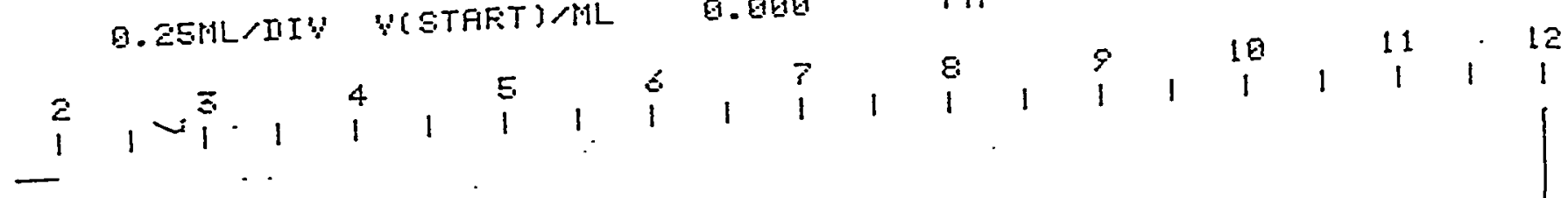

Karath
Daplicate

$$
\frac{100 \mu L \rho 00-1701(2)}{5 / 9 / 00}
$$

1

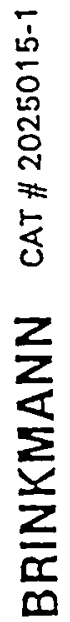

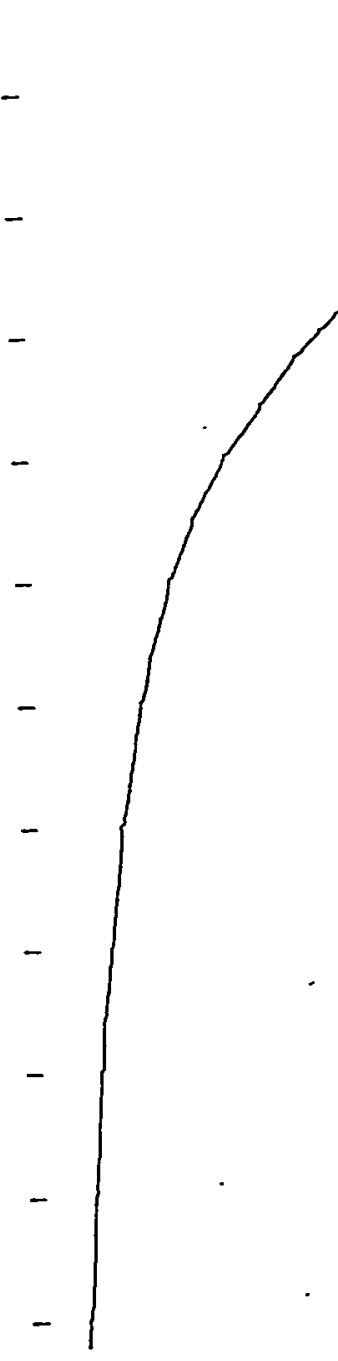

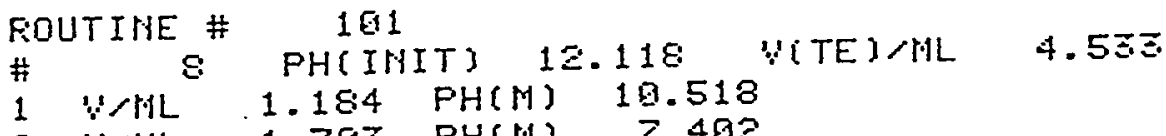

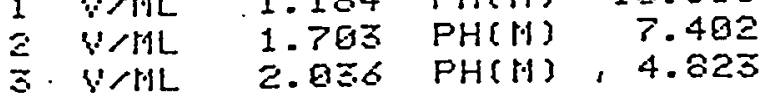

3 



\section{Project io. 29953}

Battelle

... Putting Technology To Work

inisinal Distribution

File/LB

Date $\quad$ May 9,2000

To D. E. Kurath

From

S. K. Fiskum wik trokem

Subject Radiochemical-Analyses for AP-101 Composite ASR 5778

A sample of the composite from tank AP-101 (00-1701) was analyzed in triplicate for total alpha, total beta, gamma energy analysis, ${ }^{3} \mathrm{H}$, uranium, ${ }^{90} \mathrm{Sr},{ }^{99} \mathrm{Tc}, \mathrm{Pu}$, and $\mathrm{Am} / \mathrm{Cm}$. The attached reports list measured analyte activities in the original AP101 material in units of $\mathrm{uCi} / \mathrm{ml}$ except for uranium, which is reported in ug $/ \mathrm{ml}$. The reported errors $(1-\sigma)$ represent the total propagated error including counting, dilution, yield, and calibration errors, as appropriate. Laboratory and process blank values given with each analysis are the best indicators of the method detection limits, taking into account the actual sample sizes and counting times used for each analysis.

\section{Gamma Spectrometry}

Triplicate 100- $\mu \mathrm{I}$ aliquots of AP101 original material were prepared into 2-mL geometries with deionized water (no acid digestion was applied). The small aliquot size was necessary to reduce the detector dead time attributed to the high ${ }^{137} \mathrm{Cs}$ activity. The samples were counted and analyzed directly by gamma energy analysis (GEA) according to procedure PNL-ALO-450. Because no sample manipulation was performed other than simple aliquoting and diluting, no preparation blank was prepared. In order to meet the required detection limits, the samples were counted for 14 hours each. Only ${ }^{137} \mathrm{Cs},{ }^{134} \mathrm{Cs}$, and ${ }^{60} \mathrm{Co}$ could be identified in the gamma spectra. The triplicate concentrations of ${ }^{137} \mathrm{Cs}$, ${ }^{134} \mathrm{Cs}$, and ${ }^{60} \mathrm{Co}$ agreed to within $\pm 3 \%$, well within the $<15 \%$ RSD acceptance criteria. The other requested analyte concentrations were below the minimum reporting limits requested.

Pertechnetate ${ }^{99} \mathrm{Tc}$

The radiochemical ${ }^{99} \mathrm{Tc}$ determination was requested to measure only $T c$ in the +7 oxidation state (pertechnetate). To this end, all sample manipulations had to be non-oxidizing so as not to alter the original Tc oxidation state. Small aliquots from the as-received material (no digestion) were taken for analysis according to procedure PNL-ALO-432. This procedure normally requires the use of sodium dichromate addition to oxidize the $\mathrm{T} c$ to the +7 oxidation state. The sodium dichromate addition was omitted and the procedure otherwise was performed as written. The separated fractions were then counted according to RPG-CMC-408. One sample was also counted by gamma spectrometry (according to PNL-ALO-450) to verify the absence of ${ }^{137} \mathrm{Cs}$. The LCS and matrix spike were spiked with pertechnetate and their recoveries were $99 \%$ and $84 \%$, respectively, well 
D.E. Kurath

May 9, 2000

Page 2

within project requirements. The RSD of the triplicate samples was $\$ \%$, again well within the project-required $<15 \%$ RSD.

\section{Acid Digestion}

Triplicate 0.5-mL aliquots of AP101 were digested with nitric acid according to PNL-ALO-106. Heating and nitric acid additions continued until all organic/nitric reactions had visibly ceased. The samples were then brought to a $10-\mathrm{mL}$ volume with $2 \mathrm{M} \mathrm{HNO}_{3}$. A preparation blank was run side by side with the samples. These digestions were used for the subsequent analyses of total alpha, total beta, ${ }^{239+2+0} \mathrm{Pu},{ }^{235} \mathrm{Pu},{ }^{2+1} \mathrm{Am},{ }^{2+2} \mathrm{Cm},{ }^{2+3+2+7} \mathrm{Cm}$, total $\mathrm{U}$, and ${ }^{30} \mathrm{Sr}$. A laboratory control sample (LCS) was not available for radiochemical analyses. Specific reagent spikes or blank spikes were prepared subsequent to digestion and were used as LCSs.

\section{Total Alpha}

The total alpha activity was determined by direct-plating small aliquots of the acid-digested samples onto planchets according to RPG-CMC-4001. The samples were then counted on Ludlum detectors according to RPG-CMC-408. The sample activities resulted in a 9\% RSD, well within the $<15 \%$ RSD acceptance criteria. Alpha activity was not found in the preparation blank. The LCS ${ }^{239} \mathrm{Pu}$ recovery was $99 \%$ and the matrix spike ${ }^{259} \mathrm{Pu}$ recovery was only $55 \%$. The low matrix spike recovery is attributed to the solids loading on the planchet from the sample matrix salts that attenuate/absorb the alpha emissions. This is a physical problem with the sample as it is presented to the detector and does nor indicate the analysis is out of control. What this does indicare is that the analytical method is probably biased low by as much as $45 \%$ for this matrix. A better indication of the total alpha activity is given by the summation of the alpha emitters $\left({ }^{-39+2+5} \mathrm{Pu},{ }^{233} \mathrm{Pu},{ }^{2+1} \mathrm{Am},{ }^{2+3+2+1} \mathrm{Cm}\right.$ and ${ }^{2+2} \mathrm{Cm}$ ), shown in the last column of the data report. These alpha-emitter summations range from $18 \%$ to $39 \%$ higher than the total alpha activity found by direct plating. The RSD for the summation method is $1 \%$.

\section{Total Beta}

The total beta activity was determined by directly plating small aliquots of the acid-digested samples . onto planchets according to RPG-CMC-4001. The samples were then counted on a lowbackground alpha/beta gas-flow proportional counter according to RPG-CMC-408. The detectors were calibrated for beta activity relative to ${ }^{90} \mathrm{Sr} /{ }^{90} \mathrm{Y}$. The beta energy of ${ }^{137} \mathrm{Cs}$ is similar to that of ${ }^{90} \mathrm{Sr}$ and will have a counting efficiency similar to that of pure ${ }^{80} \mathrm{Sr}$. The total beta analyses compared to the ${ }^{137} \mathrm{Cs}$ determinations shows that virtually all of the beta activity is due to ${ }^{137} \mathrm{C}$ and the two values are in excellent agreement. The precision, measured by the RSD, is 5\%, within experimental error. The LCS and matrix spike showed excellent ${ }^{90} \mathrm{Sr} /{ }^{90} \mathrm{Y}$ recoveries at $100 \%$ and $103 \%$, respectively.

\section{Plutonium, Americium, and Curium}

The $\mathrm{Pu}$ and $\mathrm{Am} / \mathrm{Cm}$ separations were performed according to PNL-ALO-417; the separated fractions were precipitation plated according to PNL-ALO-496; and the samples were counted by alpha spectrometry according to PNL-ALO-422. Plutonium recovery was traced with ${ }^{2+2} \mathrm{Pu}$. The curium is known to follow the americium and both these isotopes were traced with ${ }^{2+3} \mathrm{Am}$. 
Plutonium radiochemical yields were excellent at $>90 \%$. Radiochemical yields for Am ranged from $70 \%$ to $86 \%$. In both cases, ample counts were obtained to define sample activities. Neither $\mathrm{Pu}$, Am nor $\mathrm{Cm}$ were detected in the preparation blank. The LCS and matrix spike for Pu resulted in $98 \%$ and $101 \%$ yield-corrected recovery. This indicates the chemistry and analyses were not biased. The LCS and matrix spike for the Am (and $\mathrm{Cm}$ ) fractions resulted in $94 \%$ and $91 \%$ yield-corrected recovery. The ${ }^{239+2+0} \mathrm{Pu}$ analyses resulted in $2 \% \mathrm{RSD}$, for ${ }^{235} \mathrm{Pu}$ the RSD was $5 \%$. The ${ }^{2+1} \mathrm{Am}$ resulted in $2 \% \mathrm{RSD}$, the ${ }^{2+3+2++} \mathrm{Cm}$ resulted in $29 \% \mathrm{RSD}$. This latter high RSD reflects the much higher uncertainty associated with the analytical results, which are approximately 5 orders of magnitude less than the requested detection limit.

\section{Strontium-90}

The Sr separation was performed according to PNL-ALO-476 and radiochemical yields were traced with ${ }^{85} \mathrm{Sr}$. The separated fractions were then beta-counted according to RPG-CMC-408 and gamma counted according to PNL-ALO-450 (for ${ }^{85} \mathrm{~S}$ determination and ${ }^{137} \mathrm{Cs}$ impurity assessment). Two of the separated fractions contained a small amount of ${ }^{137} \mathrm{Cs}$ and a correction to the beta count rate was applied for these samples. Strontium-90 was nor found in the preparation blank. The RSD is $0.3 \%$, indicative of excellent precision. The LCS and matrix spike recoveries were $92 \%$ and $99 \%$, respectively, indicating good accuracy.

\section{Total Uranium}

Total uranium was measured in triplicate aliquots taken from the acid digestion according to procedure PNNL-AIO-4014 using Kinetic Phosphoresence Analysis (KPA). The triplicate results showed excellent agreement with a RSD of $1 \%$. A small amount of uranium was detected in the acid digestion process blank; however, the level was a factor of 10,000 lower than the uranium seen in the samples. A blank prepared at the time of the analysis did not detect any uranium. Uranium standards analyzed before and after the samples agreed within $3 \%$ of the known values.

\section{Tritium}

Tritium was analyzed by distillation of direct sample material using procedure PNL-AIO-418 followed by liquid scintillation counting according to procedure PNL-ALO-474. The first distillation showed the presence of higher-energy beta activity, most likely due to ${ }^{137} \mathrm{Cs}$. A second distillation succeeded in removing most of this contamination; hotrever, two of the triplicate samples required subtraction of weak beta contamination using the ratio of the counts in the tritium energy region to the counts at higher energies, as determined from the first counting results. The triplicate results showed good agreement with a RSD of $5 \%$. A blank spike showed good recovery at $96 \%$. No tritium was detected in a blank prepared at the time of analysis in the laboratory. 
Radiochemical Processing Group

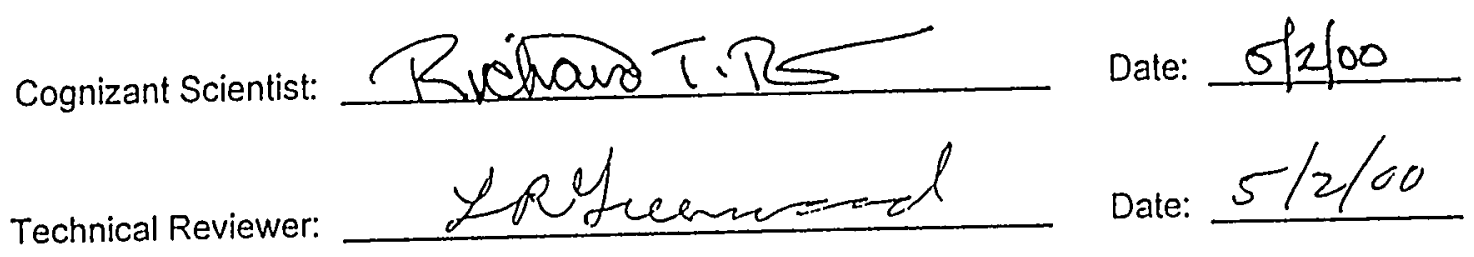

Client: Kurath

MT\&E Instrument: GEA Detector $G$

Reference Date: N.A.

Gamma Energy Analysis (Procedure PNL-ALO-450):

Measured Activity in $\mu \mathrm{Ci} / \mathrm{ml}$

\begin{tabular}{|c|c|c|c|c|c|c|c|c|c|}
\hline $\begin{array}{c}\text { Sample ID } \\
\text { ALO Number }\end{array}$ & $\begin{array}{l}\text { Co-60 } \\
\text { 1o Unc. }\end{array}$ & $\begin{array}{c}\text { Ru/Rh-106 } \\
\text { 1o Unc. }\end{array}$ & $\begin{array}{l}\text { Sb-125 } \\
\text { 1o Unc. }\end{array}$ & $\begin{array}{l}\text { Cs-134 } \\
\text { 1o Unc. }\end{array}$ & $\begin{array}{l}\text { Cs-137 } \\
10 \text { Unc. }\end{array}$ & $\begin{array}{l}\text { Eu-152 } \\
\text { 1o Unc. }\end{array}$ & $\begin{array}{l}\text { Eu-154 } \\
\text { 1o Unc. }\end{array}$ & $\begin{array}{l}\text { Eu-155 } \\
\text { 1o Unc. }\end{array}$ & $\begin{array}{l}\text { Am-241 } \\
10 \text { Unc. }\end{array}$ \\
\hline $\begin{array}{c}\text { AP-101 Composite } \\
00-01701\end{array}$ & $\begin{array}{c}3.22 E-3 \\
7 \%\end{array}$ & $<9 E-2$ & $<6 E-2$ & $\begin{array}{c}4.77 E-2 \\
3 \%\end{array}$ & $\begin{array}{c}1.44 E+2 \\
2 \%\end{array}$ & $<2 E-3$ & $<2 E-3$ & $<4 E-2$ & $<4 \mathrm{E}-2$ \\
\hline $\begin{array}{l}\text { AP-101 Composite Dup. } \\
\text { 00-01701 Dup }\end{array}$ & $\begin{array}{c}3.40 \mathrm{E}-3 \\
7 \%\end{array}$ & $\angle 9 E-2$ & $<6 E-2$ & $\begin{array}{c}4.81 E-2 \\
3 \%\end{array}$ & $\begin{array}{c}1.44 E+2 \\
2 \%\end{array}$ & $<3 E-3$ & $<2 E-3$ & $<4 E-2$ & $<4 E-2$ \\
\hline $\begin{array}{c}\text { AP-101 Composite Trip. } \\
\text { 00-01701 Trip }\end{array}$ & $\begin{array}{c}3.24 \mathrm{E}-3 \\
7 \%\end{array}$ & $<9 E-2$ & $<6 \mathrm{E}-2$ & $\begin{array}{c}4.62 E-2 \\
3 \%\end{array}$ & $\begin{array}{c}1.45 E+2 \\
2 \%\end{array}$ & $<2 E-3$ & $<2 E-3$ & $<4 E-2$ & $<4 E-2$ \\
\hline RSD & $3.0 \%$ & & & $2.1 \%$ & $0.7 \%$ & & & & \\
\hline
\end{tabular}


Client: Kurath

Cognizant Scientist:

concur: LRofreensol
Date :

$5 / 8 / 00$

Date :

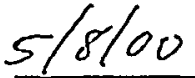

Measured Activities (uCi/ml) with 1-sigma error

\begin{tabular}{|c|c|c|c|c|c|c|c|c|}
\hline $\begin{array}{l}\text { ALO ID } \\
\text { Client ID }\end{array}$ & $\begin{array}{l}\text { Total } \\
\text { Alpha } \\
\text { Error \% }\end{array}$ & $\begin{array}{l}\text { Pu-239+ } \\
\text { Pu-240 } \\
\text { Error \% }\end{array}$ & $\begin{array}{l}\text { Pu-238 } \\
\text { Error \% }\end{array}$ & $\begin{array}{l}\text { Pu-236 } \\
\text { Error \% }\end{array}$ & $\begin{array}{l}\text { Am-241 } \\
\text { Error \% }\end{array}$ & $\begin{array}{c}\text { Cm-243+ } \\
\text { Cm-244 } \\
\text { Error \% }\end{array}$ & $\begin{array}{l}\mathrm{Cm}-242 \\
\text { Error \% }\end{array}$ & $\begin{array}{l}\text { Alpha* } \\
\text { Sum }\end{array}$ \\
\hline $\begin{array}{l}00-1701 \mathrm{~PB} \\
\text { AP-101 Comp }\end{array}$ & $<7 . E-5$ & $<2 . E-7$ & $<2 . E-7$ & $<2 . E-7$ & $<5 . E-7$ & $<8, E-8$ & $<8 . E-8$ & \\
\hline $\begin{array}{l}00-1701 \\
\text { AP-101 Comp }\end{array}$ & $\begin{array}{c}2.55 \mathrm{E}-4 \\
14 \%\end{array}$ & $\begin{array}{c}1.24 E-4 \\
4 \%\end{array}$ & $\begin{array}{c}1.39 E-5 \\
6 \%\end{array}$ & $<9$.E-8 & $\begin{array}{c}1.73 E-4 \\
5 \%\end{array}$ & $\begin{array}{c}1.34 \mathrm{E}-6 \\
19 \%\end{array}$ & $<1 . E-7$ & $3.12 E-4$ \\
\hline $\begin{array}{l}\text { 00-1701Dup } \\
\text { AP-101 Comp }\end{array}$ & $\begin{array}{c}2.22 \mathrm{E}-4 \\
14 \%\end{array}$ & $\begin{array}{c}1.28 \mathrm{E}-4 \\
4 \%\end{array}$ & $\begin{array}{c}1.49 E-5 \\
6 \%\end{array}$ & $<9 . E-8$ & $\begin{array}{c}1.65 E-4 \\
5 \%\end{array}$ & $\begin{array}{c}7.40 E-7 \\
24 \%\end{array}$ & $<9 . E-8$ & 3.09E-4 \\
\hline $\begin{array}{l}\text { 00-1701 T } \\
\text { AP-101 Comp }\end{array}$ & $\begin{array}{c}2.65 E-4 \\
14 \%\end{array}$ & $\begin{array}{c}1.27 E-4 \\
4 \%\end{array}$ & $\begin{array}{c}1.54 \mathrm{E}-5 \\
6 \%\end{array}$ & $<2 . E-7$ & $\begin{array}{c}1.70 E-4 \\
5 \%\end{array}$ & $\begin{array}{c}1.02 E-6 \\
21 \%\end{array}$ & $<2 . E-7$ & $3.13 \mathrm{E}-4$ \\
\hline RSD & $9 \%$ & $2 \%$ & $5 \%$ & & $2 \%$ & $29 \%$ & & $1 \%$ \\
\hline Matrix Spike & $55 \%{ }^{*}$ & $101 \%$ & & & $91 \%$ & $\cdot$ & & \\
\hline Blank Spike & $99 \%$ & $98 \%$ & & & $94 \%$ & & & \\
\hline Blank & $<8 . E-5$ & & & & & & & \\
\hline
\end{tabular}

*The low matrix spike recovery is attributed to plated solids causing absorption/attenuation of alpha emissions.

The ramifications of this are the sample activities are probably similarly affected. The sum of the alpha emitters in the last column is thus the best estimate of the total alpha activity.

The total alpha, total beta, $\mathrm{Pu}, \mathrm{Am}, \mathrm{Sr}$, and $\mathrm{U}$ analyses were performed on sample aliquots prepared according to

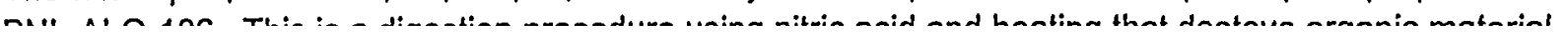


Client: Kurath

Cognizant Scientist:

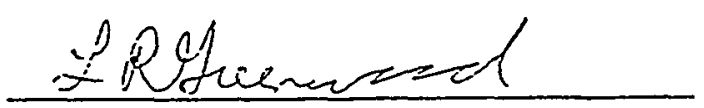

Date: $5 / 4 / 06$

Concur:

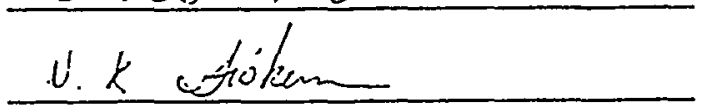

Date: $5 / 8 / 00$

Measured Activities (uCi/ml) with 1-sigma error

\begin{tabular}{lccc} 
ALO ID & $\begin{array}{c}\text { Beta } \\
\text { Error } \%\end{array}$ & $\begin{array}{c}\text { as pertechnetate } \\
\text { Error } \%\end{array}$ & $\begin{array}{c}\text { Sr-90 } \\
\text { Error } \%\end{array}$ \\
\cline { 2 - 4 } 00-1701 PB & $8.57 E-5$ & $<2 . E-5$ & $<2 . E-4$ \\
AP-101 Comp & $31 \%$ & & \\
00-1701 & $1.46 E+2$ & $4.71 E-2$ & $8.71 E-2$ \\
AP-101 Comp & $4 \%$ & $4 \%$ & $3 \%$ \\
00-1701Dup & $1.40 E+2$ & $4.34 E-2$ & $8.77 E-2$ \\
AP-101 Comp & $4 \%$ & $4 \%$ & $3 \%$ \\
00-1701 T & $1.54 E+2$ & $5.10 E-2$ & $8.75 E-2$ \\
AP-101 Comp & $4 \%$ & $4 \%$ & $3 \%$ \\
Matrix Spike & $103 \%$ & $84 \%$ & $99 \%$ \\
Blank Spike &. & & \\
Method detection limit & $2 . E-1^{* *}$ & $6 . E-5$ & $<6 . E-4$
\end{tabular}

**Calculated with respect to specific sample-counting conditions, i.e., small sample size, short count time. A larger prepartion blank sample aliquot was taken and longer counting times applied, resulting in a lower detection limit for the preparation blank.

The total alpha, total beta, $\mathrm{Pu}, \mathrm{Am}, \mathrm{Sr}$, and $\mathrm{U}$ analyses were performed on sample aliquots prepared according to PNL-ALO-106. This is a digestion procedure using nitric acid and heating that destoys organic material.

Tc-99 determination was performed on an aliquot with no acid digestion, no sample oxidation. Thus, the Tc-99 represents the pertechnetate form. 
Battelle Pacific Northwest Laboratory

Radiochemical Processing Group-325 Building

Chemical Measurements Center

Client: Kurath

Cognizant Scientist:

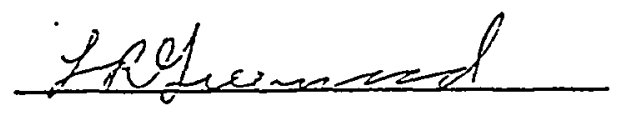

Date: $5 / 3 / 00$

Concur:

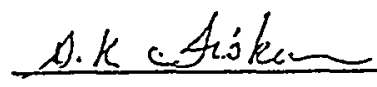

Date :

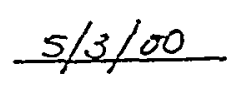

ALO ID

Uranium

Client ID

ug/ml

00-1701 PB

AP-101 Comp

00-1701

AP-101 Comp

00-1701Dup

AP-101 Comp

00-1701 T

AP-101 Comp

\begin{tabular}{cc} 
Error $\%$ & $+1-\%$ \\
\hline $5.41 \mathrm{E}-3$ & $3 \%$
\end{tabular}

5.17E+1

$3 \%$

$5.12 E+1 \quad 3 \%$

$5.03 E+1 \quad 3 \%$

RSD

$1 \%$

Blank

$<1$.E-5

$\begin{array}{lccc} & \text { Standard } & \text { Measured } & \text { Ratio } \\ \text { Prerun Standard 1 } & 1.00 E-2 & 9.92 E-3 & 0.992 \\ \text { Prerun Standard 2 } & 1.00 E-1 & 1.02 E-1 & 1.020 \\ \text { Prerun Standard 3 } & 1.00 E \div 0 & 1.09 E+0 & 1.089 \\ & & & \\ \text { Post Standard 1 } & 1.00 E-2 & 9.71 E-3 & 0.971 \\ \text { Post Standard 2 } & 1.00 E-3 & 1.01 E-3 & 1.010\end{array}$

The total alpha, total beta, $\mathrm{Pu}, \mathrm{Am}, \mathrm{Sr}$, and $\mathrm{U}$ analyses were performed on sample aliquots prepared according to PNL-ALO-106. This is a digestion procedure using nitric acid and heating that destoys organic material. 
Client: Kurath

Cognizant Scientist

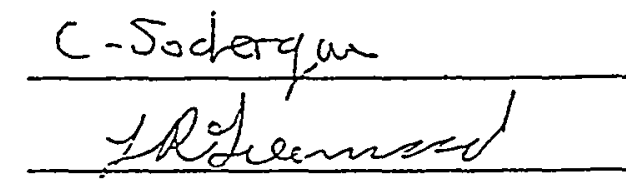

Date: $\quad 5-9-00$

Concur:

Date: $5-9-00$

Measured Activities (uCi/ml) with 1-sigma error

\begin{tabular}{|c|c|}
\hline $\begin{array}{l}\text { ALO ID } \\
\text { Client ID }\end{array}$ & $\begin{array}{l}\text { Tritium } \\
\text { Error \% }\end{array}$ \\
\hline $00-1701$ & $5.05 E-3$ \\
\hline AP-101 Comp & $4 \%$ \\
\hline 00-1701Dup & $4.84 E-3$ \\
\hline AP-101 Comp & $3 \%$ \\
\hline $00-1701 T$ & $4.60 E-3$ \\
\hline AP-101 Comp & $3 \%$ \\
\hline RSD & $5 \%$ \\
\hline Blank Spike & $96 \%$ \\
\hline Blank & $<2 . E-4$ \\
\hline
\end{tabular}

Note: Tritium was determined by liquid scintillation counting following two successive distillations of direct sample material. Weak contamination was observed in the beta spectra of the first two results reported above. This contamination was subtracted out of the tritium results reported above. (We used data from a previous attempt at this analysis to accurately calculate the amount of contamination to subtract.) The third result above did not show any significant contamination. 
Date $\quad$ May 12,2000

To D. E. Kurath

From

L.R. Greenwood ipdermats

Subjecl C-14 Analyses for AP-101 Composite ASR 5778

Direct samples of the composite from tank AP-101 (00-1701) were analyzed in triplicate for C-14 following procedure PNI-ALO-482. The samples are combusted in a Coulometrics Carbon Analyzer Furnace causing oxidation of all carbon species present to $\mathrm{CO}_{2}$. A natural carbon compound is added as a carrier and all of the $\mathrm{CO}_{2}$ released is collected in a sodium hydroxide trap. The trap solution is then counted by liquid scintillation counting according to procedure PNI-ALO474. The triplicate results showed good agreement with a relative standard deviation of $5 \%$. The blank and sample spikes showed good recovery at $97 \%$ and $96 \%$, respectively. Due to the inadvertent spiking of a system blank prior to the analysis, some carryover was seen in the prior blanks. However, a system blank analyzed following the analyses did not show any contamination. 
Battelle Pacific Northwest Laboratory

Radiochemical Processing Group-325 Building

Chemical Measurements Center

Client: Kurath

Cognizant Scientist:

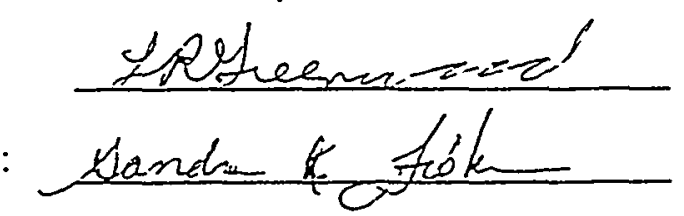

Concur:

Date: $5 / 12 / 06$

Date: $5 / 12 / 00$

Procedures PNL-ALO-482/474

\section{Measured Activities (uCi/ml) with 1-sigma error}

\begin{tabular}{lcc}
$\begin{array}{lc}\text { ALO ID } \\
\text { Client ID }\end{array}$ & & $\begin{array}{c}\text { C-14 } \\
\text { Error } \%\end{array}$ \\
\cline { 1 - 1 } 00-1701 & & $2.56 \mathrm{E}-4$ \\
AP-101 Comp & $8 \%$ \\
00-1701Dup & & $2.55 \mathrm{E}-4$ \\
AP-101 Comp & $8 \%$ \\
00-1701 T & & $2.77 \mathrm{E}-4$ \\
AP-101 Comp & $8 \%$ \\
& $5 \%$ \\
Blank & $<4 . \mathrm{E}-5$ \\
Sample Spike & $96 \%$ \\
Standard & $97 \%$
\end{tabular}




\section{Baltelle}

Internal Distribution

File/LB
Datc $\quad$ May 18,2000
To D. E. Kurath
From L. R. Greenwood $\mathcal{J} R \mathrm{~g}$
Subject

\section{Se-79 Analyses for AP-101 Composite ASR 5778}

Direct samples of the composite from tank AP-101 (00-1701) were analyzed in triplicate for Se-79 following procedure PNL-ALO-440. Each sample was spiked with $20 \mathrm{mg}$ Se carrier in solution to be used for yield correction. Anion and cation exchange was used to remove most radiochemical interferences. Selenium was distilled as selenium bromide and then reduced to.elemental form. The chemical yield was determined gravimetrically by weighing the recovered elemental selenium. The selenium is then dissolved and the Se-79 activity was determined by liquid scintillation counting according to procedure PNL-ALO-474. The liquid scintillation spectra did not show clear evidence for a Se-79 peak and there appears to be some weak beta contamination evident in the higher energy region of the beta spectrum. Hence, the results probably have a high bias. We did not rerun or attempt to further correct the data since the measured $\mathrm{Se}-79$ activities are below the requested MRQ value of $9.0 \mathrm{E}-5 \mathrm{uCi} / \mathrm{ml}$. The nominal MDI was $2 . \mathrm{E}-5 \mathrm{uCi} / \mathrm{ml}$. The sample activity averaged $5.8 \mathrm{E}-5$ $\mathrm{uCi} / \mathrm{ml}$ with an $\mathrm{RSD}$ of $18 \%$. The RSD acceptance criteria of $<15 \%$ was exceeded, although the measurement uncertainties. were as high as $11 \%$ on one sample and the sample activity is only a factor of three higher than the MDL. Since Se-79 is not available as a standard, C-14 was used to calibrate the detector since C-14 has.nearly the same beta energy as Se-79. Due to the lack of a Se79 standard, blank and sample spikes are not possible. The sample carrier recoveries were low at $27 \%$ to $63 \%$ and the blank recovery was $68 \%$. Sample activities were yield-corrected. A process blank did not show any evidence of contamination. 
Battelle Pacific Northwest Laboratory

Radiochemical Processing Group-325 Building

Chemical Measurements Center

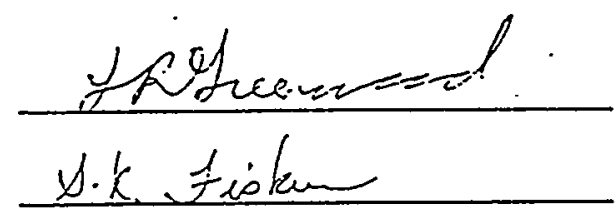

$00-1701$

$5 / 18 / 2000$
Client: Kurath

Cognizant Scientist:

Concur:

$\cdots$

Procedures PNL-ALO-440/474

\begin{tabular}{|c|c|c|}
\hline $\begin{array}{l}\text { ALO ID } \\
\text { Client ID }\end{array}$ & & $\begin{array}{c}\text { Se-79 } \\
\text { Error \% }\end{array}$ \\
\hline $00-1701$ & & $5.56 \mathrm{E}-5$ \\
\hline AP-101 Comp & & $8 \%$ \\
\hline 00-1701Dup & & $6.97 E-5$ \\
\hline AP-101 Comp & & $5 \%$ \\
\hline $00-1701 \mathrm{~T}$ & & $4.93 E-5$ \\
\hline AP-101 Comp & & $11 \%$ \\
\hline & RSD & $18 \%$ \\
\hline Blank & & $<3 . E-6$ \\
\hline Blank Spike R & covery & $68 \%$ \\
\hline
\end{tabular}

Date: $5 / 18 / 60$

Date: $5 / 18 / 00$

Note: The beta energy spectra did not show clear evidence for a Se-79 peak and there appears to be some beta contamination at higher beta energies. Hence, the results probably have a high bias. All measurements are below the requested MRQ value of $9.0 \mathrm{E}-5 \mathrm{uCi} / \mathrm{ml}$. 


\section{B. Battelle}

Date May 10,2000

329 File

To Dean Kurath

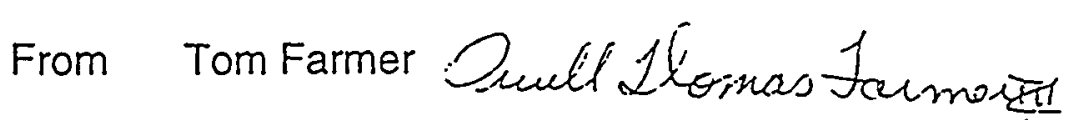

Subject ICPMS Analysis AP101 Samples

(ALO\# 001701)

Pursuant to your request, the 6 samples that you submitted for analysis were analyzed on our radioactively-contained ICPMS for the selected analytes; semiquantitative analysis was necessary on certain isotopes for which a standard was not available (see below). The concentration results for the isotopes of interest are displayed on the attached spreadsheets.

Dilutions of Isotope Products standards for ${ }^{129}$ I, ${ }^{237} \mathrm{~Np}$ and ${ }^{239} \mathrm{Pu}$, an Amersham ${ }^{99} \mathrm{Tc}$ standard, an NIST uranium standard (4321 b), an ${ }^{127}$ I standard, made from Fisher potassium iodide (LOT\# 35260), and CPI single element standards for $A s, B, B e, C e$, $\mathrm{Co}, \mathrm{Cs}, \mathrm{Eu}, \mathrm{Li}, \mathrm{Mo}, \mathrm{Pr}, \mathrm{Rb}, \mathrm{Sb}, \mathrm{Se}, \mathrm{Ta}, \mathrm{Te}, \mathrm{Th}, \mathrm{Tl}, \mathrm{V}, \mathrm{W}$ and $\mathrm{Sn}$, were used to generate the calibration curves. Independent standards of each analyte were used as the continuing calibration verification (CCV) standards. The $1 \%$ high-purity nitric acid solution used to dilute the standards and samples was used as a reagent blank. The results are reported in $\mu \mathrm{g}$ analyte $/ \mathrm{ml}(\mathrm{ppm})$, or $\mu \mathrm{Ci}$ analyte $/ \mathrm{ml}$ of original sample material.

In general, the results for the quality control samples (i.e., calibration verification standards, duplicates, and matrix spikes) are well within acceptance criteria. One of the CCV results for tellurium and tantalum and the spike recovery for thallium, were outside the acceptance window ( $<20 \%$ for the CCV and $<30 \%$ for the Spike). Tellurium and tantalum did have another CCV results that was acceptable. CCV results for Thallium were also acceptable. Also the the duplicate and triplicate for arsenic and the duplicate for molybdenum were outside the the acceptance window (<15\%).

The ${ }^{99} \mathrm{Tc}$ values reported assume that the Ru present is exclusively fission-product $R u$, and therefore does not have an isotope at $\mathrm{m} / \mathrm{z} 99$; i.e., everything observed at $\mathrm{m} / \mathrm{z} 99$ is due to ${ }^{99} \mathrm{Tc}$. From the appearance of the Ru isotopic abundance, this appears to be a reasonable assumption; the fingerprint exhibited is obviously not natural.

Values for the following isotopes were obtained using responses from related isotopes: ${ }^{126} \mathrm{Sn}$ (obtained from ${ }^{118} \mathrm{Sn}$ ), ${ }^{231} \mathrm{~Pa}$ (obtained from ${ }^{232} \mathrm{Th}$ ), and ${ }^{240} \mathrm{Pu},{ }^{241} \mathrm{AMU},{ }^{242} \mathrm{AMU}$, ${ }^{243} \mathrm{AMU}$ (obtained from ${ }^{239} \mathrm{Pu}$ ). Because standards were not used and the concentrations of the isotopes were determined indirectly, these results should be considered semiquantitative.

If you have any questions regarding this analysis, please give me a call at 372-0700 or James Bramson at 376-0624. 
AP101 Analysis OJ

May 17, 2000

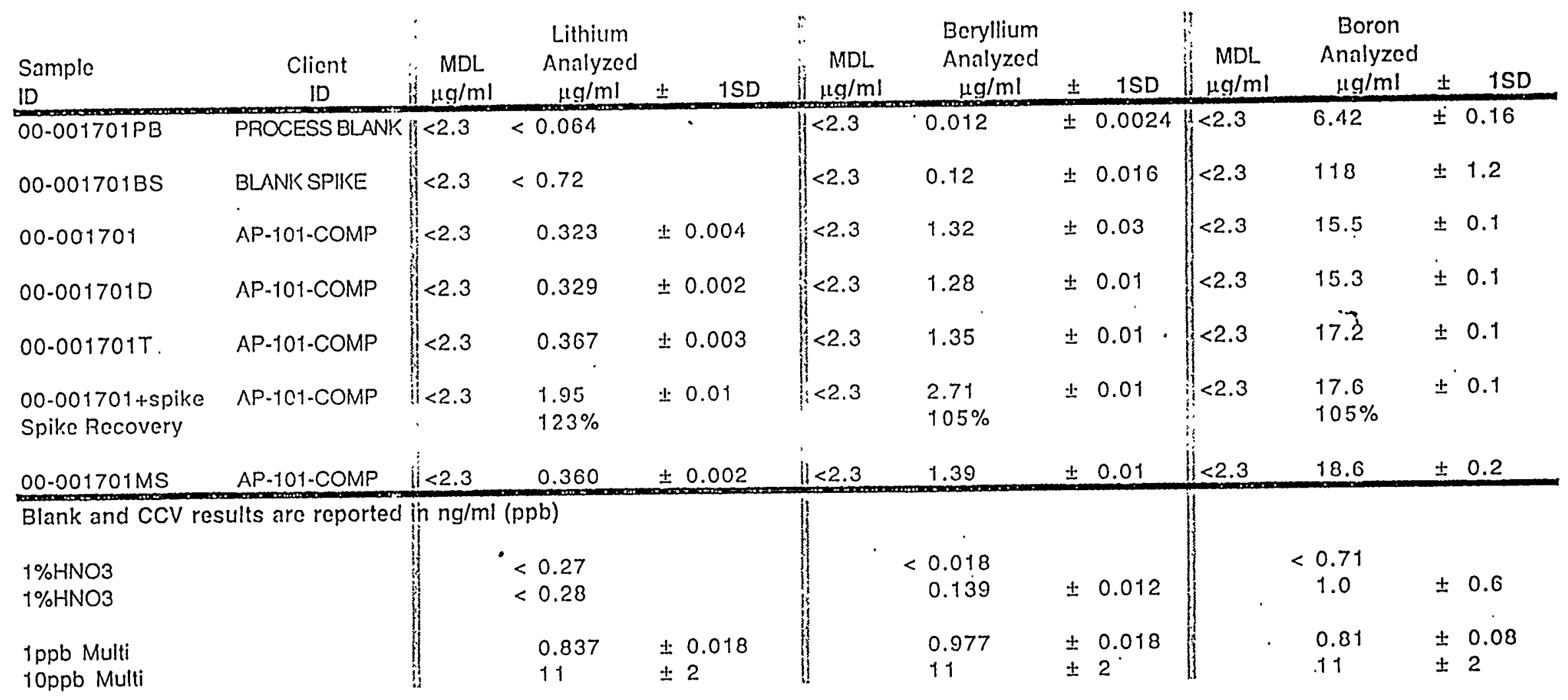


May 17, 2000 (revised May 18, 2000)

\begin{tabular}{|c|c|c|c|c|c|c|c|c|c|c|c|c|c|}
\hline $\begin{array}{c}\text { Sample } \\
\text { ID }\end{array}$ & $\begin{array}{c}\text { Client } \\
\text { ID } \\
\end{array}$ & $\begin{array}{c}\mathrm{MDL} \\
\mu \mathrm{g} / \mathrm{ml}\end{array}$ & $\begin{array}{c}\text { Vanadium } \\
\text { Analyzed } \\
\mu \mathrm{g} / \mathrm{ml}\end{array}$ & \pm & $1 S D$ & $\begin{array}{c}\mathrm{MDL} \\
\mu \mathrm{g} / \mathrm{ml}\end{array}$ & $\begin{array}{l}\text { Cobalt } \\
\text { Analyzed } \\
\mu \mathrm{g} / \mathrm{ml}\end{array}$ & \pm & ISD & $\begin{array}{ll}\mathrm{MDL} \\
\mu \mathrm{g} / \mathrm{ml}\end{array}$ & $\begin{array}{l}\text { Arsenic } \\
\text { Analyzed } \\
\mu \mathrm{g} / \mathrm{ml}\end{array}$ & \pm & $1 S D$ \\
\hline $00-001701 \mathrm{~PB}$ & PROCESS BLANK & $<<2.3$ & $<0.79$ & & & $<<2.3$ & 0.014 & \pm & 0.003 & $<2.3$ & 0.13 & \pm & 0.004 \\
\hline $\begin{array}{l}00-001701 \mathrm{BS} \\
\text { Spike Recovery }\end{array}$ & BLANK SPIKE & $<2.3$ & $<8.8$ & & & $<2.3$ & $<0.139^{\circ}$ & & & $y<2.3$ & $\begin{array}{l}373 \\
117 \%\end{array}$ & & \\
\hline $00-001701$ & AP-101-COMP & $<2.3$ & $<0.77$ & & & $<2.3$ & 0.356 & \pm & 0.005 & $<<2.3$ & 1.46 & \pm & 0.03 \\
\hline $00-001701 \mathrm{D}$ & $A P-101-C O M P$ & $<2.3$ & $<0.75$ & & & $<2.3$ & 0.331 & 上 & 0.007 & $<2.3$ & 1.15 & \pm & 0.044 \\
\hline $00-001701 \mathrm{~T}$ & $A P-101-C O M P$ & $<2.3$ & $<0.72$ & & & $<2.3$ & 0.369 & \pm & 0.001 & & $\begin{array}{lll}1.18 & \\
& 7\end{array}$ & \pm & 0.017 \\
\hline $\begin{array}{l}\text { 00-001701+spike } \\
\text { Spike Recovery }\end{array}$ & AP-101-COMP & $\because<2.3$ & $\begin{array}{l}2.23 \\
110 \%\end{array}$ & \pm & 0.01 & $<2.3$ & $\begin{array}{l}1.75 \\
108 \%\end{array}$ & \pm & 0.01 & $<2.3$ & $\begin{array}{l}2.97 \\
109 \%\end{array}$ & \pm & 0.02 \\
\hline $\begin{array}{l}\text { 00-001701MS } \\
\text { Spike Recovery }\end{array}$ & AP-101-COMP & $:<2.3$ & $<0.60$ & & & $<2.3$ & 0.368 & \pm & 0.003 & $<2.3$ & $\begin{array}{l}29.7 \\
120 \% \\
\end{array}$ & \pm & 0.05 \\
\hline \multicolumn{14}{|c|}{ Spike Recovery } \\
\hline $\begin{array}{l}1 \% \text { HNO3 } \\
1 \% \text { HNO3 }\end{array}$ & & 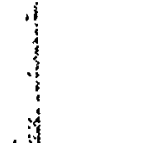 & $\begin{array}{l}<3.3 \\
<3.4\end{array}$ & & & 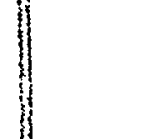 & $\begin{array}{l}0.053 \\
0.132\end{array}$ & \pm & 0.009 & 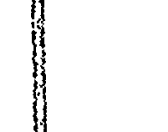 & $\begin{array}{l}<0.27 \\
<0.28\end{array}$ & & \\
\hline $\begin{array}{l}\text { 1ppb Multi } \\
\text { 10ppb Multi }\end{array}$ & & 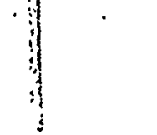 & $\begin{array}{l}0.970 \\
12\end{array}$ & & $\begin{array}{l}0.043 \\
2\end{array}$ & 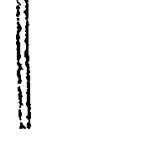 & $\begin{array}{l}0.979 \\
11\end{array}$ & & $\begin{array}{l}0.009 \\
2\end{array}$ & & $\begin{array}{l}0.942 \\
11\end{array}$ & & $\begin{array}{l}0.035 \\
2\end{array}$ \\
\hline
\end{tabular}


AP101 Analysis OYF 18 may 00

May 17, 2000 (revised May 18, 2000)

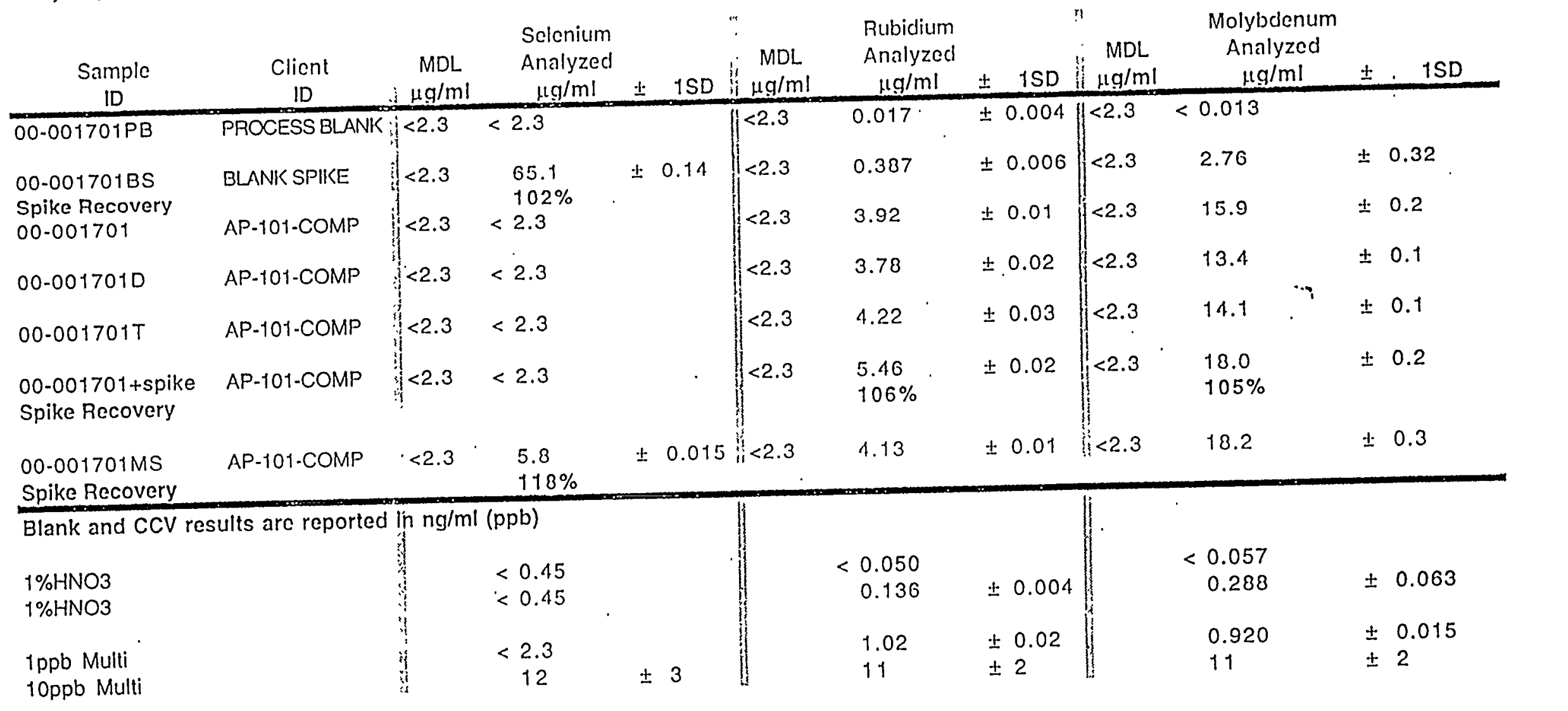




\section{AP101 Analysis OTF .}

May 17, 2000

\begin{tabular}{|c|c|c|c|c|c|c|c|c|c|c|c|c|c|}
\hline $\begin{array}{l}\text { Sample } \\
\text { ID }\end{array}$ & $\begin{array}{c}\text { Client } \\
\text { ID }\end{array}$ & $\begin{array}{c}\mathrm{MDL} \\
\mu \mathrm{Ci} / \mathrm{ml}\end{array}$ & $\begin{array}{c}\text { Technelium } 99 \\
\text { Analyzed } \\
\mu \mathrm{Ci} / \mathrm{ml}\end{array}$ & \pm & 1SD & $\begin{array}{c}\mathrm{MDL} \\
\mu \mathrm{g} / \mathrm{ml}\end{array}$ & $\begin{array}{c}\text { Antimony } \\
\text { Analyzed } \\
\mu \mathrm{g} / \mathrm{ml}\end{array}$ & \pm & $1 S D$ & $\begin{array}{c}\mathrm{MDL} \\
\mu \mathrm{g} / \mathrm{ml}\end{array}$ & $\begin{array}{r}\text { Telluriun } \\
\text { Analyze } \\
\mu \mathrm{g} / \mathrm{ml}\end{array}$ & $\begin{array}{l}n \\
d \\
d\end{array}$ & 1SD \\
\hline $00-001701 \mathrm{~PB}$ & PROCESS BLANK & $\mid<1.5 \mathrm{E}-03$ & $<2.5 \mathrm{E}-04$ & & & $<2.3$ & 0.0289 & \pm & 0.0029 & $\|<2.3$ & $<0.17$ & & \\
\hline $00-001701 B S$ & BLANK SPIKE & $<1.5 E-03$ & $<3.1 E-03$ & & & $<2.3^{\circ}$ & 0.301 & 上 & 0.040 & $f<2.3$ & $<1.9$ & & \\
\hline $00-001701$ & AP-101-COMP & $<1.5 \mathrm{E}-03$ & $5.14 E-02$ & \pm & $3.9 E-04$ & $<2.3$ & 0.0454 & \pm & 0.0030 & $<2.3$ & $<0.17$ & & \\
\hline 00-001701D. & AP-101-COMP & $<1.5 \mathrm{E}-03$ & 4.76E-02 & \pm & $8.4 \mathrm{E}-04$ & $<2.3$ & 0.0410 & \pm & 0.0038 & $<2.3$ & $<0.16$ & & \\
\hline $00.001701 \mathrm{~T}$ & $A P-101-C O M P$ & $<1.5 E-03$ & $4.80 E-02$ & \pm & $1.7 E-02$ & $<2.3$ & 0.0396 & \pm & 0.0013 & $<2.3$ & $i<0.16$ & & \\
\hline $\begin{array}{l}00-001701+\text { spike } \\
\text { Spike Recovery }\end{array}$ & $A P-101-C O M P$ & $<1.5 E-03$ & $\begin{array}{l}6.91 E-02 \\
101 \%\end{array}$ & \pm & $9.5 E-04$ & $<2.3$ & $\begin{array}{l}1.23 \\
94 \%\end{array}$ & \pm & 0.004 & $<2.3$ & $\begin{array}{l}1.04 \\
73 \%\end{array}$ & \pm & 0.029 \\
\hline $00-001701 \mathrm{MS}$ & AP-101-COMP & $\ddot{i}<1.5 E-03$ & $4.96 \mathrm{E}-02$ & \pm & $2.2 E-03 i$ & $i<2.3$ & 0.0420 & \pm & 0.0056 & $i<2.3$ & 0.196 & \pm & 0.064 \\
\hline \multicolumn{14}{|c|}{ Blank and CCV results are reported in $\mathrm{ng} / \mathrm{ml}(\mathrm{ppb})$} \\
\hline $\begin{array}{l}1 \% \text { HNO3 } \\
1 \% \text { HNO3 }\end{array}$ & & 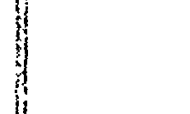 & $\begin{array}{r}<0.027 \\
0.047\end{array}$ & \pm & 0.032 & & $\begin{array}{r}<0.062 \\
0.267\end{array}$ & \pm & 0.035 & & $\begin{array}{l}<0.72 \\
<0.73\end{array}$ & & \\
\hline $\begin{array}{l}\text { 1ppb Multi } \\
\text { 10ppb Multi }\end{array}$ & & 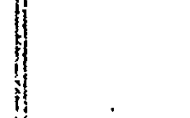 & & & & 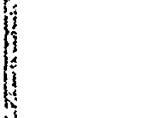 & $\begin{array}{l}1.06 \\
11\end{array}$ & $\begin{array}{l} \pm \\
\pm\end{array}$ & $\begin{array}{l}0.05 \\
2\end{array}$ & & $\begin{array}{l}1.36 \\
11.3\end{array}$ & \pm & $\begin{array}{l}0.10 \\
1.2\end{array}$ \\
\hline $5 p p b$ Tc-99 & & & 4.92 & \pm & 0.09 & & & · & & & & & \\
\hline $5 p p b$ Tc-99 & . & & 4.90 & \pm & 0.17 & & & & & & & & \\
\hline 20ppb Co & & I & $<0.031$ & & & 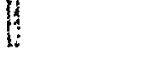 & & & & & & & \\
\hline
\end{tabular}


AP101 Analysis 0 tr

May 17, 2000

\begin{tabular}{|c|c|c|c|c|c|c|c|c|c|c|}
\hline $\begin{array}{l}\text { Sample } \\
\text { ID }\end{array}$ & $\begin{array}{c}\text { Client } \\
\text { ID }\end{array}$ & $\begin{array}{c}M D L \\
\mu \mathrm{Ci} / \mathrm{ml}\end{array}$ & $\begin{array}{c}\text { Tin } 120 \\
\wedge \text { nalyzed } \\
\mu \mathrm{Ci} / \mathrm{ml}\end{array}$ & $\begin{array}{c}\text { Analyzed } \\
\mu \mathrm{g} / \mathrm{ml}\end{array}$ & \pm & $1 S D$ & $\begin{array}{cc}n & \\
: & \mathrm{MDL} \\
i & \mu \mathrm{Ci} / \mathrm{ml}\end{array}$ & $\begin{array}{c}\text { lodine } 129 \\
\text { Analyzed } \\
\mu \mathrm{Ci} / \mathrm{ml}\end{array}$ & \pm & $1 S D$ \\
\hline $00-001701 \mathrm{~PB}$ & PROCESS BLANK & < $<6.0$ E-03 & $<1.3 \mathrm{E}-03$ & $\mid<0.013$ & & & $\|<1.8 E-05$ & $<2.5 \mathrm{E}-06$ & & \\
\hline $00-001701 B S$ & BLANK SPIKE & $<6.0 \mathrm{E}-03$ & $<1.0 \mathrm{E}-02$ & $<0.18$ & & & $<1.8 E-0.5$ & $<3.4 \mathrm{E}-05$ & & \\
\hline $00-001701$ & AP-101-COMP & $<6.0 \mathrm{E}-03$ & $<8.6 E-01$ & $2: 42$ & $\because$ & 0.04 & $<1.8 \mathrm{E}-05$ & 7.72E-05 & \pm & $5.2 E-06$ \\
\hline $00-001701 \mathrm{D}$ & $A P-101-C O M P$ & $<0.0 E-03$ & $<0.0 E-04$ & 2.49 & \pm & 0.10 & $<1.8 \mathrm{E}-05$ & 7.73E-05 & \pm & $3.9 E-06$ \\
\hline $00.001701 \mathrm{~T}$ & AP-101-COMP & $<<6.0 E-03$ & $<8.2 E-04$ & 2.73 &. \pm & 0.08 & $<1.8 \mathrm{E}-05$ & $8.71 E-05$ & \pm & $2.7 \mathrm{E}-06$ \\
\hline $\begin{array}{l}\text { 00-001701+spike } \\
\text { Spike Recovery }\end{array}$ & AP-101-COMP & $\begin{array}{l}<6.0 \mathrm{E}-03 \\
\because\end{array}$ & $<8.2 E-04$ & $\begin{array}{l}3.48 \\
94 \%\end{array}$ & \pm & 0.17 & $\begin{array}{l}l .8 \mathrm{E}-05 \\
\vdots \\
\vdots\end{array}$ & $\begin{array}{l}1.20 E-04 \\
99 \%\end{array}$ & \pm & $1.0 E-05$ \\
\hline 00-001701MS & AP-101-COMP & $i<6.0$ E-03 & $<7.4 \mathrm{E}-04$ & 2.93 & \pm & 0.04 & $b<1.8 E-05$ & $9.10 E-05$ & \pm & 2.3E-0G \\
\hline \multicolumn{11}{|c|}{ Blank and CCV results are reported if $\mathrm{ng} / \mathrm{ml}(\mathrm{ppb})$} \\
\hline $\begin{array}{l}1 \% \text { HNO3 } \\
1 \% \text { HNO3 }\end{array}$ & & 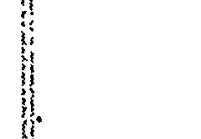 & $\begin{array}{l}<0.13 \\
<0.13\end{array}$ & $\begin{array}{l}0.423 \\
0.160\end{array}$ & \pm & $\begin{array}{l}0.013 \\
0.012\end{array}$ & & $\begin{array}{c}<0.061 \\
<0.120 \\
.\end{array}$ & & $\cdot$ \\
\hline $\begin{array}{ll}0.502 p p b & 1-127 \\
5.02 p p b \quad \mid-127\end{array}$ & & 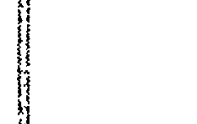 & . & 0.551 & $\begin{array}{l} \pm \\
\pm\end{array}$ & $\begin{array}{l}0.024 \\
0.28\end{array}$ & $\cdot$ & & & \\
\hline $\begin{array}{l}0.1 \mathrm{ppb} \mid-129 \\
1 \mathrm{ppb} \mid-129\end{array}$ & . & 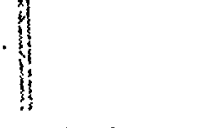 & & 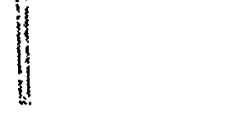 & & & 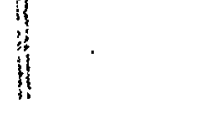 & $\begin{array}{l}0.0981 \\
1.12\end{array}$ & & $\begin{array}{l}0.0133 \\
0.01\end{array}$ \\
\hline
\end{tabular}

"Calculated from response of different isotope. Should be considered semiquantitative. 


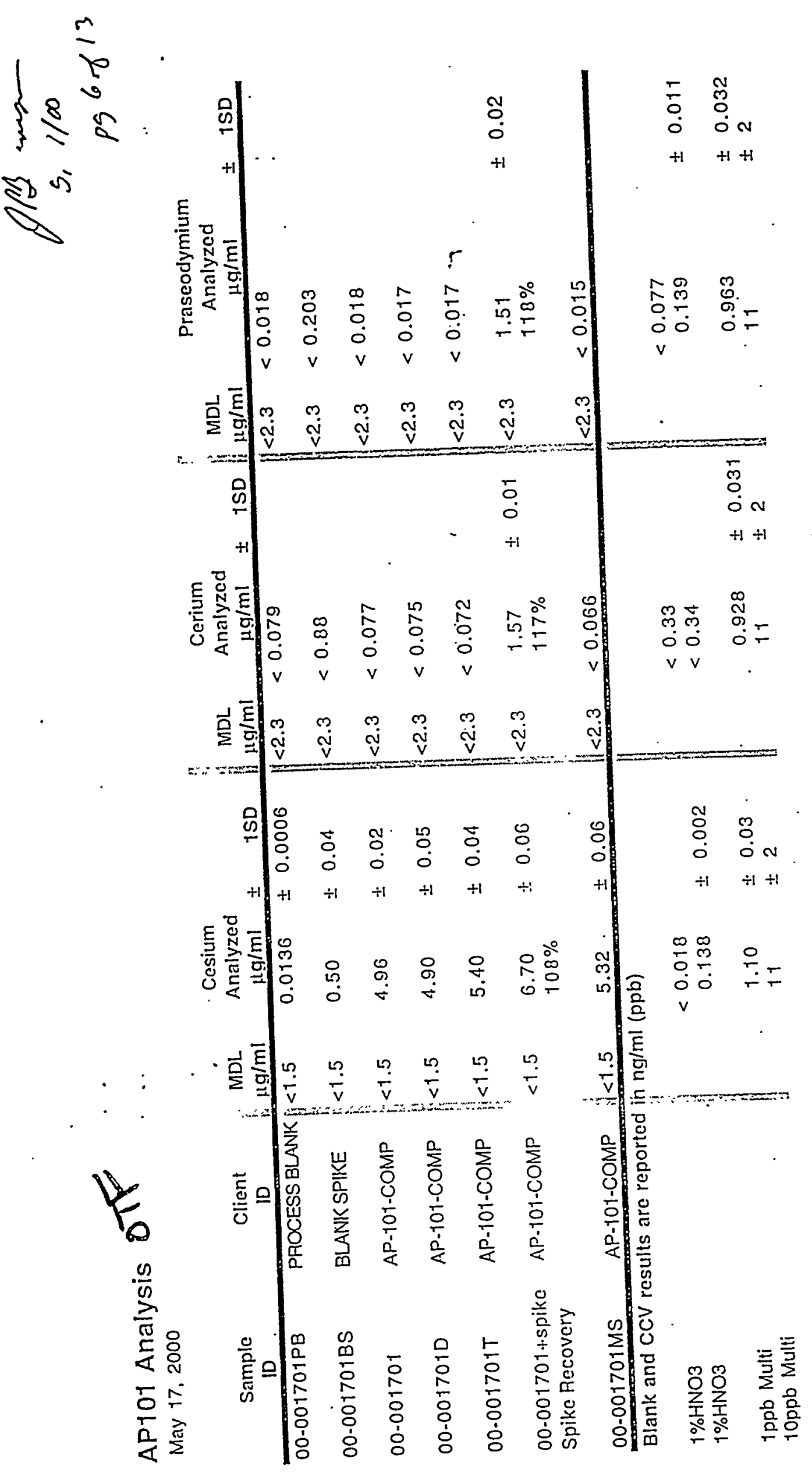




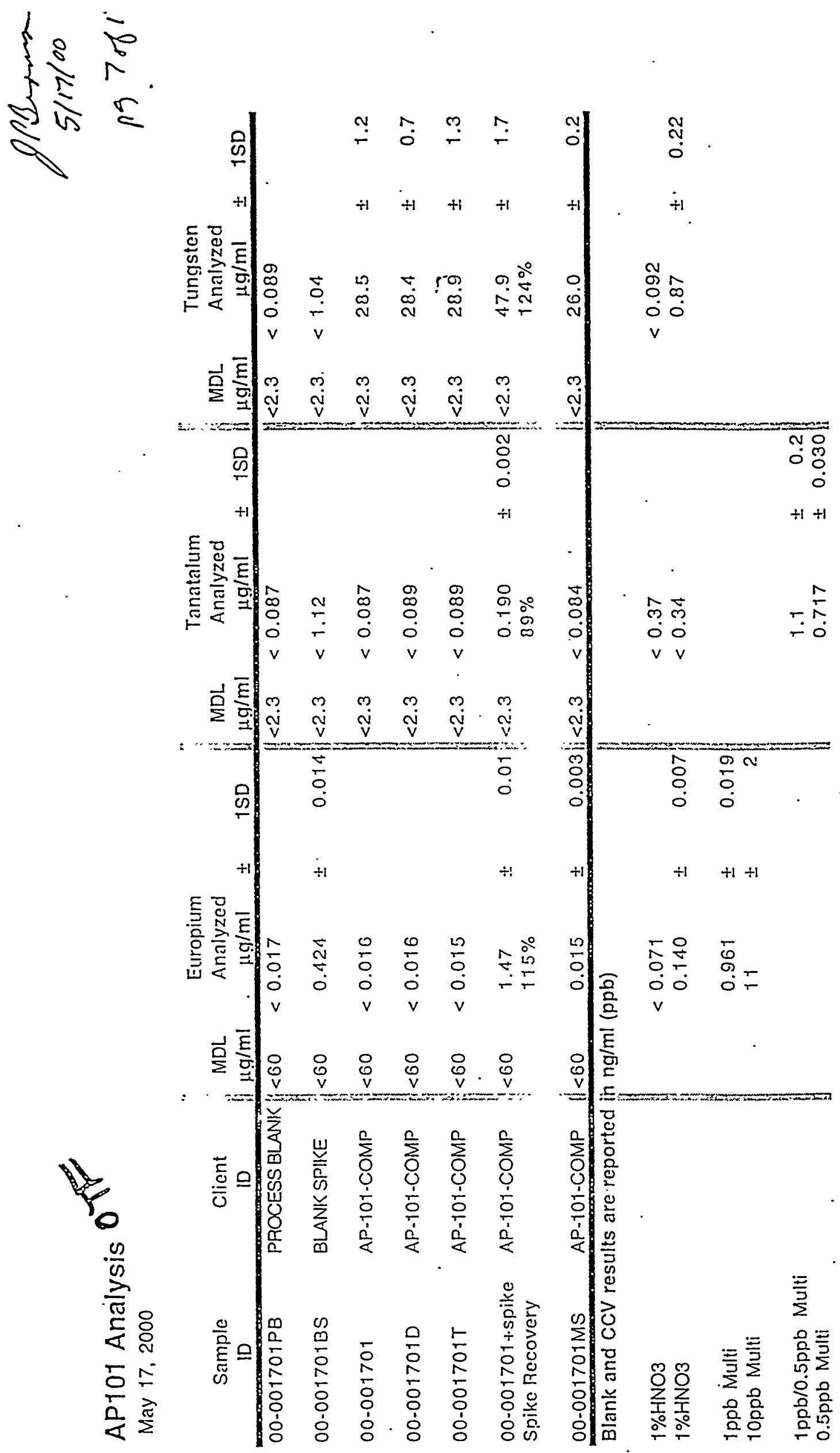





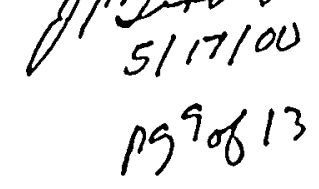

AP101 Analysis

May 17,2000

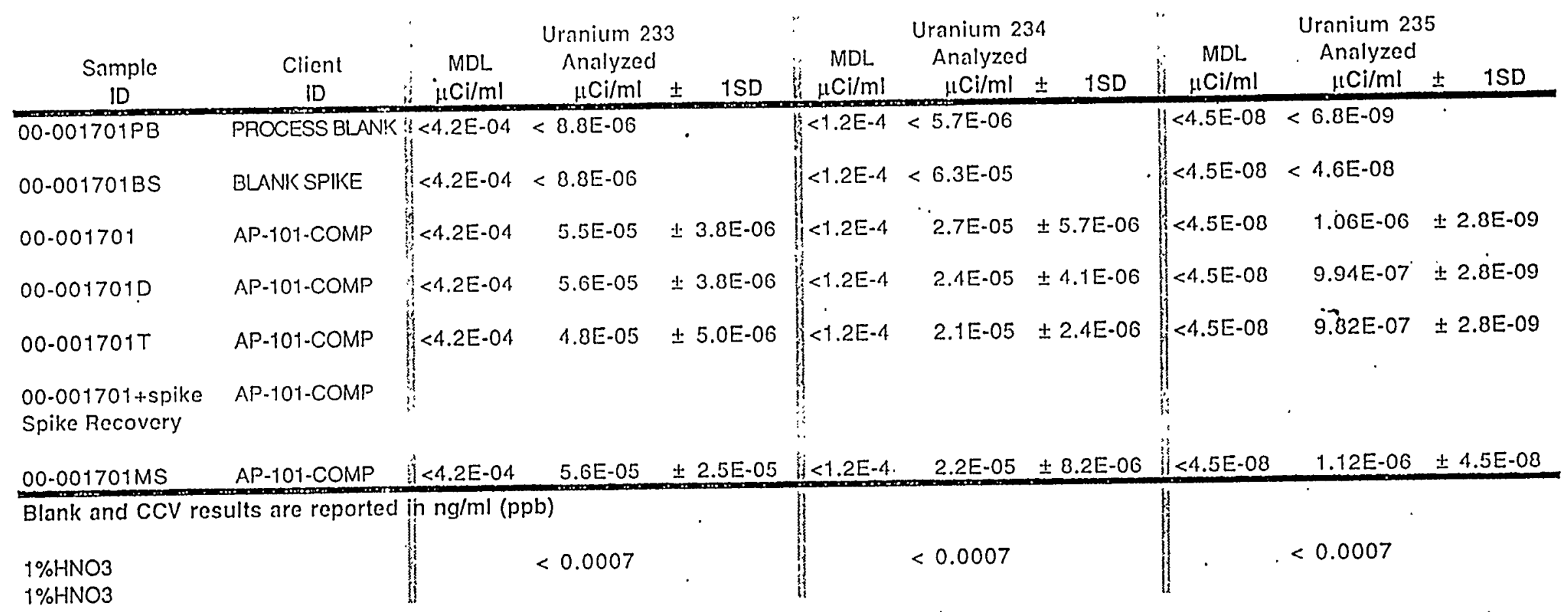




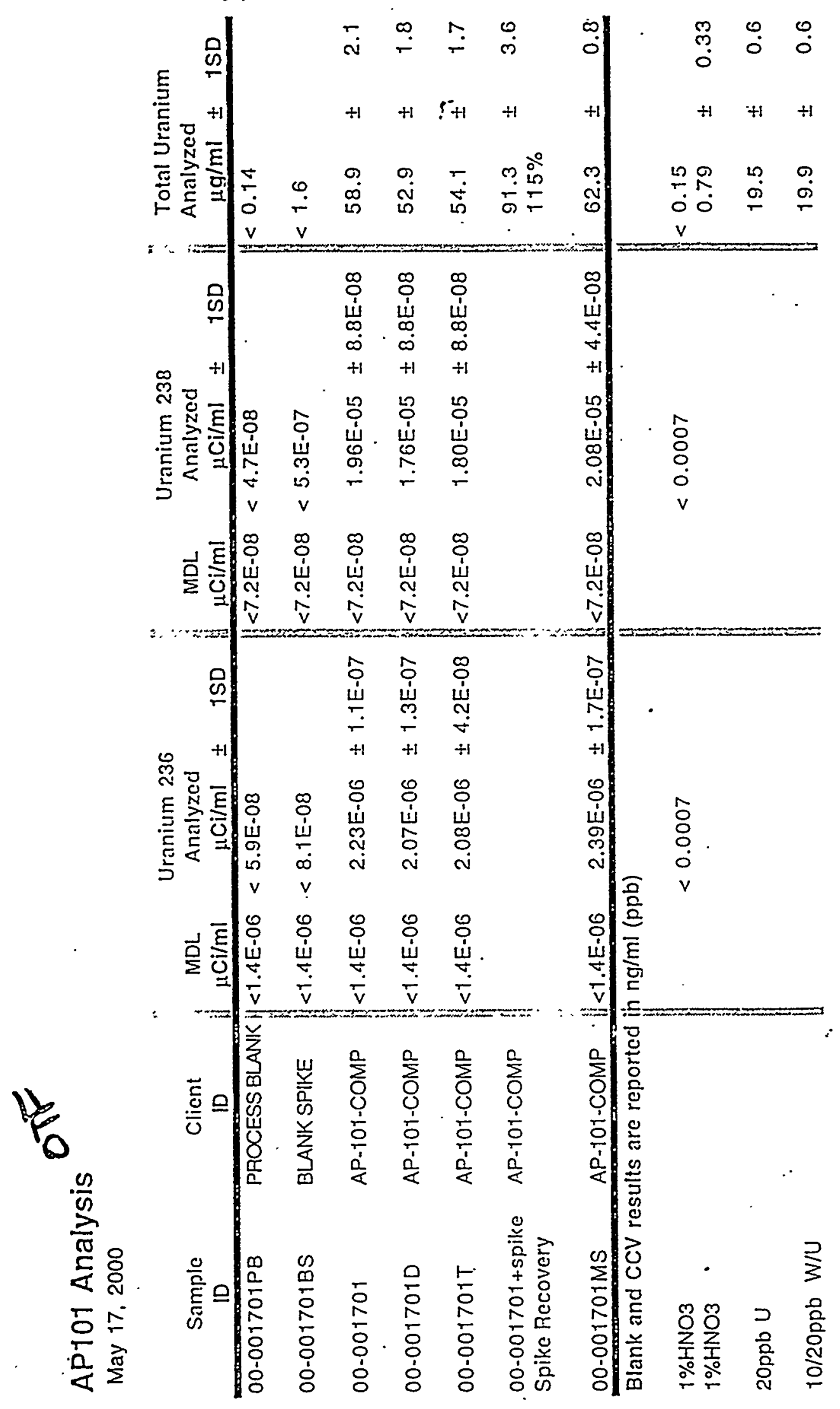


AP101 Analysis

Mày 17, 2000

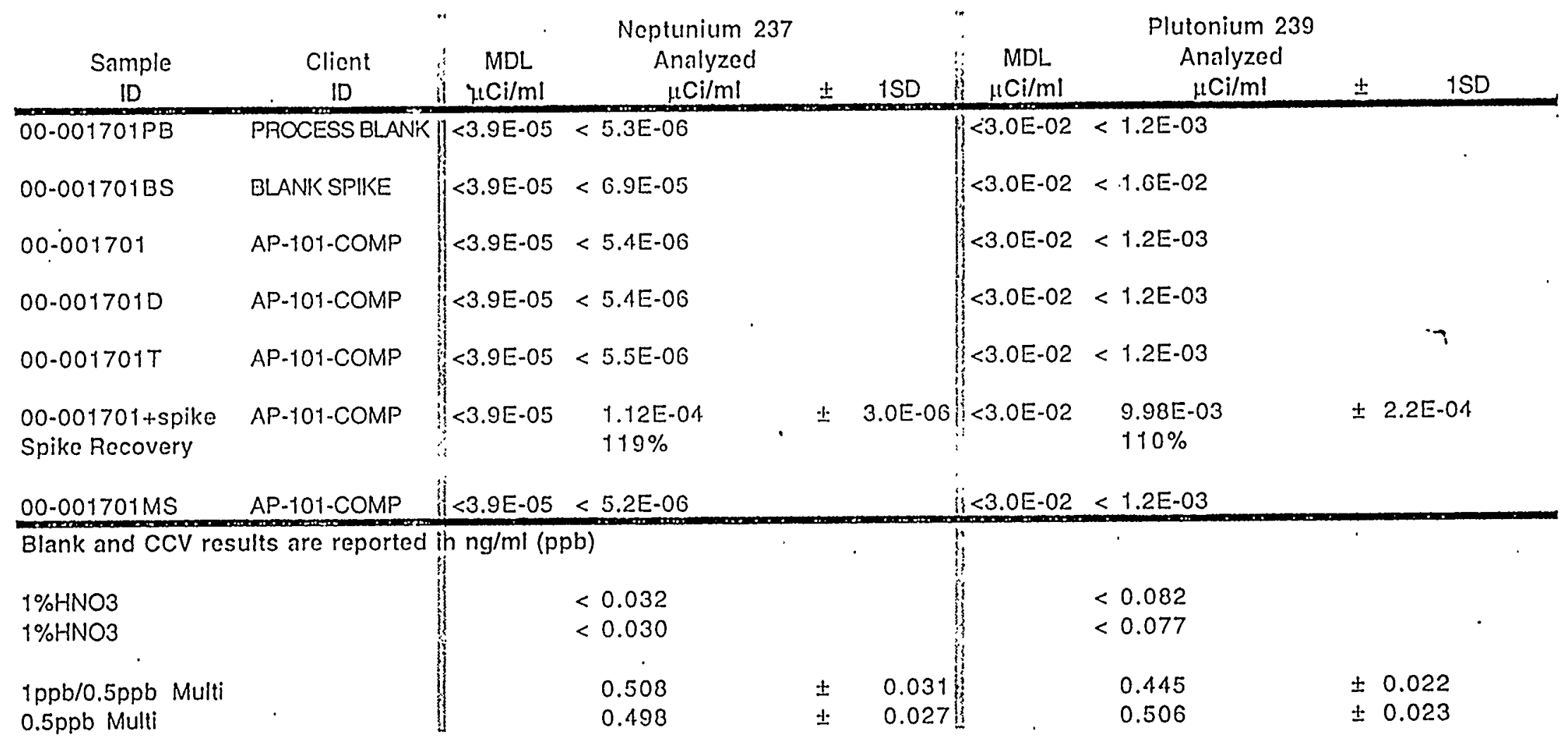




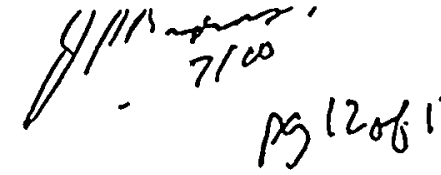

AP101 Analysis

May 17,2000

\begin{tabular}{|c|c|c|c|c|c|c|}
\hline $\begin{array}{l}\text { Sample } \\
\text { ID }\end{array}$ & $\begin{array}{c}\text { Client } \\
\text { ID }\end{array}$ & $\begin{array}{cc}\mathrm{MDL} \\
\mu \mathrm{Ci} / \mathrm{ml}\end{array}$ & $\begin{array}{c}\text { Plutonium } 240 \\
\text { Analyzed } \\
\mu \mathrm{Ci} / \mathrm{ml}\end{array}$ & $\begin{array}{c}\text { *AMU } 241 \\
\text { Analyzed } \\
\mu \mathrm{g} / \mathrm{ml}\end{array}$ & $\begin{array}{c}\text { AMU } 242 \\
\text { Analyzed } \\
\mu \mathrm{g} / \mathrm{ml}\end{array}$ & $\begin{array}{c}\text { AMU } 243 \\
\text { Analyzed } \\
\mu \mathrm{g} / \mathrm{ml}\end{array}$ \\
\hline $00-001701 \mathrm{~PB}$ & PROCESS BLANIK & $\|<3.0 E-02$ & $<2.4 \mathrm{E}-03$ & $\mid<0.011$ & $\|<0.010$ & $<0.0069$ \\
\hline $00-001701 B S$ & BLANK SPIKE & $<3.0 \mathrm{E}-02$ & $<3.1 E-02$ & $<<0.14$ & $<0.13$ & $<0.090$ \\
\hline $00-001701$ & AP-101-COMP & $<3.0 E-02$ & $<2.4 \mathrm{E}-03$ & $k<0.011$ & $r<0.010$ & $<0.0071$ \\
\hline 00-001701D & AP-101-COMP & $<3.0 \mathrm{E}-02$ & $<2.1 E-03$ & $<<0.011$ & $<0.010$ & $<0.0072$ \\
\hline $00-001701 \mathrm{~T}$ & AP-1.01-COMP & $<3.0 \mathrm{E}-02$ & $<2.4 E-03$ & $j<0.011$ & $y<0.010$ & $<0.0072$ \\
\hline $\begin{array}{l}\text { 00-001701+spike } \\
\text { Spike Recovery }\end{array}$ & AP-101-COMP & $<3.0 \mathrm{E}-02$ & $<2.4 \mathrm{E}-03$ & $\mid<0.011$ & $<0.010$ & $<0.0071$ \\
\hline $00-001701 \mathrm{MS}$ & AP-101-COMP & $i<3.0 E-02$ & $<2.3 \mathrm{E}-03$ & $k<0.010$ & $\{<0.0099$ & $<<0.0068$ \\
\hline \multicolumn{7}{|c|}{ Blank and CCV results are reported in $\mathrm{ng} / \mathrm{ml}(\mathrm{ppb})$} \\
\hline $\begin{array}{l}1 \% \text { HNO3 } \\
1 \% \text { HNO3 }\end{array}$ & & & $\begin{array}{l}<0.044 \\
<0.041\end{array}$ & $\begin{array}{l}<0.045 \\
<0.042\end{array}$ & $\begin{array}{l}<0.043 \\
<0.040\end{array}$ & $\begin{array}{l}<0.029 \\
<0.028\end{array}$ \\
\hline
\end{tabular}

"Calculated from response of different isotope. Should be considered semiquantitative. 


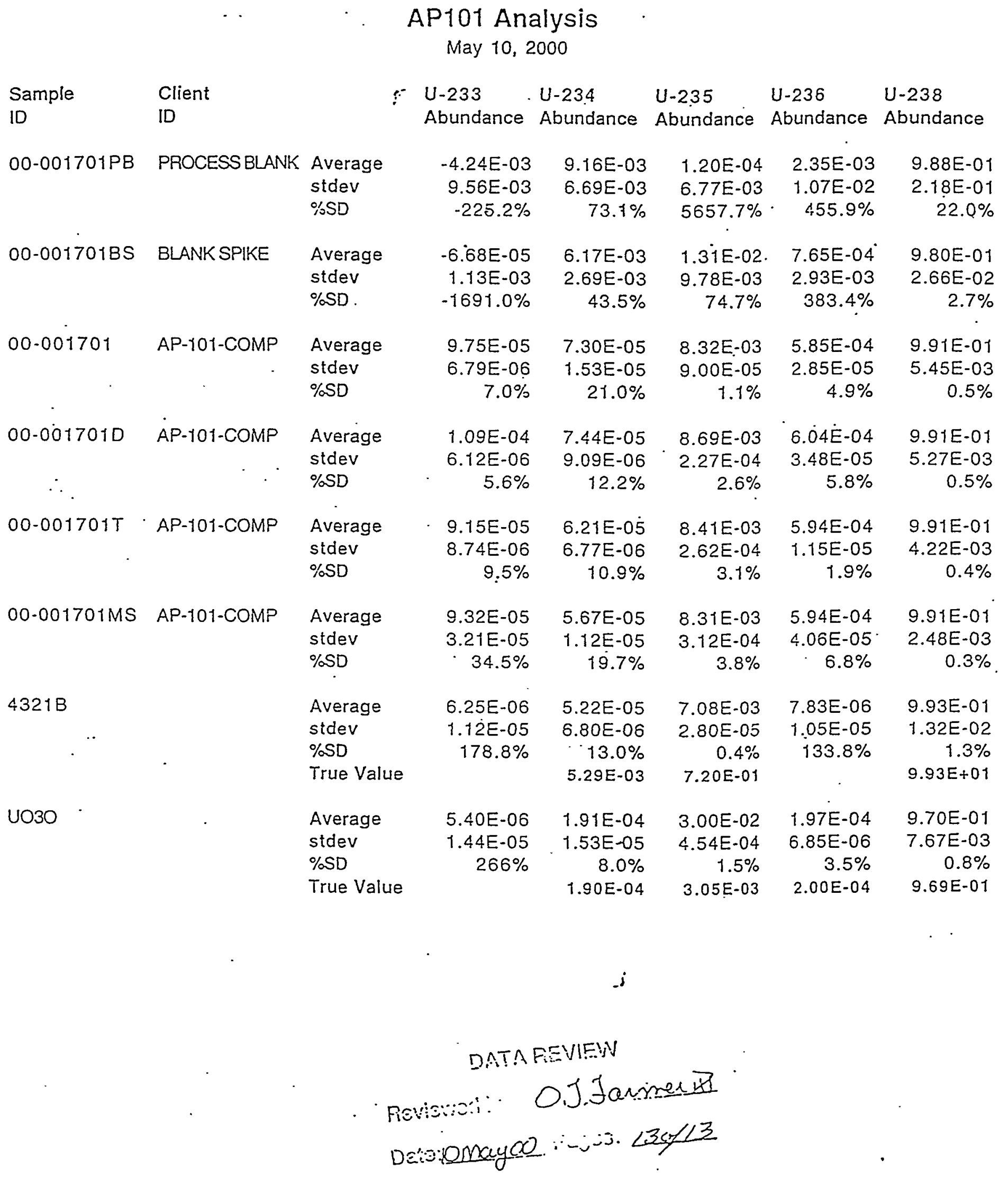




\section{AP101 MDL's}

\begin{tabular}{|c|c|c|c|c|c|c|c|c|c|c|c|c|c|c|c|}
\hline $\begin{array}{l}\text { Sample } \\
\text { Number }\end{array}$ & $\begin{array}{l}\text { Client } \\
\text { Number }\end{array}$ & $\begin{array}{l}\mathrm{Li} \\
\mu \mathrm{g} / \mathrm{ml}\end{array}$ & $\begin{array}{l}\mathrm{Be} \\
\mu \mathrm{g} / \mathrm{ml}\end{array}$ & $\begin{array}{l}\text { B } \\
\mu \mathrm{g} / \mathrm{ml}\end{array}$ & $\begin{array}{l}\mathrm{V} \\
\mu \mathrm{g} / \mathrm{ml}\end{array}$ & $\begin{array}{l}C_{0} \\
\mu \mathrm{g} / \mathrm{ml}\end{array}$ & $\begin{array}{l}\text { As } \\
\mu \mathrm{g} / \mathrm{ml}\end{array}$ & $\begin{array}{l}\text { Se } \\
\mu \mathrm{g} / \mathrm{ml}\end{array}$ & $\begin{array}{l}F b \\
\mu \mathrm{g} / \mathrm{ml}\end{array}$ & $\begin{array}{l}\mathrm{Mo} \\
\mu \mathrm{g} / \mathrm{ml}\end{array}$ & $\begin{array}{l}\text { Tc-99 } \\
\mu \mathrm{Cl} / \mathrm{ml}\end{array}$ & $\begin{array}{l}\mathrm{Sb} \\
\mu \mathrm{g} / \mathrm{ml}\end{array}$ & $\begin{array}{l}\text { Te } \\
\mu \mathrm{g} / \mathrm{m} \mid\end{array}$ & & $\begin{array}{l}\mathrm{Se}-126 \\
\mu \mathrm{Cl} / \mathrm{ml}\end{array}$ \\
\hline 00.001701 & $A P-101-C O M P$ & 0.063 & 0.004 & 0.16 & 0.007 & 0.012 & 0.063 & 2.3 & 0.011 & 0.013 & 2.6E-04 & 0.014 & & 0.17 & 8.6E-0. \\
\hline $00-0017010$ & AP-101-COMP & 0.061 & 0.004 & 0.16 & 0.007 & 0.012 & 0.062 & 2.3 & 0.011 & 0.013 & $2.6 E-04$ & 0.014 & . & 0.16 & 8.6E-04 \\
\hline $00.001701 T$ & AP-101-COMP & 0.059 & 0.004 & 0.15 & 0.007 & 0.011 & 0.059 & 2.3 & 0.011 & 0.012 & $2.6 E-04$ & 0.013 & & 0.16 & 8.2E-0.1 \\
\hline
\end{tabular}

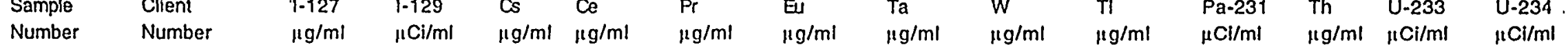

$\begin{array}{lllllllllllllllllllll}00-001701 & \text { AP-101-COMP } & 0.037 & 6.7 E-06 & 0.004 & 0.077 & 0.018 & 0.016 & 0.087 & 0.23 & 0.011 & 1.0 E-04 & 0.011 & 8.8 E-06 & 5.7 E-06 \\ 00-001701 D & \text { AP-101-COMP } & 0.037 & 6.7 E-06 & 0.004 & 0.075 & 0.017 & 0.016 & 0.089 & 0.22 & 0.011 & 1.1 E-04 & 0.011 & 8.8 E-06 & 5.7 E-06\end{array}$

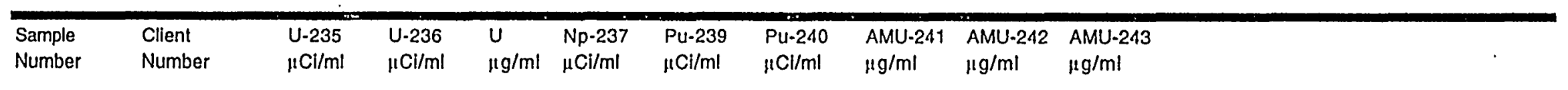

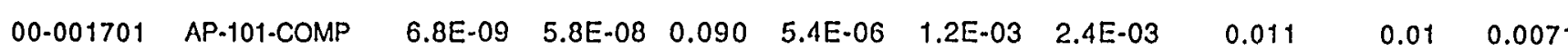

$\begin{array}{llllllllll}00-001701 D & \text { AP-101-COMP } \quad 6.8 E-09 & 5.8 \mathrm{E}-08 & 0.086 & 5.4 \mathrm{E}-06 & 1.2 \mathrm{E}-03 & 2.4 \mathrm{E}-03 & 0.011 & 0.01 & 0.0072\end{array}$

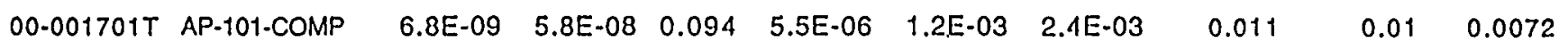


WO/Project: $\cdots \quad$ W54906/29953

- Client: $\quad$ D. Kurath

ACL Numbers: 00-01701

ASR Number 5778

Procedure: PNNL-ALO-131, "Mercury Digestion"

PNNL-ALO-201, "Mercury Analysis"

Analyst: J. J. Wagner

Digestion Date: May 10, $2000 \quad$ Analysis Date: May 11, 2000

M\&TE: Hg system (WD14126); Mettler AT400 Balance (360-06-01-029) See Chemical Measurement Center 98620 RIDS for Hg File for Calibration, Standards Preparations, and Maintenance Records.

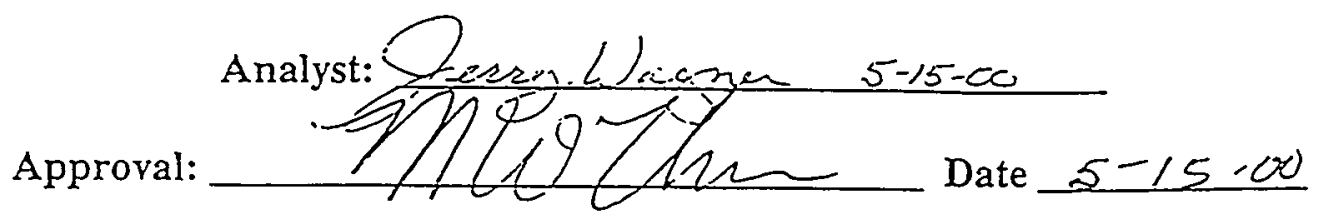

Final Results:

The samples were analyzed by cold vapor atomic absorption spectrophotometry for inorganic mercury as specified in ASR 5778. Four aliquots of $0.2 \mathrm{ml}$ including one for matrix spike, was processed and diluted to a final volume of $25 \mathrm{ml}$ per procedure ALO-131. No additional dilution was performed. Concentration of all sample aliquots measured were near instrument detection limit and several times lower than MRQ $(1.5 \mu \mathrm{g} / \mathrm{ml})$ listed in Table 2, "Supernate Analyses Required by Contract Specification 7 and Opportunistic Analytes". The mercury concentration results are presented in the table below. 


\begin{tabular}{|c|c|c|c|c|c|c|}
\hline LàbID & Solid SampleID & $\begin{array}{l}\text { Aqueous } \\
\text { on } \\
\text { ming }\end{array}$ & $\begin{array}{l}\text { Aqueous } \\
\text { DigFctr }\end{array}$ & 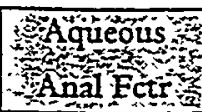 & 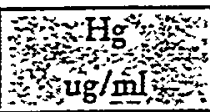 & PRPD \\
\hline $00-01701-\mathrm{PB}$ & Reagent Process Blank & 0.20 & 125 & 1 & 0.026 & \\
\hline $00-01701$ & AP-101 COMP & 0.20 & 125 & 1 & $<0.025$ & \\
\hline 00-01701DUP & AP-101 COMP & 0.20 & 125 & 1 & $<0.025$ & \\
\hline $00-01701$ TRI & AP-101 COMP & 0.20 & 125 & 1 & 0.032 & $N / A$ \\
\hline & & & & & & \\
\hline & & & & & & \\
\hline
\end{tabular}

$\mathrm{RPD}=$ Relative Percent Difference (between sample and duplicate/replicate).

"Sample volume" used for the process blank is an average volume of the samples.

$\mathrm{N} / \mathrm{A}=\mathrm{RPD}$ is not calculated when results are less than $5 \times$ IDL

\section{Notes:}

1) "Final Results" have been corrected for all dilution performed on the sample during processing or analysis.

2) The low calibration standard is defined as the estimated detection limit (IDL) for the reported results and assumes non-complex aqueous matrices. Actual detection limits or quantitation limits for specific sample matrices may be determined, if requested.

3) Routine precision and bias is typically $\pm 15 \%$ or better for non-complex aqueous samples that are free of interference.

\section{Q.C. Comments:}

Following are results of quality control checks performed during $\mathrm{Hg}$ analyses. In general, quality control checks met the requirements of the governing QA Plan.

Working Blank Spike/Process Blank Spike: Process Blank Spike recovery is $100 \%$, well within the acceptance criteria of $80 \%$ to $120 \%$.

Matrix Spiked Sample: A matrix spike was prepared for the samples submitted under this ASR. Recovery of the matrix spike is $97 \%$, well within the acceptance criteria of $75 \%$ to $125 \%$.

Duplicate/replicates: RPD is not calculated since all replicate results are less than $5 \times$ IDL.

Laboratory Control Sample (liquid): Sample recovery of mercury in SRM-1641d (certified by NIST to contain $1.60 \pm 0.018 \mu \mathrm{g} / \mathrm{ml}$ ) was recovered within acceptance criteria of $75 \%$ to $125 \%$.

System Blank/Processing Blanks: A system blank was process during the analysis of the sample. The concentration measured was within about two times detection limit or less. Samples were about the same concentration as the process blank.

Quality Control Calibration Verification Check Standards: Six mid-range verification standards were analyzed throughout the analysis run. All were within the acceptance criteria of $80 \%$ to $120 \%$ recovery for the verification standard. 


\section{Baltelle}

... Putting Technology To Work

Date May 18, 2000

To D. E. Kurath

From

Subject
Internal Distribution

File/LB

Ammonia was measured in triplicate sample aliquots of the composite from tank AP-101 (00-1701) using an ion selective electrode according to procedure PNL-ALO-226. The ammonia probe was calibrated using five standards spanning ammonia concentrations from $1.0 \mathrm{E}-2$ to $1.0 \mathrm{E}-6 \mathrm{moles} / \mathrm{liter}$. The method of standard additions was used to determine the ammonia concentrations by first taking a direct reading and then adding a known standard to each sample. The triplicate concentrations are in good agreement with an RSD of $6 \%$. The method detection limit was estimated at $0.2 \mathrm{ug} / \mathrm{ml}$, well below the requested MRQ value of $140 \mathrm{ug} / \mathrm{ml}$. 
Chemical Measurements Center

Slient: Kurath

Cognizant Scientist:

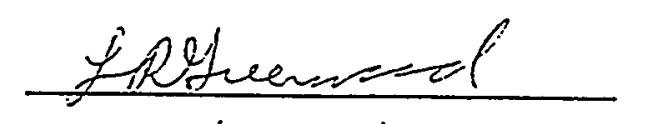

Date: $5 / 18 / 08$

Concur:

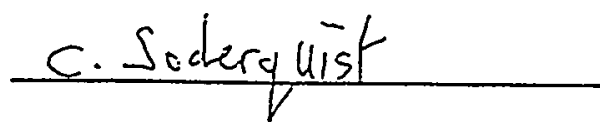

Date: $5-19-00$

Procedure: PNL-ALO-226

\section{Measured Concentrations (ug/ml) with 1-sigma error}

ALO ID

Client ID

$\mathrm{NH}_{3}$

00-1701

Error \%

AP-101 Comp

1.83

$9 \%$

00-1701Dup

1.70

AP-101 Comp

$10 \%$

00-1701 T

1.61

AP-101 Comp

$10 \%$

RSD

$6 \%$

1DL

0.2 
Date $\quad$ May 19,2000

To D. Kurath

From

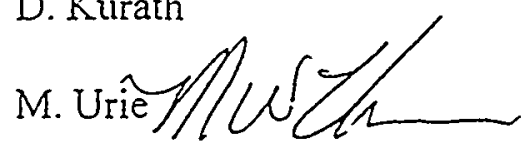

Subject Cyanide Results for AP-101 Sample

\begin{tabular}{|l|l|c|c|c|c|}
\hline \hline RPL Number: & Sample ID & $\begin{array}{c}\text { CN } \\
(\mu g / \mathrm{ml})\end{array}$ & $\begin{array}{c}\text { RPD } \\
(\%)\end{array}$ & $\begin{array}{c}\text { RSD } \\
(\%)\end{array}$ & $\begin{array}{c}\text { Spike } \\
\text { Rec (\%) }\end{array}$ \\
\hline \hline $00-1701$ & AP-101 Sample & 5.81 & $\cdots$ & $\cdots$ & $\cdots$ \\
\hline $00-1701 \mathrm{D}$ & AP-101 Duplicate & 5.56 & 4.4 & --- & $\cdots$ \\
\hline $00-1701$ T & AP-101 Triplicate & 5.73 & $\cdots$ & 2.2 & $\cdots$ \\
\hline $00-1701 \mathrm{MS}$ & AP-101 Matrix Spike & $-\cdots$ & $\cdots$ & $\cdots$ & 95 \\
\hline
\end{tabular}

The CN results for AP-101 composite samples analyzed on May 11, 2000 per ASR 5778 are reported in the Table above. The composite samples were transferred from the Shielded Analytical Laboratory and prepared for distillation and analyzed at the CN Workstation. The AP-101 samples were distilled with the addition of sulfamic acid to ensure there would be no interference from high nitrates present in the sample. The samples were analyzed using a Lachat QuickChem AE Autoanalyzer (WC36517). The reporting limits are estimated to be approximately $0.25 \mu \mathrm{g} \mathrm{CN} / \mathrm{ml}$ based on the sample quantity distilled. No Quality Control or other measurement problems were encountered.

An independent mid-range calibration check solution run at the beginning, middle, and end of the analysis batcl gave an average recovery of $100 \%$. These calibration check standards ranged from $99 \%$ recovery to $100 \%$ recovery which is within the $85 \%$ to $115 \%$ acceptance criteria of the governing QA plan.

The AP-101 composite was analyzed in triplicate. The Relative Percent Difference (RPD) between the Sample and Duplicate was $4.4 \%$ and the Relative Standard Deviation (RSD) for the triplicates was 2.2\%. Based on the RPD and RSD, the measurement precision meets the Quality Control criteria established by Table 4 of the ASR.

For the liquid AP-101 composite, the Laboratory Control Sample (LCS) was a distilled Blank Spike sample. The liquid LCS recovery' was $101 \%$, well within the Quality Control parameters established by Table 4 of the ASR. Beside the liquid LCS, as solid LCS was also processed. The solid LCS was analyzed at $112 \mu \mathrm{g} / \mathrm{g}$ and $165 \mu \mathrm{g} / \mathrm{g}$. well within the certified advisory range of $77 \mu \mathrm{g} / \mathrm{g}$ to $301 \mu \mathrm{g} / \mathrm{g}$. However, the solid LCS does not meet the ASR Quality Control criteria.

The spike recovery for the spiked AP- 101 composite was $95 \%$, well within the acceptance criteria of $75 \%$ to $125 \%$.

All sample preparation sheets, standard preparation information, and analytical data are included with this report. 
PNWD-3046

BNFL-RPT-046, Rev. 0

\section{Distribution}

No. of

Copies

OFFSITE

2 DOE/Office of Scientific and Technical Information
No. of

Copies

\section{ONSITE}

$5 \quad$ British Nuclear Fuels, Limited

M. E. Johnson (4)

A. Thompson

BN-FL

BN-FL

19 Pacific Northwest National Laboratory

P. R. Bredt

J. A. Campbell

P7-25

P8-08

O. T. Farmer

P8-08

S. K. Fiskum

P7-22

L. R. Greenwood

P7-22

D. E. Kurath

P7-28

G. J. Lumetta

G. M. Mong

E. V. Morrey

P7-22

P8-08

P7-28

R. T. Ratner

P7-22

C. Z. Soderquist

P7-22

R. G. Swoboda

P7-22

M. W. Urie

P7-22

J. J. Wagner

$\mathrm{P} 7-22$

Technical Report Files (5) K1-06

Distr. 1 